
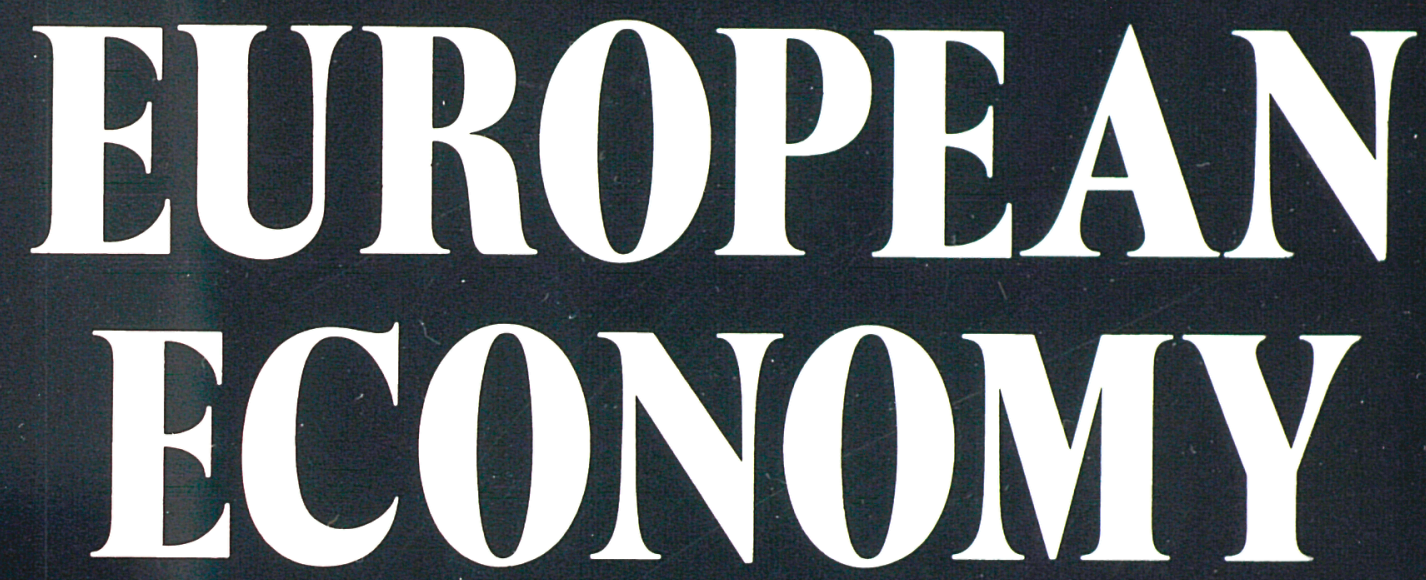

EUROPEAN COMMISSION

DIRECTORATE-GENERAL FOR ECONOMIC AND FINANCIAL AFFAIRS

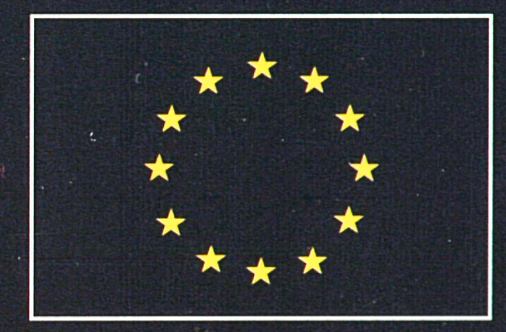

REPORTS AND STUDIES

INCOME INSURANCE IN EUROPEAN AGRICULTURE

No 2

1999 
European Economy appears twice a year. It contains important reports and communications from the Commission to the Council and the Parliament on the economic situation and developments. As a complement to European Economy, the series Reports and studies will be published on problems concerning economic policy.

Three supplements accompany the main periodical:

- Series A - 'Economic trends' appears monthly except in August and describes in a more succinct way financial and economic developments in the European Union.

- Series B - 'Business and consumer survey results' gives the main results of opinion surveys of chief executives (orders, stocks, production outlook, etc.) and of consumers (economic and financial situation and outlook, etc.) in the Community, and other business cycle indicators. It also appears monthly, with the exception of August.

- Series $\mathrm{C}$ - 'Economic reform monitor' provides brief overviews of economic developments and the progress of reform in the 10 countries of central Europe with which the EU has negotiated association agreements, as well as in the two largest transitional economies to have emerged from the former Soviet Union: Russia and Ukraine. It appears four times a year.

Subscription terms are shown on the back and the addresses of the sales offices are shown on page 3 of the cover.

Unless otherwise indicated the texts are published under the responsibility of the Directorate-General for Economic and Financial Affairs of the European Commission, rue de la Loi 200, B-1049 Brussels, to which enquiries other than those related to sales and subscriptions should be addressed. 


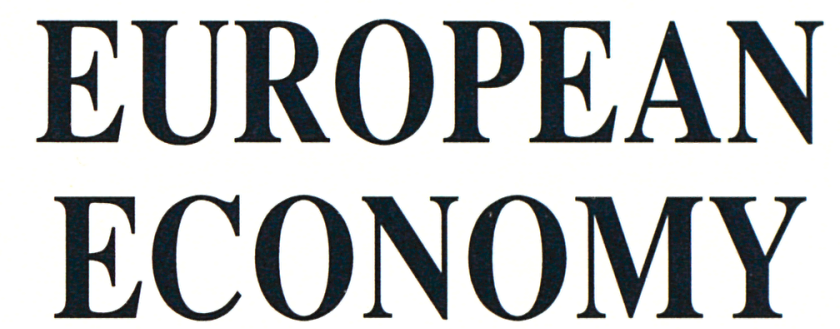

Directorate-General for Economic and Financial Affairs 



\section{Income insurance in European agriculture}




\section{Authors}

Ir M. P. M. MEUWISSEN (Department of Economics and Management, Wageningen Agricultural University, the Netherlands)

Dr Ir R. B. M. HUIRNE (Department of Economics and Management, Wageningen Agricultural University, the Netherlands)

Prof. Dr J. B. HARDAKER (Honorary Visiting Professor, Department of Economics and Management, Wageningen Agricultural University, the Netherlands, and Emeritus Professor, Department of Agricultural and Resource Economics, University of New England, Australia)

\section{Scientific advisory group}

Prof. Dr J. R. BLACK (Department of Agricultural Economics, Michigan State University, Michigan)

Prof. Dr C.-H. HANF (Department of Agricultural Economics, University of Kiel, Germany)

Prof. Dr J. R. SKEES (Department of Agricultural Economics, University of Kentucky, Kentucky)

\section{Steering group}

A. C. J. BULLENS (Interpolis Reinsurance, the Netherlands)

Ir W. A. VAN OOSTEROM (Rabobank Nederland, the Netherlands)

G. J. M. PIERIK (Interpolis, the Netherlands)

Drs N. SIMON ARTIGAS (Interpolis Reinsurance, the Netherlands) 


\section{Abbreviations and symbols used}

\section{Member States}

$\begin{array}{ll}\text { B } & \text { Belgium } \\ \text { DK } & \text { Denmark } \\ \text { D } & \text { Germany } \\ \text { WD } & \text { West Germany } \\ \text { EL } & \text { Greece } \\ \text { E } & \text { Spain } \\ \text { F } & \text { France } \\ \text { IRL } & \text { Ireland } \\ \text { I } & \text { Italy } \\ \text { L } & \text { Luxembourg } \\ \text { NL } & \text { The Netherlands } \\ \text { A } & \text { Austria } \\ \text { P } & \text { Portugal } \\ \text { FIN } & \text { Finland } \\ \text { S } & \text { Sweden } \\ \text { UK } & \text { United Kingdom } \\ \text { EU-9 } & \text { European Community excluding Greece, Spain and Portugal } \\ \text { EU-10 } & \text { European Community excluding Spain and Portugal } \\ \text { EU-12- } & \text { European Community, 12 Member States including West Germany } \\ \text { EU-12+ } & \text { European Community, 12 Member States including Germany } \\ \text { EU-15+ } & \text { European Community, 15 Member States including Germany } \\ \text { EU-11 } & \text { Group of 11 Member States participating in monetary union } \\ & \end{array}$

\section{Currencies}

$\begin{array}{ll}\text { ECU } & \text { European currency unit } \\ \text { EUR } & \text { Euro } \\ \text { ATS } & \text { Austrian schilling } \\ \text { BEF } & \text { Belgian franc } \\ \text { DEM } & \text { German mark (Deutschmark) } \\ \text { DKK } & \text { Danish krone } \\ \text { ESP } & \text { Spanish peseta } \\ \text { FIM } & \text { Finnish markka } \\ \text { FRF } & \text { French franc } \\ \text { GBP } & \text { Pound sterling } \\ \text { GRD } & \text { Greek drachma } \\ \text { IEP } & \text { Irish pound (punt) } \\ \text { ITL } & \text { Italian lira } \\ \text { LUF } & \text { Luxembourg franc } \\ \text { NLG } & \text { Dutch guilder } \\ \text { PTE } & \text { Portuguese escudo } \\ \text { SEK } & \text { Swedish krona } \\ \text { CAD } & \text { Canadian dollar } \\ \text { CHF } & \text { Swiss franc } \\ \text { JPY } & \text { Japanese yen } \\ \text { RUR } & \text { Russian rouble } \\ \text { USD } & \text { US dollar }\end{array}$




\section{Other abbreviations}

$\begin{array}{ll}\text { ACP } & \text { African, Caribbean and Pacific States having signed the Lomé Convention } \\ \text { ECSC } & \text { European Coal and Steel Community } \\ \text { EDF } & \text { European Development Fund } \\ \text { EIB } & \text { European Investment Bank } \\ \text { EMCF } & \text { European Monetary Cooperation Fund } \\ \text { EMS } & \text { European Monetary System } \\ \text { ERDF } & \text { European Regional Development Fund } \\ \text { Euratom } & \text { European Atomic Energy Community } \\ \text { Eurostat } & \text { Statistical Office of the European Communities } \\ \text { GDP }(\text { GNP) } & \text { Gross domestic (national) product } \\ \text { GFCF } & \text { Gross fixed capital formation } \\ \text { LDCs } & \text { Less developed countries } \\ \text { Mio } & \text { Million } \\ \text { Mrd } & \text { 1 000 million } \\ \text { NCI } & \text { New Community Instrument } \\ \text { OCTs } & \text { Overseas countries and territories } \\ \text { OECD } & \text { Organisation for Economic Cooperation and Development } \\ \text { OPEC } & \text { Organisation of Petroleum Exporting Countries } \\ \text { PPS } & \text { Purchasing power standard } \\ \text { SMEs } & \text { Small and medium-sized enterprises } \\ \text { toe } & \text { Tonne of oil equivalent } \\ : & \text { Not available }\end{array}$

Eurolecu: Statistical series expressed in monetary terms from 31.12.1998 backwards are labelled in ecu. Other monetary references to periods starting from 1.1.1999 onwards are labelled in euro. 


$\begin{array}{ll}\text { Abbreviations key } \\ \text { B } & \text { Belgium } \\ \text { D } & \text { Germany } \\ \text { D-BRD } & \text { Germany - Bundes Republik Deutschland } \\ \text { DK } & \text { Denmark } \\ \text { E } & \text { Spain } \\ \text { EL } & \text { Greece } \\ \text { F } & \text { France } \\ \text { FIN } & \text { Finland } \\ \text { I } & \text { Italy } \\ \text { IRL } & \text { Ireland } \\ \text { L } & \text { Luxembourg } \\ \text { NL } & \text { The Netherlands } \\ \text { P } & \text { Portugal } \\ \text { S } & \text { Sweden } \\ \text { UK } & \text { United Kingdom } \\ \text { EU } & \text { European Union } \\ \text { US } & \text { United States of America } \\ \text { AWU } & \text { Annual working unit } \\ \text { CAP } & \text { Common agricultural policy of the EU } \\ \text { ESU } & \text { Economic size unit (1 ESU = 1,200 ecu standard gross margin) } \\ \text { FWU } & \text { Family working unit } \\ \text { WTO } & \text { World Trade Organisation } \\ \text { NR } & \text { Net return to labour and management } \\ \end{array}$





\section{Foreword}

I ncome from farming is usually considered to be rather volatile due to a whole series of stochastic factors that affect production and prices. Price and production risks may increase in the future. International trade agreements can be expected to lead to further price liberalisation and to more exposure of farmers to competitive market forces. As trade is expanded, new quality requirements are likely to be defined for farm products which might increase production risk. There may thus be a need for measures that stabilise incomes without interfering significantly with markets for agricultural products, the more so with enlargement towards central and eastern European countries whose agricultural output still constitutes a large proportion of total gross domestic production.

One possible way to address income stabilisation is through some form of insurance. Whether there might be a case for farm income insurance in Europe in the future, under what conditions and in what form might such an income insurance scheme be feasible are the central questions studied by this report. The report, undertaken by a panel of experts in the field, explores a number of issues such as insurance coverage, loss assessment, multi-year versus single year insurance contracts, mandatory versus voluntary participation, etc. Feasibility is tested with a Monte Carlo simulation using panel data from six Member States. The investigation also includes a description of the agricultural sector in Europe, a review of current experiences on income insurance in other countries and a summary of the main conclusions of a European workshop on the topic.

While intended to be a contribution to the debate on agricultural policy strategy, it does not necessarily reflect the opinion of the Commission, nor pre-empt any particular approach to deal with the issues raised. 



\section{Executive summary}

\section{Introduction}

Income from farming is usually considered to be rather volatile due to a whole series of stochastic factors that affect production and prices. Throughout the years, various risk management tools have been used to reduce, or to assist farmers to absorb, some of these risks. The common agricultural policy of the European Union has taken away some of the risks, for example, by guaranteeing minimum prices for many agricultural products.

However, price and production risks are likely to increase in the future. International trade agreements can be expected to lead to price liberalisation and to more exposure of farmers to competitive market forces. Furthermore, as trade is expanded, new quality requirements are likely to be defined for farm products, such as stricter rules for use of fertilisers, herbicides and medicines for animals. As a result, production risk is also likely to increase.

These developments affect the variability in income from farming. As a consequence, there may be a need for complementary measures that stabilise and safeguard incomes without interfering significantly with markets for agricultural products. One possible way to address income stabilisation would be to provide some form of insurance.

\section{Goal of study}

The goal of this study was to examine whether there might be a case for farm income insurance in the EU in the future. The central question was under what conditions and in what form such an income insurance scheme might be feasible. An income insurance scheme might partly replace tools and mechanisms currently available to help European farmers cope with risk. In discussing the feasibility of an agricultural income insurance the following conditions were taken into consideration:

1. interference/disturbance with markets should be kept to a minimum;

2. income insurance schemes need to be in compliance with WTO agreements;

3. any income insurance scheme needs to be developed in such a way that it can be run by the private sector, without, in principle, government involvement;

4. an income insurance scheme may not be used to finance or compensate a long-term sector decline; and

5. income insurance schemes must be applicable to both the northern and the southern European countries.

\section{Materials and methods}

An extended literature review was carried out as the first step in the research. Furthermore, a workshop was held in Tilburg on 29 January 1998 with 20 experts from insurance, reinsurance and financial companies from six EU countries. The goal of the workshop was to discuss the idea of different types of income insurance schemes with an extensive group of selected experts to see whether income insurance might be a feasible and practical concept and, if so, for which commodities and risks, and in what form.

In discussing insurance schemes it is essential to have individual farm data because aggregated data from large areas would hide individual farm yield fluctuations. A large panel data set, containing individual farm yield data from the period 1989-95 (FADN Information European Commission), was analysed. The data set includes annual data from six EU countries (Denmark, France, Germany (BRD), Greece, Italy and the 
Netherlands) and six agricultural commodities (wheat, potatoes, sugar beet, beef, milk and piglets). The total data set covers 49 regions and about 13000 farms. Furthermore, price data were analysed (Eurostat, 1997).

Based on the data analyses, a Monte Carlo simulation model was developed. Monte Carlo simulation can be described as a method of analysis in which a computer model of the problem situation is created which can be used to determine the distributions of output variables of interest, given information about the stochastic input variables (calculated from the data set). Monte Carlo simulation is considered an appropriate and very flexible method of investigating aspects that are stochastic in nature, such as yields and prices that determine income from farming.

\section{Main conclusions}

In discussing the feasibility of an income insurance scheme for European agriculture, two questions are central: (1) is it possible to develop a scheme that is attractive to commercial insurers and (2) will such schemes appeal to farmers?

\section{Is it possible to develop a scheme that is attractive to commercial insurers?}

Insurers will offer some form of income insurance if they can make a profit by doing so without exposing themselves to unbearable risk. This implies that serious problems of adverse selection, moral hazard and systemic risk have to be solved in the design of any income insurance scheme for it to be viable for the insurer.

\section{Asymmetric information}

Asymmetric information exists when the would-be insured knows more about the risk being insured than does the insurer. Such asymmetry of information can lead to unacceptable problems of adverse selection and moral hazard for the insurer.

To prevent problems of asymmetric information an income insurance scheme should ideally cover only:

- accidental and unintentional losses - where losses can be influenced by the farm management of the insured, problems of moral hazard are likely to arise;
- income measures for which proper risk classification and rate making is possible - this requires the availability of sufficient and reliable data; and

- losses that are determinable and measurable - for a proper loss assessment, the amount of loss and the issue of whether the loss is caused by an insured event need to be unambiguous.

In practice, all these conditions may not be fully satisfied, yet it may still be possible to develop a workable income insurance scheme attractive to insurers. For example, moral hazard problems of management influence on the outcome of the insured event can be minimised by such measures as the use of deductibles (excesses) or no-claims bonuses, as is the case in vehicle accident insurance.

The severity of problems of asymmetric information depends to a large degree on the income measure insured. The pros and cons of different measures are reviewed below.

\section{Whole-farm income insurance}

Insuring whole-farm income as such is not possible because it includes aspects such as farm operating costs and inventories, which are strongly influenced and easily manipulated by the insured individual. Furthermore, in calculating premium rates, sufficient data on wholefarm incomes calculated in an acceptable and consistent way may not be available.

\section{Whole-farm gross revenue insurance}

Insurance for the gross revenue earned from a combination of several commodities on a farm is only feasible if the revenues from each of the commodities substantially fulfil the requirements listed below for commodity gross revenue insurance. If there are only a few commodities for which these conditions are met, wholefarm gross revenue insurance is not possible, although commodity-specific gross revenue insurance may be feasible, as discussed below.

\section{Commodity gross revenue insurance}

Insuring the gross revenue earned from production of a given commodity implies insuring the product of the price and yield of that commodity. For insurers to set 
adequate premiums, they need information on the joint distribution of prices and yields. Since prices and yields may not be stochastically independent, the information needed to derive the full joint distribution is considerable. An extra difficulty arises if the nature of the stochastic dependency changes over time, e.g. as a result of market liberalisation.

In addition to issues of jointness, problems of asymmetric information arise in relation to the marginal distributions of the price and yield components, as discussed below.

\section{Yields}

Yields calculated on an area basis (rather than individual farm or field yields) cannot be influenced much by the individual farmer and could, therefore, be a good basis for insurance. However, this is only true if the area yields can be measured reliably. Furthermore, for reasons of basis risk for farmers contemplating buying insurance, area-yield data can only be used in insurance contracts in areas where yields are highly correlated across farms.

If individual farm yields are to be used, insurance instruments such as deductibles (excesses), no-claim bonuses, monitoring the behaviour of insured individuals (good farming practices), and the monitoring of crops just before or at harvest time are necessary to reduce the moral hazard problem inherent in the use of farm-level data.

With respect to livestock commodities, insurance against low yields is likely to face problems. The following points relate to individual farm yields, not to area yields; area yields would not be an option for most livestock because yield variations, at least in the case of intensively reared livestock, are not caused to any large degree by environmental factors affecting many farms in an area.

- Fluctuations in livestock yields are generally less than in crop yields. The fluctuations that do occur, especially for intensively reared livestock, are much more a management issue than for crops (for which weather-related events cause part of the fluctuation), implying extra difficulties of moral hazard for the would-be insurer.
- Most livestock commodities do not have a clear 'harvesting' time, as with crops. Livestock farms either produce output throughout the year (e.g. piglets) or have a multi-year production cycle (e.g. beef cattle). Moreover, the timing of 'harvesting' for some livestock systems is quite flexible. Both aspects may allow insured farmers to manipulate the timing of sales in order to make a claim on the insurer. There are also likely to be related complications in selecting the moment the insurance policy is to be written and in determining the period in the future to which it is to apply.

\section{Prices}

For price insurance two prices are essential: the strike price, i.e. the price that triggers a payment, and a measure of the actual price on which the amount of any indemnity payment can be based. At the moment the insurance contract is written, the level of the strike price must be agreed. To prevent adverse selection, insurers need reliable data to establish an accurate strike price and a related premium rate. In this regard, the following aspects are important.

- Due to the existence of price cycles (especially with respect to livestock commodities), insurers should use as much actual market information as possible, possibly extended with some historical price data. Futures markets may be helpful instruments.

- Price cycles are a reason for reconsidering the level of strike prices each year.

- If commodities are not reasonably uniform and a wide variety of different grades (and different prices) exist, the establishment of strike prices may be difficult.

After having set the strike price for a specific commodity of a certain grade, insurers need a good measure of the actual price of the commodity of a certain grade at harvest or sale time. Prices realised by individual farmers are likely to be problematical since they are too much influenced by the management of the insured. Observed spot market prices can be useful in wellfunctioning markets with a good reporting system. Well-functioning markets are those with a high degree of market integration, meaning that prices for the same commodity in different places are fairly similar. For this to happen, price information needs to be public. 


\section{Business interruption insurance for specific diseases}

Where a form of income insurance is not feasible for certain disease risks, as could be the case for example with classical swine fever and foot-and-mouth disease, a specific disease risk insurance for catastrophic losses may still be possible. In this report, regionally organised mutual insurance funds are proposed to deal with such disease risks. Losses covered in this regard will mainly refer to losses from business interruption.

A mutual farm insurance fund is a fund that is operated by farmers themselves. Incentives to prevent losses are central to the success of these funds. Farmers who participate pay a premium to cover administrative costs and reinsurance (i.e. to provide the 'infrastructure'). The fund then indemnifies members against the specified losses. If one member suffers a loss, other members may have to pay a surcharge to fund the indemnity. In mutual insurance funds, the role of insurance companies is restricted to that of administrator and reinsurer. With respect to asymmetric information problems, the advantages of using mutual insurance funds are that moral hazard is reduced due to farmers' familiarity with each other's production circumstances and that the availability of reliable data is less important because of the use of surcharges (i.e. accurate premiums need not be set beforehand). The latter is especially useful since epidemic disease outbreaks are rare events for which data are seldom available.

Mutual insurance funds should be organised regionally to make best use of the farmers' familiarity with each other's production circumstances. Regionally organised funds face the risk that all farmers in the fund face losses at the same time (since the mutual fund covers risks that have systemic characteristics). To deal with such problems, a pool of individual mutuals could be organised (possibly at a European level), since at such a level risks will be more or less independent.

\section{Systemic risk}

Regardless of the exact form(s) of income insurance, the risks covered (i.e. production risks, epidemic disease risks such as classical swine fever, and price risks) are to some extent systemic. This implies that sufficient traditional reinsurance capacity may not be available. For this reason, and because capital market opportuni- ties are not (yet) widely developed, some form of publicprivate partnership may well be necessary for insurers to enter this income insurance market. There are two main ways (or a combination of the two) in which governments might become involved: they could agree to provide reinsurance coverage to insurance companies at zero costs, or they could do so at fully commercial rates. Both alternatives have pros and cons.

\section{Governments provide reinsurance at zero costs}

Arguments in favour of this option include the following points.

- Governments already provide free disaster relief. An insurance system in which governments provide reinsurance is likely to be more efficient than disaster relief. Disaster relief is very ad hoc and often involves problems of 'who receives the money'. There are also considerable administrative costs incurred in setting up special agencies to organise and provide the disaster relief. By providing reinsurance, governments can use the experience and capacity of insurance companies which are experienced in dealing with moral hazard and adverse selection and have the capacity to handle large numbers of claims.

- Although free reinsurance is a form of subsidy and therefore a potential source of economic distortion, a case can be made that some subsidy is appropriate to correct for the market failure inherent in farmers' risk aversion. Society as a whole may be assumed to be more or less risk indifferent so far as farm income risks are concerned (because the risks are negligible when nationally spread across all members of society). It is socially preferable that farmers allocate their resources closer to the point where expected marginal costs and expected marginal returns are equal. Because risk-averse farmers will generally stop short of the social optimum, a small subsidy, embodied in reinsurance, may be socially beneficial.

- Having the government financially involved may address a moral hazard problem in government behaviour; many catastrophes (for example epidemic disease outbreaks and losses from floods) can be either prevented or magnified by government policy. Having governments financially responsible for 
some losses might be an incentive for them to put into place appropriate hazard management policies.

\section{Governments provide reinsurance at fully commercial rates}

Arguments in favour of this option are outlined below.

- Governments can potentially provide reinsurance cheaper than private market reinsurers can. Governments have substantial advantages because of their deep credit capacity and their unique position as the largest social entity in a country. These advantages enable them to diversify claims intertemporally and to spread risks broadly.

- Provided that governments charge for providing reinsurance at rates that will cover costs, some of these functions will be taken over by the private sector as capital and commodity markets deepen (privatising the market).

\section{Comments on both options}

The following comments apply to both options.

- Moral hazard of insurance companies can be prevented if governments reinsure only part of the risks underwritten by the insurers.

- Reinsurance agreements between governments and insurers can be based on a stop loss and/or a quota share basis. Since governments have no experience in the reinsurance market, rent seeking behaviour by insurers is to be minimised by ensuring that both governments and insurance companies have the same information about insured risks and size of losses.

- Free disaster relief will reduce the incentives for farmers to buy insurance. If governments provide reinsurance at zero costs, political pressure to provide free disaster relief will be less.

\section{Will income insurance schemes appeal to farmers?}

The reason why farmers may be willing to buy a form of income insurance is that they are risk averse. They are therefore willing to pay a premium to avoid losses, especially catastrophic losses that threaten the survival of the farm business. Although it is possible to make some theoretical estimates, the exact amount of money farmers are willing to pay for specific forms of income insurance cover can only be established by pilot testing.

Besides the level of risk aversion of farmers and the exact form of the insurance, other factors that influence the extent to which schemes will appeal to farmers are the availability of other risk management strategies, the variability of yields and prices, the price/yield correlation, the ad hoc support provided by governments in case of disasters, and farmers' perception of risks.

If governments subsidise income insurance to some extent, the likelihood that insurers will set premiums at levels that farmers will find attractive will be higher. On the other hand, the availability of other forms of subsidy that give farmers higher and more stable incomes, such as price support schemes, reduce the chances that farmers will want to buy commercial income insurance.

Another factor of importance is the level of risk reduction provided by an insurance scheme. Our simulation study showed that the risk of a low income is less in the case of gross revenue insurance than in case of yield-only insurance. The exact effect for a specific commodity, however, depends on the variability of the price of the commodity, the number and size of catastrophic events, the size of the deductible (excess), the price at which yield shortfalls are indemnified, the price taken into consideration to establish the revenue guarantee level and the stochastic dependency between yields and prices.

From a farmers' point of view, forms of income insurance that cover losses at a higher level of aggregation (i.e. gross revenue insurance as opposed to yield-only insurance) will be more appealing since such schemes are closer to whole-farm income, and, hence, to the welfare of a farm family.

\section{Recommendations and further research}

If a form of income insurance is introduced in Europe, the following recommendations should be borne in mind.

- Only aspects for which 'moral hazard' and 'adverse selection' can be dealt with adequately should be included in a scheme. 
- Gross revenue insurance should only be considered for crop, and not for livestock, commodities.

- Insurance should start with true market commodities, i.e. commodities for which no price support is available.

- If governments provide reinsurance (at zero costs, at fully commercial rates, or as a combination of these two options) they should only reinsure part of the risk underwritten by insurers.

- Before wide introduction, some pilot tests should first be carried out. In pilot tests the interest of farmers in insurance schemes that cover systemic risks such as floods, droughts and epidemic diseases can become clear, as well as the interest of insurance companies in setting up (mutual insurance funds for) such schemes. In setting up such pilot tests it is crucial for later implementation that governments are involved to no more than the necessary minimum extent, using transparent rules for such aspects as stop losses, i.e. from the beginning there should be no asymmetric information between insurers and governments.

Since the time available for this study was short (only nine months) and it was the first study in this field in a
European context, further research should be carried out on the following aspects, among others:

- More statistical analyses of data, for example with respect to:

— joint distributions of prices and yields;

- correlations between individual and area yields;

- price variability within years;

- the opportunities to use, for example, Chicago Board of Trade futures and commodity prices or Rotterdam harbour prices as measures of insurable price.

- More simulation studies to cover a broader range of insurance topics, for example with respect to the effect of area-based insurance schemes and the impact of the availability and uptake of new insurance products on the overall risk management strategies adopted by farmers.

- The availability of accurate data on which to base insurance premiums and indemnities.

- More generally, the opportunities to replace publicfunded risk management programmes with more market-based solutions. This includes the development of futures and options markets to cover price risks, the reinsurance of systemic risks, and more market-based agreements with governments if they provide financial back-up. 


\section{Contents}

2. The agricultural sector in Europe

2.1. Features of agriculture in Europe 9

2.1.1. General figures 9

2.1.2. Livestock farming 11

2.1.3. Crop farming 13

2.1.4. Agricultural commodities 13

2.1.5. Agricultural income 13

2.2. Current income protection for farmers $\quad 15$

2.2.1. EU price and income policy 15

2.2.2. EU agricultural budget expenditures 16

3. Important aspects of risk and insurance: a literature review 19

3.1. Short introduction to the theory of risk 19

3.1.1. Impacts of risk 19

3.1.2. Subjective expected utility 20

3.1.3. Measures of risk aversion $\quad 20$

3.1.4. Risk analysis with preferences unknown $\quad 21$

3.1.5. Risk and insurance $\quad 21$

3.1.6. Risk management strategies $\quad 21$

3.2. Insurable risks 22

3.2.1. Asymmetric information 22

3.2.2. Systemic risks 23

3.2.3. Requirements of insurable risks 23

3.3. Reinsurance 25

3.4. Insurance coverage and loss assessment 25

3.4.1. Insurance coverage $\quad 25$

3.4.2. Loss assessment 27

3.4.3. Combining insurance coverage and loss assessment 28

3.5. Multi-year versus single year insurance contracts 28 
3.7. Experiences with insurance schemes for agricultural risks 30

$\begin{array}{lr}\text { 3.7.1. Crop insurance } & 30\end{array}$

3.7.2. Mutual insurance schemes for contagious diseases $\quad 31$

$\begin{array}{ll}\text { 3.7.3. Revenue insurance } & 31\end{array}$

3.7.4. Income stabilisation accounts $\quad 33$

3.8. Need for insurance schemes 33

3.9. Role of governments $\quad 34$

3.10. Future perspectives

$\begin{array}{ll}\text { 3.10.1. Systemic risks } & 37\end{array}$

3.10.2. Asymmetric information between insurer and farmer $\quad 37$

3.10.3. Insurance of independent risks that remain after the systemic component of risk
is taken care of

4. Agricultural income insurance in Europe 39

4.1. A discussion framework $\quad 39$

4.2. Whole-farm income $\quad 39$

4.3. Gross revenue insurance 41

4.4. Price $42-42$

4.5. Yield insurance 44

4.6. Business interruption $\quad 45$

5. Data analysis and simulation 47

$\begin{array}{lll}\text { 5.1. Introduction } & 47\end{array}$

5.2. Materials and methods 47

$\begin{array}{lr}\text { 5.2.1. Data analysis } & 47\end{array}$

$\begin{array}{lr}\text { 5.2.2. Monte Carlo simulation } & 47\end{array}$

5.3. Yield-only insurance $\quad 49$

$\begin{array}{lr}\text { 5.3.1. Results from data analysis } & 49\end{array}$

5.3.2. Implications for individual farmers: simulation results 50

5.3.3. Implications for insurers: simulation results 52

5.4. Gross revenue insurance $\quad 56$

5.4.1. Implications for individual farmers: simulation results $\quad 56$

$\begin{array}{ll}\text { 5.4.2. Yield-only insurance versus gross revenue insurance } & 57\end{array}$

$\begin{array}{lr}\text { 5.5. Discussion } & 59\end{array}$ 
6. Conclusions, discussion, recommendations and further research

6.1. Main conclusions 61

6.1.1. Is it possible to develop a scheme that is attractive to commercial insurers? 61

6.1.2. Will income insurance schemes appeal to farmers? $\quad 64$

6.2. European Commission's conditions for income insurance schemes 65

6.3. Recommendations and further research 65

$\begin{array}{ll}\text { References } & 67\end{array}$

$\begin{array}{ll}\text { Annex I - Income measures } & 73\end{array}$

Annex II - Financial performance of agricultural insurance programmes 74

Annex III - Workshop on income insurance in European agriculture 75

Annex IV - Data analysis of European agriculture: farm yield data and price data 79

$\begin{array}{ll}\text { Annex V - Simulation of the effect of insurance } & 87\end{array}$ 
Tables 1. Number of farms, total agricultural area per country, and the average agricultural area per farm (1993)

2. Number of farms (1 000) per sector (data for 1993)

3. Percentage of farms per economic size category (data for 1993)

4. Average sources of income for agricultural households

5. Numbers of livestock (1 000)

6. Average net value-added at factor costs per AWU and average net return to labour and management per FWU per sector for EU-12, and for countries with the extremes $(1992 / 93)$

7. Net value-added at factor costs per AWU and net return to labour and management per FWU per category for EU-12, and for countries with the extremes (data for 1992/93)

8. Average sugar beet and potato prices $(\mathrm{ECU} / 100 \mathrm{~kg})$ and their coefficients of variation (1986-95)

9. Total EU budget and budget expenditures for the common agricultural policy (CAP)

10. Advantages (+) and disadvantages ( - ) of individually and area-based insurance coverage for yields, using production history data

11. Advantages (+) and disadvantages (-) of individually and area-based assessment of yield losses

12. Problems, requirements and opportunities of insuring agricultural risks 36

13. Comparison of different insured aspects on problems of asymmetric information and reinsurance, ranging from -- (bad performance) to ++ (good performance)

14. Yield data: commodities and regions selected for illustration of yield-only insurance

15. Yield data expressed relative to farm averages

16. Commodity prices (1986-95) for potatoes, wheat and sugar beet

17. Effect of yield-only insurance for individual farmers (500@RISK iterations)

18. Effect of yield-only insurance with the occurrence of catastrophes (500@RISK iterations) 53

19. Loss ratio: fluctuation related to number of insured farmers and type of risk (500@RISK iterations)

20. Spread of indemnity payments of a pool with 100 farmers (500 @RISK iterations) 55

21. Payments of the European Commission (EC) to four insurers with and without the existence of a solidarity fund (500@RISK iterations)

22. Effect of gross revenue insurance for individual farmers (500@RISK iterations) 57

23. Effect of gross revenue insurance with increased CV for prices (500 @ RISK iterations) 58

24. Indemnity payments under yield-only and gross revenue insurance: an example 58

25. Financial performance of seven agricultural insurance programmes $\quad 74$

26. Participants $\quad 75$

27. Explanation of livestock unit (LU) $\quad 79$




Graphs 1. Livestock per farm (cattle and pigs: data for 1995; poultry: data for 1993) 12

2. Production of barley, potatoes and sugar beet per hectare (1996) 12

3. Net value-added per AWU and net return to labour and management per FWU 13

4. Independent versus systemic risks (Miranda and Glauber, 1997) 23

5. Insurance coverage for price and yield: (1) time period from which data can be used, (2) alternative types of data, and (3) alternative levels of data

6. Loss assessment: (1) time period from which data can be used, (2) alternative types of data, and (3) alternative levels of data

7. Scheme to determine the need for insurance, based on price variability, yield variability and price/yield correlation

8. Net return to labour and management

9. Net return to labour and management (with and without insurance) for a sugar beet farmer in Marche (Italy)

10. CDF of premiums received (P) minus indemnities paid (I) for wheat in Pays de la Loire (insurance pool of 100 farmers)

11. Schematic presentation of value-added and income (Eurostat, 1997) 73

12. PDF for wheat farmers in Makedonia-Thraki 



\section{Introduction}

Income from farming is usually considered to be rather volatile due to a whole series of stochastic factors that affect production and prices. Throughout the years, various risk management tools have been used to reduce, or to assist farmers to absorb, some of these risks. The common agricultural policy (CAP) of the European Union (EU) has taken away some of the risks, for example by assuring minimum prices for many agricultural products.

However, price and production risks are likely to increase in the future. International trade agreements can be expected to lead to price liberalisation and to more exposure of farmers to competitive market forces. Furthermore, as trade is expanded, new quality requirements are likely to be defined for farm products, such as stricter rules for use of fertilisers, herbicides and medicines for animals. As a result, production risk is also likely to increase.

Such developments affect the variability in income from farming. As a consequence, there may be a need for complementary measures that stabilise and safeguard incomes without interfering significantly with markets for agricultural products. One possibility that addresses income stabilisation is to provide insurance schemes.

The goal of this study is to examine whether there might be a case for farm income insurance in the EU in the future. The central question is under what conditions and in what form such an income insurance scheme might be feasible. An income insurance scheme might partly replace tools and mechanisms currently available to help European farmers cope with risk. In discussing the feasibility of agricultural income insurance the following conditions have to be taken into consideration: (1) interference/disturbance with markets should be kept to a minimum, (2) income insurance schemes need to be in compliance with WTO agreements, (3) any income insurance scheme needs to be developed in such a way that it can be run by the private sector, without, in principle, government involvement, (4) an income insurance scheme may not be used to finance or compensate a long-term sector decline, and (5) income insurance schemes must be applicable to both the northern and the southern European countries.

The report starts with a short overview of European agriculture (Chapter 2). Aspects such as size of farms, commodities produced, and variance in income earned are addressed. The current income protection provided by the EU price and income policy is also discussed.

Chapter 3 discusses important aspects of risk and insurance. Requirements of insurable risks are discussed, as well as problems of moral hazard, adverse selection and systemic risks. Also existing experiences with respect to 'income like' insurance schemes in other countries are addressed. The chapter furthermore includes a discussion on the need for income-related insurance schemes in European agriculture and the need for government involvement in such schemes. The chapter concludes with a discussion on future perspectives in the field of asymmetric information and systemic risk problems.

Chapter 4, entitled 'Agricultural income insurance in Europe', discusses the idea of income insurance in detail. Feasibility aspects of different income measures are discussed, starting at an aggregated level with whole-farm income insurance and portfolio revenue insurance. Then, aspects of gross revenue insurance on a commodity by commodity basis, and aspects of price and yield coverage are addressed. The chapter concludes by discussing business interruption insurance for epidemic disease risks.

In Chapter 5 a panel-data set with yield and price data is analysed and used as a basis for a simulation model. With the simulation model, the effect of gross revenue insurance and yield-only insurance on the stability of the farmer's income is illustrated. Also implications for insurers and the effect of reinsurance are explained. In Chapter 6 all preceding aspects are brought together and discussed in an integrated way. 



\section{The agricultural sector in Europe}

European agriculture varies among countries and among regions within countries. Yield per production unit, for example, varies due to factors such as differences in the availability and costs of technical equipment (for example, irrigation systems), education of farmers and size of holdings. Differences in environmental and welfare requirements can also influence production results. Technical and financial results can further vary among countries and regions according to sales prospects, transport facilities, the existence of production-marketing chains and the availability of seasonal labour. At farm level, differences also exist in the relative influence price and yield fluctuations have on a farmer's income. In a number of regions in the EU, agriculture is characterised by part-time farming. For part-time farmers, price decreases and low yields influence total income relatively less than is the case for full-time farmers.
To get more insight into the features of European agriculture, Section 2.1 lists some general figures about the number of farms, the size of farms, the number of livestock and the production per hectare of some major crops. Furthermore the concept of 'income' is defined and income differences among countries and sectors are described. In Section 2.2 the influence of the CAP on commodity prices is illustrated. Furthermore, the EU budget expenditures for the CAP are listed for the years 1991 to 1995.

\subsection{Features of agriculture in Europe}

\subsubsection{General figures}

In this section some general figures about European agriculture are shown. Data refer to both crop and livestock farms. For EU-12, Table 1 illustrates the number

Table 1

Number of farms, total agricultural area per country and the average agricultural area per farm (1993)

\begin{tabular}{|c|c|c|c|}
\hline & Number of farms & $\begin{array}{l}\text { Agricultural area } \\
(1000 \mathrm{ha})\end{array}$ & $\begin{array}{c}\text { Average agricultural area } \\
\text { per farm (ha) }\end{array}$ \\
\hline B & 76200 & 1354 & 17.6 \\
\hline DK & 73700 & 2722 & 37.1 \\
\hline D & 606000 & 17162 & 28.1 \\
\hline EL & 819200 & 5163 & 4.3 \\
\hline $\mathrm{E}$ & 1384000 & 29756 & 17.9 \\
\hline F & 801400 & 30136 & 35.1 \\
\hline IRL & 159400 & 4407 & 26.8 \\
\hline 1 & 2488400 & 16743 & 5.9 \\
\hline L & 3400 & 127 & 37.4 \\
\hline NL & 119600 & 1977 & 16.8 \\
\hline $\mathrm{P}$ & 488900 & 3992 & 8.1 \\
\hline UK & 243500 & 17240 & 67.3 \\
\hline EU-12 & 7263700 & 130779 & 16.4 \\
\hline
\end{tabular}

Source: Eurostat (1997). 
Table 2

Number of farms (1 000) per sector (data for 1993)

\begin{tabular}{|c|c|c|c|c|c|c|c|c|}
\hline & $\begin{array}{l}\text { Field } \\
\text { crops }\end{array}$ & $\begin{array}{l}\text { Horti- } \\
\text { culture }\end{array}$ & $\begin{array}{l}\text { Permanent } \\
\text { crops }\end{array}$ & $\begin{array}{l}\text { Grazing } \\
\text { livestock }\end{array}$ & $\begin{array}{l}\text { Pigs and } \\
\text { poultry }\end{array}$ & $\begin{array}{l}\text { Mixed } \\
\text { cropping }\end{array}$ & $\begin{array}{c}\text { Mixed } \\
\text { livestock }\end{array}$ & $\begin{array}{c}\text { Livestock } \\
\text { and cropping }\end{array}$ \\
\hline B & 8.5 & 6.1 & 2.8 & 36.9 & 5.6 & 2.1 & 5.0 & 9.2 \\
\hline DK & 31.9 & 1.5 & 0.8 & 15.1 & 5.2 & 3.1 & 3.1 & 13.1 \\
\hline$D$ & 124.1 & 13.9 & 48.6 & 226.2 & 20.6 & 26.8 & 45.6 & 100.3 \\
\hline$E L$ & 201.9 & 14.7 & 395.6 & 46.3 & 2.5 & 93.2 & 19.0 & 45.9 \\
\hline E & 225.8 & 70.5 & 554.9 & 287.3 & 18.9 & 102.9 & 42.6 & 68.7 \\
\hline $\mathrm{F}$ & 151.6 & 23.0 & 128.4 & 305.4 & 12.8 & 47.7 & 46.4 & 85.8 \\
\hline IRL & 4.4 & 0.5 & 0.1 & 148.7 & 0.7 & 0.2 & 0.4 & 4.3 \\
\hline 1 & 601.8 & 32.4 & 1088.3 & 280.0 & 11.0 & 280.8 & 39.5 & 120.5 \\
\hline L & 0.2 & 0.0 & 0.6 & 1.9 & 0.1 & 0.0 & 0.2 & 0.3 \\
\hline $\mathrm{NL}$ & 14.6 & 16.8 & 5.9 & 58.0 & 11.1 & 2.7 & 5.6 & 5.1 \\
\hline$P$ & 50.4 & 13.9 & 132.6 & 40.0 & 8.2 & 129.3 & 46.7 & 67.8 \\
\hline UK & 42.2 & 6.2 & 3.7 & 161.1 & 7.4 & 3.5 & 3.2 & 14.1 \\
\hline EU-12 & 1457.3 & 199.4 & 2362.2 & 1606.8 & 104.0 & 692.4 & 257.1 & 535.1 \\
\hline
\end{tabular}

Source: Eurostat (1997)

of farms, the total agricultural area and the average agricultural area per farm.

As Table 1 shows, most farms are located in the southern European countries (Greece, Spain and Italy). If the number of farms is compared with the agricultural area available, the highest farm density also occurs in these countries (with the exception of Spain). The average agricultural area per farm is the highest in the United Kingdom, whereas Greece has the least area per farm.

Table 2 shows the distribution of the total number of farms over different farming categories. Categories are based on the typology used in the EU system. In this

Table 3

Percentage of farms per economic size category (1) (data for 1993)

\begin{tabular}{|c|c|c|c|c|c|}
\hline & $<4 \mathrm{ESU}$ & 4-16 ESU & $16-40 \mathrm{ESU}$ & 40-100 ESU & $>100 \mathrm{ESU}$ \\
\hline B & 20.3 & 20.9 & 22.5 & 28.2 & 8.1 \\
\hline DK & 5.6 & 32.6 & 23.6 & 25.6 & 12.6 \\
\hline D & 31.7 & 27.4 & 22.8 & 15.1 & 3.0 \\
\hline EL & 53.0 & 38.6 & 7.5 & 0.9 & $\approx 0.0$ \\
\hline$E$ & 60.1 & 28.1 & 8.6 & 2.5 & 0.7 \\
\hline $\mathrm{F}$ & 27.7 & 22.8 & 26.3 & 18.3 & 4.9 \\
\hline IRL & 33.2 & 37.5 & 20.2 & 8.2 & 0.9 \\
\hline I & 68.2 & 21.8 & 6.6 & 2.6 & 0.8 \\
\hline L & 23.5 & 20.6 & 23.5 & 32.4 & 0.0 \\
\hline NL & 1.7 & 22.6 & 18.9 & 35.2 & 21.6 \\
\hline$P$ & 73.5 & 21.4 & 3.7 & 1.1 & 0.3 \\
\hline UK & 31.9 & 22.8 & 17.8 & 17.9 & 9.6 \\
\hline EU-12 & 53.5 & 25.9 & 11.6 & 6.8 & 2.2 \\
\hline
\end{tabular}


system, farms are assigned to a category according to the farm's main agricultural activity.

As Table 2 shows, for the northern European countries Belgium, Germany, Ireland, Luxembourg, the Netherlands and the United Kingdom, most farms are in the category 'grazing livestock'. The same is true for France. In the southern European countries, permanent crop farming prevails. Concerning the mixed farms, most can be found in Spain, Greece and Portugal. For EU-12 as a whole there are more crop farms than livestock farms.

Table 3 shows the percentage distribution of the total number of farms by economic size categories. In the southern European countries more than $50 \%$ of the farms are found in the smallest economic size category. Of the remaining countries, France, Germany, Ireland and the United Kingdom also have a lot of small farms; more than $50 \%$ of their farms are smaller than 16 ESU. In Belgium, Denmark and Luxembourg most farms belong to the categories 16-40 and 40-100 ESU. Only in the Netherlands are more than half of the farms bigger than 40 ESU. Table 3 gives insight into the economic size of farms.

Table 4 shows the extent to which farmers' incomes depend on farming activities. Farm income contributes on average less than $80 \%$ of total household income in all countries. In Italy the average percentage of income
Table 4

\section{Average sources of income for agricultural households}

\begin{tabular}{lcc}
\hline & Farm sources & Non-farm sources \\
\hline DK & 39 & 61 \\
\hline D-BRD & 47 & 53 \\
F & 62 & 38 \\
IRL & 68 & 32 \\
I & 31 & 69 \\
L & 66 & 34 \\
NL & 77 & 23 \\
UK & 57 & 43 \\
\hline
\end{tabular}

Source: Folmer, Keyzer, Merbis, Stolwijk and Veenendaal (1995).

from farming is especially low. Dutch farmers have the highest share of income from farming.

\subsubsection{Livestock farming}

Table 5 shows the total numbers of livestock per country. France has the highest numbers of cattle and poultry. The number of sheep is highest in the United Kingdom, whereas Greece has the most goats. The number of pigs is highest in Germany. Graph 1 shows the average numbers of the main types of livestock per farm.

Table 5

Numbers of livestock (1 000) (1)

\begin{tabular}{|c|c|c|c|c|c|}
\hline & Cattle & Sheep & Goats & Pigs & Poultry \\
\hline B & 3286 & 179 & 8 & 7268 & 28592 \\
\hline DK & 2090 & 157 & - & 11084 & 19816 \\
\hline D & 15953 & 2014 & - & 24674 & 86230 \\
\hline EL & 575 & 7716 & 4901 & 916 & 31853 \\
\hline$E$ & 5494 & 18950 & 2279 & 18126 & 104409 \\
\hline$F$ & 20647 & 10452 & 1055 & 14531 & 263613 \\
\hline IRL & 6532 & 7919 & 16 & 1542 & 12973 \\
\hline I & 7270 & 10389 & 1321 & 8063 & 149828 \\
\hline$L$ & 204 & 6 & 1 & 68 & 65 \\
\hline NL & 4654 & 1916 & 56 & 14398 & 98433 \\
\hline $\mathrm{P}$ & 1324 & 2786 & 616 & 2402 & 32588 \\
\hline UK & 11561 & 44266 & 79 & 7335 & 14913 \\
\hline EU-12 & 79590 & 106756 & 10336 & 110407 & 973585 \\
\hline
\end{tabular}

(') For cattle and pigs data refer to 1995; for sheep, goats and poultry, data are from 1993.

Sources: Eurostat (1997) and LEI/CBS (1997). 
Graph 1: Livestock per farm (cattle and pigs: data for 1995; poultry: data for 1993)



Sources: Eurostat (1997) and LEI/CBS (1997).

Graph 2: Production of barley, potatoes and sugar beet per hectare (1996)

$1000 \mathrm{~kg}$



Source: Eurostat (1997) 
As Graph 1 shows, the number of livestock per farm is much higher in the northern European countries than in the southern European countries. The number of livestock per farm is especially high in the Netherlands.

\subsubsection{Crop farming}

Graph 2 shows the differences in production results per hectare for three major crops. The production per hectare of barley and potatoes is higher in the northern European countries than in the southern European countries. Concerning the production per hectare of sugar beet, no clear distinction between northern and southern countries can be made; France, Greece and the Netherlands have a high production, whereas Ireland has the lowest production per hectare.

\subsubsection{Agricultural commodities}

Though a variety of crop and animal products is being produced within the EU, three major product groups can be distinguished: dairy products, grain and beef. Concerning the production of grain, Europe is the world's largest producer of barley. For beef, Europe is the second largest producer (following the US). Within the EU, considerable dif- ferences exist in productivity and prices for crop and animal products. Average production of, for example, barley in EU-12 is 5 tonne per hectare. However, productivity differs among countries, from 1.4 tonne per hectare in Portugal to 7.4 tonne per hectare in Belgium. Also prices vary among countries. For example, in 1995 prices of barley were 1.5 times higher in Italy than in Austria (Eurostat, 1997). It is likely that even more pronounced variations in productivity and prices would be found if analyses were conducted at district instead of country level.

\subsubsection{Agricultural income}

Before analysing differences in 'agricultural income', the concept of 'income' needs to be properly defined. Various income measures are in use. Annex I gives an overview of some of the more commonly applied measures.

The net value-added at factor costs is an indicator of the economic performance of a farm; it is the reward for family and hired labour, debt and equity capital, and management. To compare performances between farms, the net value-added at factor costs is often expressed per annual working unit (AWU) (Graph 3). Net return to

\section{Graph 3: Net value-added per AWU and net return to labour and management per FWU}
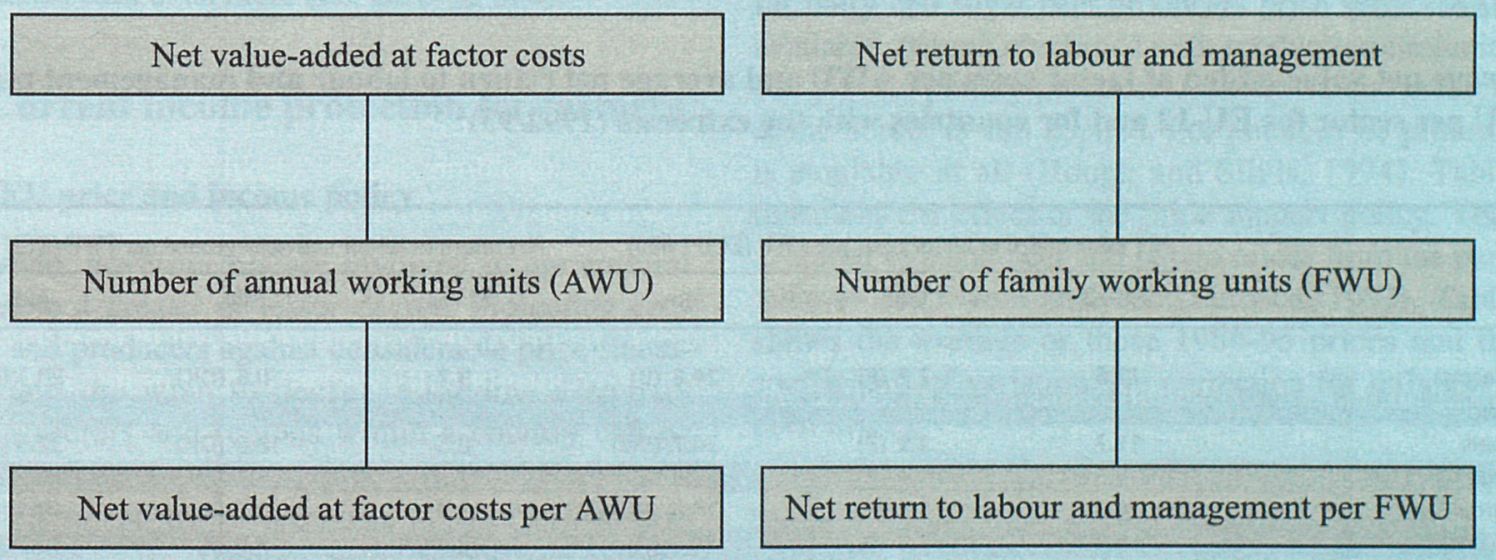
labour and management is the reward for family labour, management and equity capital. Because the number of 'family working units' (FWU) varies considerably among farms (on average 1.3 with a spread across countries from 0.9 to 1.5 ), the net return to labour and management is often expressed per FWU (Graph 3).

The issue of which of the various concepts presented would be best to use for income insurance will be addressed in Chapter 4. To illustrate the differences between net value-added at factor costs per AWU and net return to labour and management per FWU, Table 6 shows both concepts per sector.

As Table 6 shows, both the net value-added at factor costs per AWU and the net return to labour and management per FWU are highest for the pig and poultry sector. At country level, Portugal scores lowest in all sectors in terms of net value-added at factor costs per AWU. However, the net return to labour and management per FWU is not always lowest in Portugal; Denmark scores lowest on some sectors. According to the European Commission (1995), the differences in the ranking of Denmark between the two income measures are due to the fact that Danish farmers have relatively high levels of debt. Furthermore, in Denmark, part-time farming prevails and the European Commission argues that for part-time farmers, in general, income is not the main factor in taking management decisions.

The values shown in Table 6 show per sector the average return to labour and management levels for EU-12 and the maximum and minimum income levels for countries. However, considerable differences between income categories exist. Table 7 gives an overview.

As Table 7 shows, for EU-12 the net value-added at factor costs per AWU is about 13 times higher in the largest economic size category when compared to the smallest category (ECU 39700 versus ECU 3 100). Differences are even bigger when the net return to labour and management per FWU is considered.

Table 6 gives a representative overview of net valueadded and net income. However, the income data presented so far, while providing a useful overview, are not sufficiently comprehensive for analysing incomes for the purpose of assessing the scope for income insurance; more detailed data about the spread of incomes are needed. A simple comparison of Tables 6 and 7 shows that income differences are larger than presented in Table 6. In Table 6, for instance, the highest average net return to labour and management per FWU of ECU 53700 was received on Italian pig and poultry farms.

Table 6

Average net value-added at factor costs per AWU and average net return to labour and management per FWU per sector for EU-12 and for countries with the extremes (1992/93)

\begin{tabular}{|c|c|c|c|c|c|c|}
\hline & \multicolumn{3}{|c|}{ Net value-added at factor costs per AWU (ECU 1000$)$} & \multicolumn{3}{|c|}{ Net return to labour and management per FWU (ECU 1000 ) } \\
\hline & EU-12 & Min. & Max. & EU-12 & Min. & Max. \\
\hline All farms & 11.6 & $2.2(P)$ & $24.8(B)$ & 9.2 & $0.6(\mathrm{DK})$ & 20.3 (B+UK) \\
\hline \multicolumn{7}{|l|}{ Sector: } \\
\hline Cereals & 11.7 & $3.9(P)$ & 34.7 (IRL) & 8.5 & -18.0 (DK) & 32.5 (IRL+UK) \\
\hline Arable farming & 9.5 & $1.9(P)$ & $29.6(B)$ & 7.1 & $-9.1(D K)$ & 26.9 (UK) \\
\hline Horticulture & 16.0 & $1.1(P)$ & 24.6 (NL) & 13.4 & $0.7(P)$ & 19.1 (UK) \\
\hline Viniculture & 14.7 & $2.6(P)$ & $36.0(\mathrm{~L})$ & 12.4 & $2.0(P)$ & $39.3(\mathrm{~L})$ \\
\hline Fruit culture & 7.3 & $2.4(P)$ & $23.5(\mathrm{~B})$ & 6.4 & -0.2 (UK) & $27.2(\mathrm{~B})$ \\
\hline Dairy farming & 16.3 & $3.8(P)$ & $27.3(B)$ & 12.7 & $3.3(P)$ & 25.8 (UK) \\
\hline Grazing animals & 11.4 & $2.2(P)$ & $21.7(\mathrm{~B})$ & 9.7 & $-15.0(\mathrm{DK})$ & $16.9(B)$ \\
\hline Pigs and poultry & 29.2 & $9.4(P)$ & $52.1(1)$ & 26.9 & 10.4 (D-BRD) & $53.7(1)$ \\
\hline Mixed farming & 11.2 & $1.6(P)$ & $24.0(B)$ & 8.1 & $-1.6(D K)$ & 20.8 (UK) \\
\hline
\end{tabular}

Source: European Commission (1995). 
Table 7

Net value-added at factor costs per AWU and net return to labour and management per FWU per category for EU-12 and for countries with the extremes (data for 1992/93)

\begin{tabular}{|c|c|c|c|c|c|c|}
\hline & \multicolumn{3}{|c|}{$\begin{array}{c}\text { Net value-added at factor costs } \\
\text { per AWU (ECU 1 000) }\end{array}$} & \multicolumn{3}{|c|}{$\begin{array}{l}\text { Net return to labour and management } \\
\text { per FWU (ECU 1 000) }\end{array}$} \\
\hline & EU-12 & Min. & Max. & EU-12 & Min. & Max. \\
\hline All farms & 11.6 & $2.2(P)$ & $24.8(B)$ & 9.2 & $0.6(D K)$ & $20.3(B+U K)$ \\
\hline \multicolumn{7}{|c|}{ Economic size category $\left({ }^{(}\right)$: } \\
\hline $0-5$ & 3.1 & $1.2(P)$ & 9.7 (DK) & 0.4 & $-18.8(N L)$ & 2.5 (EL) \\
\hline $5-10$ & 8.7 & $5.8(P)$ & $21.7(\mathrm{DK})$ & 7.3 & $6.8(P)$ & $7.9(B)$ \\
\hline $10-20$ & 16.2 & $10.1(\mathrm{P})$ & $27.0(\mathrm{DK})$ & 14.2 & $13.1(\mathrm{EL})$ & $15.3(\mathrm{NL})$ \\
\hline $20-30$ & 25.7 & $11.1(\mathrm{P})$ & 35.9 (DK) & 24.3 & $23.2(L)$ & 24.6 (IRL+UK) \\
\hline$>30$ & 39.7 & $16.9(\mathrm{P})$ & 49.9 (DK) & 52.4 & 42.6 (EL) & 64.2 (UK) \\
\hline
\end{tabular}

Source: European Commission (1995).

However, in Table 7 it can be seen that net incomes can be higher: in the UK, farms in the largest economic size category receive on average a net return to labour and management per FWU of ECU 64200.

Incomes can further vary according to the degree of specialisation of a farm and to its location. As Table 6 shows, dairy farmers in Belgium receive on average the highest net value-added at factor costs per AWU (ECU 27 300). However, specialised dairy farmers in Belgium receive a net value-added at factor costs per AWU of ECU 35000 (LEI, 1996). Specialised dairy farms in the Netherlands earn even more (i.e. ECU 43 300).

\subsection{Current income protection for farmers}

\subsubsection{EU price and income policy}

Worldwide, governments are involved in agricultural markets, to a greater or lesser degree. Protecting consumers and producers against considerable price fluctuations and the wish to decrease income disparity between sectors and regions within a country can be some of the reasons for this involvement. Governments can be involved by influencing market prices and incomes (price and income policy) and by measures aimed at increasing agricultural productivity.

Price and income policy can consist of market regulation (for example, import levies, export subsidies and production quotas) and direct payments (for example, per unit output, hectare or farm). Within the EU, currently, a combination of both market regulation and direct payment mechanisms is applied. However, since 1992, reforms have been introduced (MacSharry plan). These reforms were initiated by the Uruguay round of the WTO (1986-94). In the Uruguay round, free trade was a key-point and agreements were made that measures of market regulation would be reduced, but that product independent payments would still be allowed.

Since the reforms, grain and beef producers have become more dependent on direct payments. However, for dairy and sugar beet producers price support is still available, though combined with production limitations. For pig and poultry producers, among others, protection at the border is still applied. For potatoes no protection is available at all (Hoogh and Silvis, 1994). Table 8 illustrates the effect of the price support policy. Yearly averages of sugar beet and potato prices from the period 1986 to 1995 were analysed (Eurostat, 1997). Table 8 shows the average of these $1986-95$ prices and their coefficients of variation. No correction for inflation has been made.

Table 8 shows that, among countries, average sugar beet prices differ less than average potato prices. Furthermore it is shown that, within countries, potato prices vary much more from one year to another than sugar beet prices, i.e. coefficients of variation are much higher for potato prices than for sugar beet prices for all countries. In analysing the coefficients of variation for 
Table 8

Average sugar beet and potato prices $\left(^{1}\right)\left(\right.$ ECU/100 kg) and their coefficients of variation $\left(^{2}\right)(1986-95)$

\begin{tabular}{|c|c|c|c|c|}
\hline & \multicolumn{2}{|c|}{ Sugar beet } & \multicolumn{2}{|c|}{ Potatoes } \\
\hline & Average price & Coefficient of variation & Average price & Coefficient of variation \\
\hline B & 4.0 & 4.9 & 7 & 48.6 \\
\hline DK & 3.9 & 7.7 & 16 & 35.9 \\
\hline D & 4.1 & 5.9 & 12 & 28.3 \\
\hline$E L$ & 4.8 & 11.7 & 22 & 23.6 \\
\hline $\mathrm{E}$ & 5.4 & 4.3 & 17 & 21.9 \\
\hline$F$ & 3.3 & 7.5 & 9 & 40.1 \\
\hline IRL & 4.8 & 4.7 & - & - \\
\hline 1 & 5.6 & 2.9 & 23 & 19.2 \\
\hline L & - & - & 16 & 19.0 \\
\hline NL & 4.7 & 7.4 & 10 & 43.8 \\
\hline $\mathrm{P}$ & 4.5 & 4.8 & 15 & 22.9 \\
\hline FIN & 8.4 & 18.9 & 23 & 20.7 \\
\hline$S$ & 3.9 & 12.8 & 18 & 27.9 \\
\hline UK & 4.3 & 6.5 & 14 & 40.6 \\
\hline
\end{tabular}

both sugar beet and potato prices, it has to be noted that individual farmers will have experienced more variability than these data show due to factors that influence farm-gate prices, like sugar content, transport costs, deductions for excess soil content, etc.

\subsubsection{EU agricultural budget expenditures}

Because an insurance scheme might be at least a partial replacement of the current agricultural support systems and because the European Commission might play a

Table 9

Total EU budget and budget expenditures for the common agricultural policy (CAP) (1)

\begin{tabular}{|c|c|c|c|c|c|c|}
\hline & Unit & 1991 & 1992 & 1993 & 1994 & 1995 \\
\hline Total budget EU & Million ECU & 53823 & 58857 & 65269 & 68355 & 76526 \\
\hline EAGGF-Guarantee ( $\left.{ }^{1}\right)$ & Million ECU & 32386 & 32108 & 34748 & 34787 & 36973 \\
\hline EAGGF-Guidance (') & Million ECU & 2011 & 2715 & 3386 & 2619 & 2827 \\
\hline Other & Million ECU & 145 & 177 & 204 & 127 & 147 \\
\hline Total budget expenditures CAP & Million ECU & 34542 & 35000 & 38338 & 37532 & 39947 \\
\hline Receipts of CAP (levies) & Million ECU & 2763 & 2209 & 2144 & 2305 & 2182 \\
\hline Net costs CAP & Million ECU & 31779 & 32791 & 36194 & 35228 & 37765 \\
\hline Net costs CAP per inhabitant of the EU & ECU & 92.1 & 94.7 & 104.6 & 101.3 & 108.2 \\
\hline
\end{tabular}

(1) From the European Agricultural Guidance and Guarantee Fund, the main expenditures under the Guarantee Section concern price and income support, while the Guidance Section supports structural developments.

Source: European Commission (1995). 
(limited financial) role in such an insurance scheme, it is necessary to have insight into the size of current EU agricultural budget expenditures. Table 9 gives an overview.
As shown in Table 9, the major share of the total EU budget is spent on the common agricultural policy. Though the share has been decreasing over the years, it was still more than $50 \%$ in 1995 . 



\section{Important aspects of risk and insurance: a literature review}

This chapter describes aspects that are essential when discussing the insurability of agricultural risks. First, a short introduction into the theory of risk is provided. Then, problems of asymmetric information and systemic risks are addressed. Furthermore, the issue is raised as to which type of data can form the basis for insurance coverage. The same is done for the type of data on which losses can be assessed. Section 3.5 addresses the time period of insurance contracts (multiyear or single year contracts). Section 3.6 discusses aspects related to the insurance participation (mandatory versus voluntary). Experiences with insurance schemes for agricultural risks from other countries are reviewed in Section 3.7. Sections 3.8 and 3.9 discuss the need for insurance schemes and the need for government intervention in such schemes respectively. Section 3.10 concludes the chapter with a discussion on future perspectives on asymmetric and systemic risk problems.

\subsection{Short introduction to the theory of risk}

\subsubsection{Impacts of risk}

There are two reasons why risk in agriculture matters (Hardaker et al., 1997): (1) most people dislike risk and (2) downside risk.

Most people are risk averse when faced with significantly risky prospects for income or wealth. A person who is risk averse will be willing to forgo some expected return for a reduction in risk, the rate of acceptable trade-off depending on how risk averse that individual is. Evidence of farmers' risk aversion is to be found in many of their actions, such as their willingness to buy certain kinds of insurance or their tendency to prefer farming systems that are more diversified than might seem best on profit grounds alone. The existence of risk aversion means that analysis of risky choices in terms of their average or expected consequences will not always lead to the identification of the 'best' option. Farmers, like most people, do not, and will not wish to, make choices based on what will pay best 'in the long haul' if that choice means exposing themselves to an unacceptable chance of loss. Evidently, this aversion to risk has to be taken into account in developing and applying methods of decision analysis.

The great bulk of analytical investigation of risk in investment appraisal and project evaluation has been concerned with 'pure risk', that is, variation about some measure of 'representative' performance that is the focus of attention, such as the mean. It may be argued, however, that a concept of 'downside risk' is more relevant in a variety of situations including many analyses of risk in agriculture. The key consideration in the general downside-risk concept is that, in what has become normal analytical practice, attention has naturally been concentrated on a situation representing a 'standard' or 'normal' outcome, rather than a mean outcome, the usual theoretical reference outcome in risk analysis. We are, in contrast, defining downside risk as a shorthand description for those situations in which any significant deviations from the 'norm' lead to worse outcomes. Thus, when downside risk is predominant over pure risk, the normal outcome represents the upper tail of the distribution of outcomes (or possibly a probability mass towards the upper end of the distribution). Most of the technical risk associated with decisions in agriculture may be regarded as downside risk, since most significant deviations from plan are likely to have adverse, rather than favourable, consequences. Downside risk may also arise when a risky outcome depends on nonlinear interactions between a number of random variables. The yield of a crop provides an obvious example. Yields depend on a large number of random variables, such as rainfall and temperature in each stage of the growing season. Large deviations of these variables in either direction from their expected values tend to have adverse effects. 


\subsubsection{Subjective expected utility}

More than 200 years ago, Daniel Bernoulli was the first to suggest a formalised explanation of risk aversion. It was not until the 1940s that John von Neumann and Oscar Morgenstern provided the first axiomatic treatment of what is called the subjective expected utility (SEU) hypothesis, also sometimes known as Bernoulli's Principle, that forms the basis of modern utility theory (Hardaker et al., 1997).

A risky prospect is another name for a risky choice, meaning that the decision-maker faces uncertain consequences or payoffs. For every decision-maker faced with any risky prospect, there is a sum of money that would make that person just indifferent between facing the risky prospect and accepting the sum of money. This sum is the lowest price he or she would be willing to sell a desirable risky prospect for, or the highest payment he or she would make to get rid of the risk. This sure sum is called the 'certainty equivalent' (CE) of that decision-maker for that risky prospect. In general, CEs will vary between people, even for the same risky prospect, because we seldom have identical attitudes to risk. The application of the hypothesis, including the application of CEs can be illustrated by means of an example.

Consider the following decision problem in which there is a once-only choice to be made between a1 and a2, with consequences depending on which of two equally likely uncertain events $S_{1}$ or $S_{2}$ occurs:

\begin{tabular}{lccc}
\hline$S_{i}$ & $P\left(S_{i}\right)$ & $a_{1}$ & $a_{2}$ \\
\hline$S_{1}$ & 0.5 & 1000 & 500 \\
$S_{2}$ & 0.5 & 0 & 500 \\
EMV (USD) & & 500 & 500 \\
\hline
\end{tabular}

Any risk averter will prefer $a_{2}$ to $a_{1}$, while a risk preferrer will prefer $a_{1}$ to $a_{2}$. Only a person indifferent to risk, who would base choice on the expected monetary values (EMVs), would be indifferent between the two options. However, because of the evidence that almost everyone dislikes risk, at least for non-trivial money consequences, we shall concentrate on risk aversion. What follows applies with only minor modifications for decision-makers who are not risk averse.
If we progressively reduce the USD 500 payoffs for the sure thing represented by $a_{2}$, there will come a point where the decision-maker is indifferent between the two options. Suppose that, in the example above, the CE for some individual is USD 450 . We can say, therefore, that the utility of the risky prospect $\mathrm{a}_{1}$ is equal to the utility of the USD $450 \mathrm{CE}$ for this person.

It can be shown that a utility function, $U$, exists and has the following properties (Hardaker et al., 1997):

1. $U\left(a_{1}\right)>U\left(a_{2}\right)$ if, and only if, $a_{1}$ is preferred to $a_{2}$; and

2. $U\left(a_{j}\right)=E\left(U\left(a_{j}\right)\right)$, i.e. the utility of a risky prospect is its expected value.

In this case, the second of these properties implies that the utility of the risky prospect $a_{j}$ is equal to its expected utility, calculated as the probability-weighted average of the utilities of the individual consequences, while the first property implies that this utility value is equal to the utility of the certainty equivalent, i.e.:

$$
U\left(a_{1}\right)=0.5 U(1000)+0.5 U(0)=U\left(a_{2}\right)=U(450)
$$

In other words, the SEU hypothesis shows how to integrate the two components of utility (preference) and probability (degree of belief) to provide a means of ranking risky prospects, so enabling risky choice to be rationalised.

\subsubsection{Measures of risk aversion}

Risk attitudes are implied by the shape of the utility function. For example, if the utility function has a positive slope over the whole range of payoffs, the implication is that more payoff is always preferred to less. Preferences of this kind are normal for money. In the language of mathematics, the characteristic that more money is preferred to less may be written:

$$
U^{(1)}(W)>0
$$

where $U^{(\mathrm{i})}(W)$ is the $i$-th derivative of the utility function for wealth $W$. (Income can be substituted for wealth here.) So, if the first derivative of the utility function for wealth is positive (for all $W$ ), then it represents the situation of 'more is preferred to less'. Similarly, risk aversion is indicated by a utility function that shows decreasing marginal utility as the level of the payoff is increased, while indifference to risk is represented by a linear utility function. More formally, in terms of the second derivative: 
1. $U\left({ }^{2}\right)(W)<0$ implies risk aversion $(\mathrm{CE}<\mathrm{EMV})$;

2. $U\left({ }^{2}\right)(W)=0$ implies risk indifference $(\mathrm{CE}=\mathrm{EMV})$; and

3. $U\left({ }^{2}\right)(W)>0$ implies risk preference $(\mathrm{CE}>\mathrm{EMV})$.

\subsubsection{Risk analysis with preferences unknown}

A difficulty often encountered in applying the SEU model is in the elicitation of the decision-maker's utility function. The problem may be lack of access to the relevant person, inadequate introspective capacity on that person's part or the fact that more than one person may be involved. For example, there is no effective way of eliciting preferences from a board of directors. Similarly, in agriculture, it may be necessary to develop recommendations for a particular target group of farmers numbering perhaps some hundreds or even thousands. Efficiency criteria were devised in an attempt to rank choices without specifying the utility function except in limited-information terms (Hardaker et al., 1997).

Efficiency analysis depends on making some assumptions about preferences, i.e. about the nature of the utility function, thereby avoiding the need to elicit a specific function. Often bounds are placed on the level of risk aversion. Then, for all decision-makers to whom the assumptions apply, the various actions can be divided into an efficient set and an inefficient set. The inefficient set contains those actions that are dominated by (preferred less than) actions in the efficient set. Usually, the cumulative distribution functions (CDFs) of net outcomes of actions or strategies are used in the efficiency analysis. So, the entire CDF of outcomes is used, not just mean and variance. In this context it is important to avoid falling into the trap of equating risk with variance. Just because one activity has a higher variance of returns than another does not mean that it is less risk-efficient. Risk efficiency can be attained by reducing variance or by increasing expected return, or both. The point of maximum expected utility will not be attained by minimising variance alone.

\subsubsection{Risk and insurance}

There are various types of insurance contracts available to farmers, including fire and theft cover for assets, death and disability cover for proprietors, cover for workers' injuries and for public liability and mortality and infertility cover for stud stock. The principle of insurance as a risk-sharing device is that, by accepting appropriate premiums from a large number of clients, the insurance company is able to pool the risks. Moreover, by use of information on the frequency and level of claims, the company aims to set premiums at levels that will enable it to pay all claims from the aggregate contributed premiums and still leave a margin for operating costs and profit.

From the point of view of the farmer considering buying insurance, this means that the expected value of insuring is almost certainly negative. The expected value can only be positive if the farmer assesses his or her probability of making a successful claim as considerably higher than the probability judged by the company from actuarial information. Such an outcome is unlikely since most policies require the person taking out the insurance to disclose to the company any special circumstance that might increase the risk of the insured event occurring. To fail to do so is supposed to invalidate the policy. That so many agricultural insurance schemes have been complicated by such 'moral hazard' difficulties must mean that many farmers have not exactly adhered to the rules (see Section 3.2.1).

It follows from the above that insurance will usually be attractive only for risk averters, and only then for risks that are sufficiently serious to warrant paying a premium equal to significantly more than the expected loss without insurance. For most farmers, and most people, this means that insuring small, easily borne risks will not be worthwhile. However, it may well be worth insuring large risks that otherwise could threaten the continued existence of the farm business or that could seriously damage the welfare of the owners.

\subsubsection{Risk management strategies}

In the introduction to Chapter 2, a number of reasons were listed that cause production results of farms to vary across countries of the EU and across areas within countries. Additional variability in farm results can exist because agriculture in general is exposed to various sources of risks. Hardaker et al. (1997) distinguish production risks, price risks, personal risks, financial risks and institutional risks. The impact of the various sources of risks varies across farms, regions and countries.

Farmers cope with risks in various ways. Two categories of measures can be distinguished: on-farm 
measures and strategies in which risks are shared with others. Possible on-farm measures are (Hardaker et al., 1997):

- collecting information to better estimate the effects of decisions;

- avoiding or reducing the exposure to risks, for example by selecting crops for which prices are more or less guaranteed by the government instead of crops for which prices are affected by fluctuating markets;

- diversification, so as to reduce the risk to overall returns by selecting a mixture of activities that have net returns with low or negative correlation; and

- flexibility, for example in time, by growing crops with short production cycles.

Strategies to share risks with others include:

- insurance, mostly applied to large risks that otherwise could threaten the continued existence of the farm business or that could seriously damage the welfare of the owners;

- contract marketing, useful for price, production and quality agreements with both suppliers as well as buyers; and

- hedging on the futures market to reduce price risks.

Examination of the sources of risks and the various risk management strategies, suggests that, for EU farmers, institutional risks may prevail, including, for example, a decrease in price support (see also Section 2.2.1) and a decrease in financial support from the EU for farms confronted with disease outbreaks.

\subsection{Insurable risks}

In theory, all risks could be insurable as long as actuarially sound premiums are charged. Actuarially sound premiums accurately reflect the risks involved. However, in practice actuarially sound premiums can be established only at a very high price or cannot be achieved at all. A major problem in this regard is caused by 'asymmetric information', referring to a situation in which one party has more or better information than the other party. Even if the problem of asymmetric information is overcome, 'systemic risks' may still not be insurable. A risk is called systemic if losses can arise to multiple insured farmers at the same time from one peril, so exposing the insurer to a very large potential loss.

The basic requirements, according to Miranda and Glauber (1997), for agricultural risks to be insurable relate to asymmetric information and systemic risk problems. They state that for any insurable risk: (1) the insurer and the insured should have very nearly symmetric information regarding the probability distribution of the underlying risk and (2) risks should be very nearly stochastically independent across insured individuals. In this section, the aspects of asymmetric information and systemic risks are discussed. Furthermore, the general requirements of insurable risks put forward by the literature are listed.

\subsubsection{Asymmetric information}

Asymmetric information manifests itself in two ways in insurance: 'moral hazard' and 'adverse selection'. 'Moral hazard' occurs when an individual purchases an insurance policy and as a result of having purchased that policy, alters his/her behaviour (production or management practices) so as to increase the potential magnitude of a loss and/or the probability of a loss (Barnett et al., 1998). Chambers (1989) states that insurance contracts must recognise that, once adopted, people treat them as economic data and optimise accordingly. Furthermore, the problem of moral hazard could vary with the 'trend of events', meaning that the general state of the economy could influence the behaviour of insured farmers. 'Adverse selection' occurs when potential insurance purchasers have more or better information about their potential magnitude of loss and/or probability of loss than does the insurer (Barnett et al., 1998).

Tools insurers use to minimise moral hazard are: deductibles (excesses) or co-payments, both of which require the insured to bear part of the loss (a given level in case of deductibles and a percentage of the total claim in case of co-payment); no-claim bonuses, which are premium discounts granted when no claims are made and checks to make sure the insured is really meeting his/her obligations of taking proper care to prevent accidents and limit the damage if an accident occurs (Borch, 1990).

Adverse selection can be reduced by assigning insurance purchasers to various risk classifications based on 
thorough information about the magnitude and probability of loss, or even excluding high-risk people, areas, etc., from insurance. Checking an insured person's behaviour and assessing exposure to risk involves costs for the insurer. However, if these tools are not applied appropriately, moral hazard and adverse selection can mean that the insurer pays out more than the premiums received, which may make the particular type of risk uninsurable.

\subsubsection{Systemic risks}

In principal, insurance is based on the pooling of independent risks, such as the risk of burglary. If one insured individual claims a loss due to burglary, it is very unlikely that a lot of others will claim losses due to burglary at the same time. Systemic risks on the other hand, are dependent risks: a lot of people will suffer a loss at the same time. Examples of systemic risks are price and interest rate fluctuations. Generally, systemic risks are dealt with on options and futures markets. Graph 4 shows that risks from, for example, crop yields are neither perfectly independent nor perfectly systemic.
Private sector insurance companies have problems in maintaining adequate reserves and getting access to enough reinsurance capacity (see Section 3.3) when dealing with risks that have systemic characteristics. However, opportunities exist in combining insurance and capital markets (see Section 3.10).

\subsubsection{Requirements of insurable risks}

\subsubsection{Literature lists a number of requirements}

As noted, Miranda and Glauber (1997) argue that the two basic requirements for agricultural risks to be insurable deal with the absence of asymmetric information and systemic risks. The literature lists a number of other aspects that are desirable for insurable risks (US Income Task Force, 1983; Hazell, 1992; Barnett et al., 1998). In this section these aspects are categorised according to: (1) general design of an insurance scheme, (2) institutions involved and (3) ways to prevent adverse selection and moral hazard.

\section{Graph 4: Independent versus systemic risks (Miranda and Glauber, 1997)}

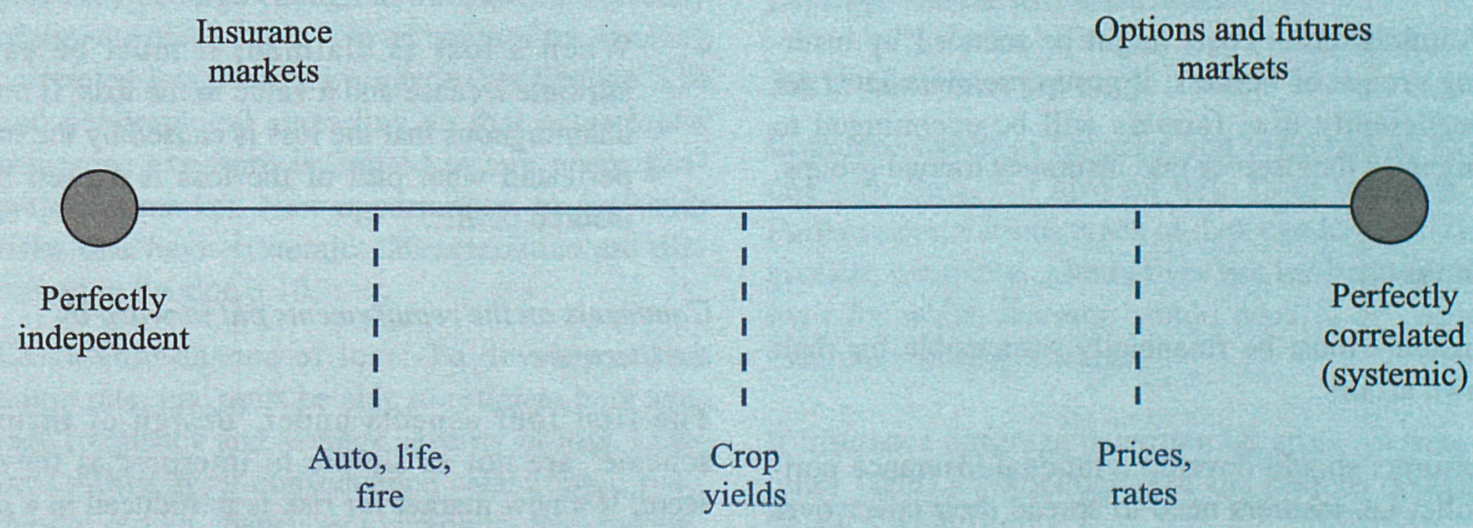




\section{Design of an insurance scheme}

- Programme should not reduce international competitiveness.

- Programme should not lead to distortion of price signals.

- $\quad$ Programme should have as little disruptive effect as possible on related farm input markets.

- $\quad$ Programme benefits should not be bid into land values.

- $\quad$ Programme benefits and costs should be set at a level to encourage substantial participation.

- Any insurance scheme should be voluntary.

- Programme should allow for changes in productivity and production practices, i.e. if productivity and production practices change, the programme must be flexible enough to adapt to the new circumstances.

- Programme should not 'bail out' those who have made poor management decisions.

- $\quad$ Programme should be simple, easy to understand and administer.

- Programme should be isolated as much as possible from political pressures.

- Administration costs need to be controlled tightly.

- Administration costs might be reduced by insuring groups of farmers; if group premium rates are sufficiently low, farmers will be encouraged to organise themselves into insurance mutual groups.

\section{Institutions involved}

- Insurers must be financially responsible for their own affairs.

- Insurers should develop a rational insurance portfolio, i.e. insurers need to spread their cover over a diversity of risks, meaning different types of policy, in different economic sectors, parts of the country and also in different countries.

- If governments provide reinsurance it should not be given for free.
Ways proposed in the literature to prevent adverse selection and moral hazard

- Premiums based on actuarial calculations are high enough to cover average indemnities, administration costs and a contribution towards building up a financial reserve.

- Compensation for actual crop damage or inputs lost; not for failure to achieve a normal or target yield.

- $\quad$ Payments under the programme set at such a level as to insure income at no more than $100 \%$ of the cash cost of production. However, this implies that the cash costs of production are identifiable and measurable; in agriculture, problems of joint costs and the valuation of some of the inputs (notably land) exist.

- Indemnities should be based upon prices in a well-defined market.

- Substantial deductibles (excesses) should be included ('substantial' depends on specific circumstances).

- $\quad$ Programme should be so structured that it does not increase risk-taking in production practices.

- Programme should cover only those production activities which are proven commercially feasible in a given area.

- Programme should not encourage farming in marginal areas that would not be in production without the insurance scheme.

- When a loss is claimed, it must be easy to attribute a cause and a value to the loss. It must be unambiguous that the loss is caused by the insured peril and what part of the loss is caused by the insured peril.

\section{Comments on the requirements put forward by}

\section{the literature}

The first four aspects under 'design of insurance scheme' are not as simple to interpret as they may seem. If a new market for risk is introduced in a particular country or group of countries, with no subsidy, but on terms that make it attractive for farmers, international competitiveness will be affected, prices will change, as will the use of other inputs, and land values will tend to rise. If these things did not happen, the scheme would have failed. 


\subsubsection{Six major requirements}

All aspects and requirements mentioned in the previous section are reflected in the following six major requirements of insurable risks (Rejda, 1992; Skees and Barnett, 1998):

1. Large number of exposure units: Pooling involves the grouping of a large number of roughly homogeneous, independent exposure units so that the law of large numbers can provide an accurate prediction of average future losses. If a classification system cannot be found that results in relatively homogeneous risk exposure units, 'adverse selection' will result and only the higher risk members of the classification will participate in the pool.

2. Accidental and unintentional loss: Losses must occur as a result of chance, an 'act of God' rather than an 'act of management'. If, as a result of purchasing insurance, management decisions are made that significantly alter the probability of loss and/or the extent of loss, 'moral hazard' will exist.

3. Determinable and measurable loss: Loss must be determinable and measurable within an acceptable level of reliability. 'This means the loss must be definite as to cause, time, place and amount' (Rejda, 1992, p. 23).

4. No catastrophic loss: If losses are positively correlated across insurance units (i.e. the underlying risk is systemic) the law of large numbers does not apply. Annual losses for the insurance pool will be extremely variable. The loss in any given year may be large enough to threaten the solvency of the insurance pool. Two techniques for insuring correlated losses are reinsurance (see Section 3.3) and geographical spreading so that catastrophe insurance exposure is limited in any given geographical market. New opportunities to deal with risks that have systemic characteristics are discussed in Section 3.10.

5. Calculable chance of loss: To develop a premium rate, one must be able to estimate both average frequency and average severity of loss. Lowprobability, high-consequence catastrophic risks present serious challenges in premium rate-making.

6. Economically feasible premium: Premiums must be affordable. The chance of loss must be in a range that does not result in extremely high premiums. At some high level of probability, the loss becomes a standard business expense instead of a risk to be transferred. While the chance of loss must not be too high, the potential for loss must be economically significant. Otherwise there will be no demand.

\subsection{Reinsurance}

Reinsurance is insurance of insurance companies; insurance companies transfer part of the risk they assume to other insurance companies (reinsurers). The traditional forms of reinsurance fall into two categories: proportional and non-proportional reinsurance. Proportional reinsurance describes a contract in which reinsurance companies take a portion of all losses, whereas nonproportional reinsurance refers to a contract in which the insurance company retains all losses up to a predetermined amount and then recovers the losses beyond that amount (subject to some limit) from the reinsurer. Nonproportional reinsurance (excess of loss or stop loss reinsurance) was developed in response to a need from insurance companies for catastrophe or high-limit reinsurance coverage (Strain, 1980).

\subsection{Insurance coverage and loss assessment}

Insurance coverage can be written and losses assessed on the basis of various types of data. This section first describes alternatives for insurance coverage, both for prices and for yields. The same is then done for loss assessment. Section 3.4.3 gives an example of an insurance scheme that uses area data for both the insurance coverage and the loss assessment.

\subsubsection{Insurance coverage}

Insurance coverage for price and yield can be based on one-year data, but also on data from multiple years. Furthermore, various types of data can be used. Graph 5 gives an overview. Alternatives not advised and alternatives for which research would need to be carried out first, are between brackets.

If insurance coverage is written on gross revenue (price times yield) a combination of the options described in Graph 5 would apply.

\section{Price}

Time period from which data can be used: Writing insurance coverage on one-year data (i.e. the data of the year the insurance is written in) provides an insurance 
Graph 5: Insurance coverage for price and yield (1): (1) time period from which data can be used, (2) alternative types of data, and (3) alternative levels of data

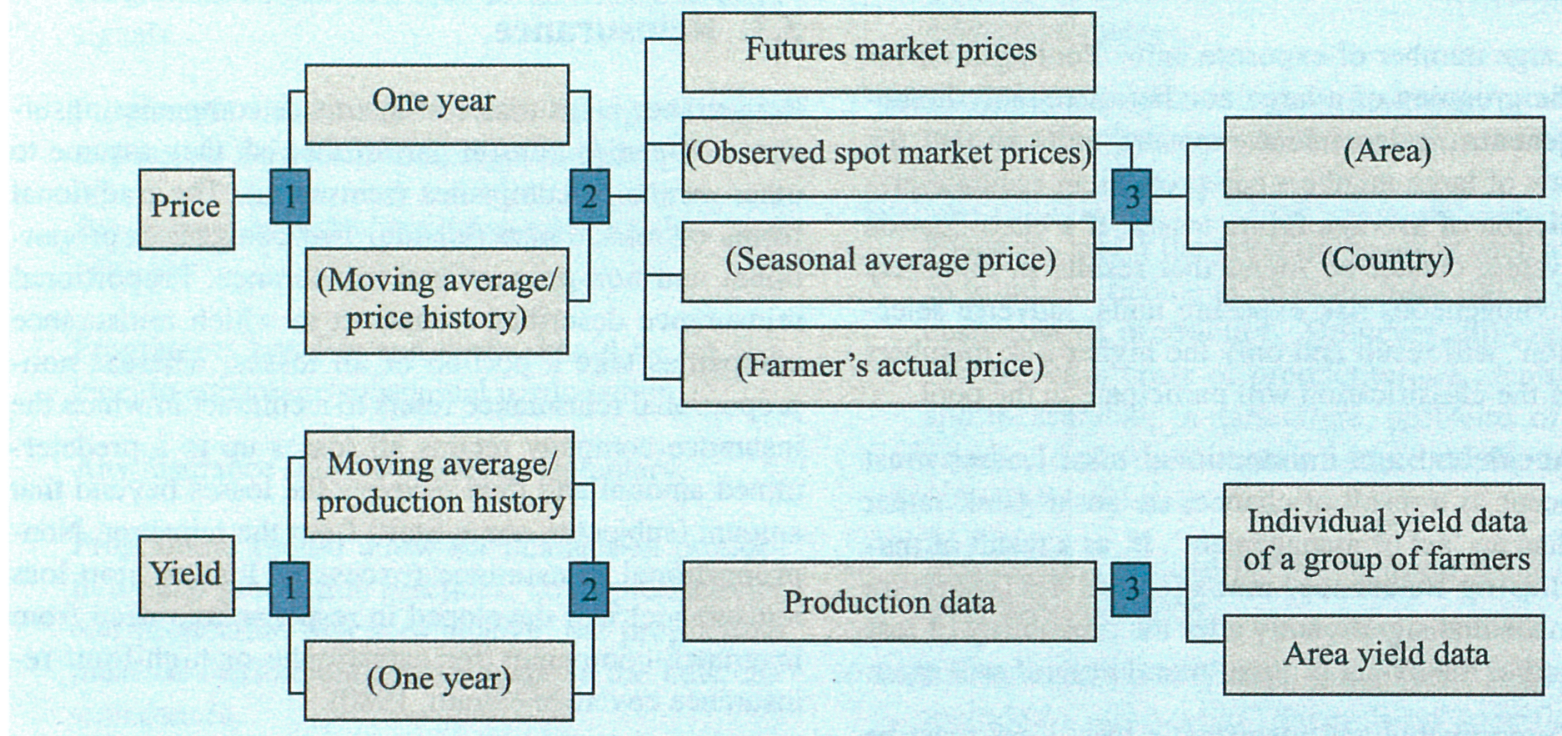

(1) Alternatives which are not recommended are given in brackets.

that uses all available information and expectations about prices in that particular year. The opposite is true when a moving average is used. If, for example, a moving average of 10 years is used, price protection is relatively low if current prices are higher than those in the preceding years. On the other hand, protection is relatively high in the case where current prices are lower than prices in preceding years.

Alternative types of data: For commodities for which a futures market exists, the futures market prices can be used as a basis for insurance, because they are independent of the marketing management decisions of a particular farmer and furthermore are easy to obtain (low transactions costs). With futures market prices, however, farmers face basis risk (see overleaf). An observed spot market price or a seasonal average price might provide suitable data, but for these two alternatives research in the field of basis risk needs to be conducted first. It is not advisable to insure the farmer's actual price, because the farmer would no longer have any incentive to strive for the best price.
Alternative levels of data: if observed spot market prices or a seasonal average price is used, the availability of data and the level of the basis risk should indicate whether it makes sense to differentiate prices at area level.

\section{Yield}

Time period from which data can be used: In writing insurance coverage on yields, it seems logical to use production history data instead of one-year data. If insurance coverage is based on historical data, information about management capacities of the farmer and local production circumstances is automatically included in the insurance.

Alternative levels of data: Yield production history data can refer to farmers' individual data, but also to area data. An area is here defined as a geographical area with nearly the same production circumstances and in which production results are highly correlated. Such areas are easier to define for crops than for livestock. If insurance coverage is written on area data, this would 
Table 10

Advantages (+) and disadvantages (-) of individually and area-based insurance coverage for yields, using production history data

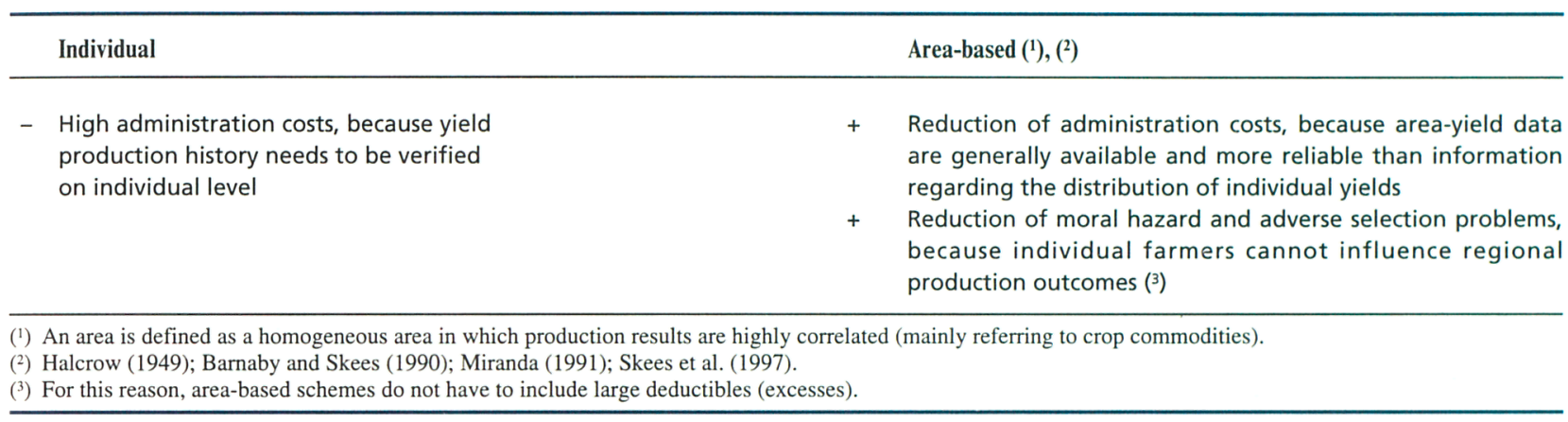

imply that the basis of premium schedules would be the same for all farmers in that area. (The exact premium an individual farmer needs to pay depends on the coverage level chosen). Table 10 shows advantages and disadvantages of writing insurance coverage for yields on strictly individual or strictly area data.

As Table 10 shows, the approach of area-based insurance coverage is worth considering because of the opportunities to reduce moral hazard, adverse selection and administrative costs. If the individual yield data of a group of farmers are used (left hand side of the table) and insurance companies supplement these data by correcting (loading or discounting) for production results of the individual farmer (so-called experience rating), problems of moral hazard would also be reduced at this side of the table, because when data are corrected for individual production results, claiming low yields in a certain year decreases the individual farmer's future coverage.

\section{Basis risk}

The basis is the expected difference between the futures price and the cash price in the producer's local market where the cash product will be sold. Basis risk is the possibility that the cash-futures basis will not move to expected or predicted levels (Purcell, 1991). Basis risk is not restricted to prices; it can also refer to, for example, to individual versus area yields.

\subsubsection{Loss assessment}

For the assessment of losses almost the same data options apply as for insurance coverage. Graph 6 gives an overview. Again, options not advised or as yet uncertain are between brackets.

If insurance coverage is written on gross revenue (price times yield) a combination of the options described in Graph 6 would apply.

\section{Price}

The remarks here are almost the same as under the insurance coverage (previous section). Multiple year loss assessment (if one bad year is not considered to be a catastrophe for a farmer) is not really an option for price since both coverage and loss assessment are likely to be on a yearly basis.

\section{Yield}

Time period from which data can be used. A multiple year loss assessment implies that insurance payments are only made if yields are bad, for example, three years in a row. Such insurance will be likely to suffer from more problems of adverse selection and moral hazard than a scheme in which yield losses are assessed on a yearly basis.

Alternative levels of data. If, in a yield insurance scheme, losses are assessed at individual level, an insured farmer receives an indemnity payment if individual yields fall below the insured trigger yield, whereas in an area-based insurance, a participating farmer receives a payment only if the area yield falls below a trigger yield. Loss assessment at area level implies that the basis for indemnity payments would be 


\section{Graph 6: Loss assessment (1): (1) time period from which data can be used, (2) alternative types of data, and (3) alternative levels of data}
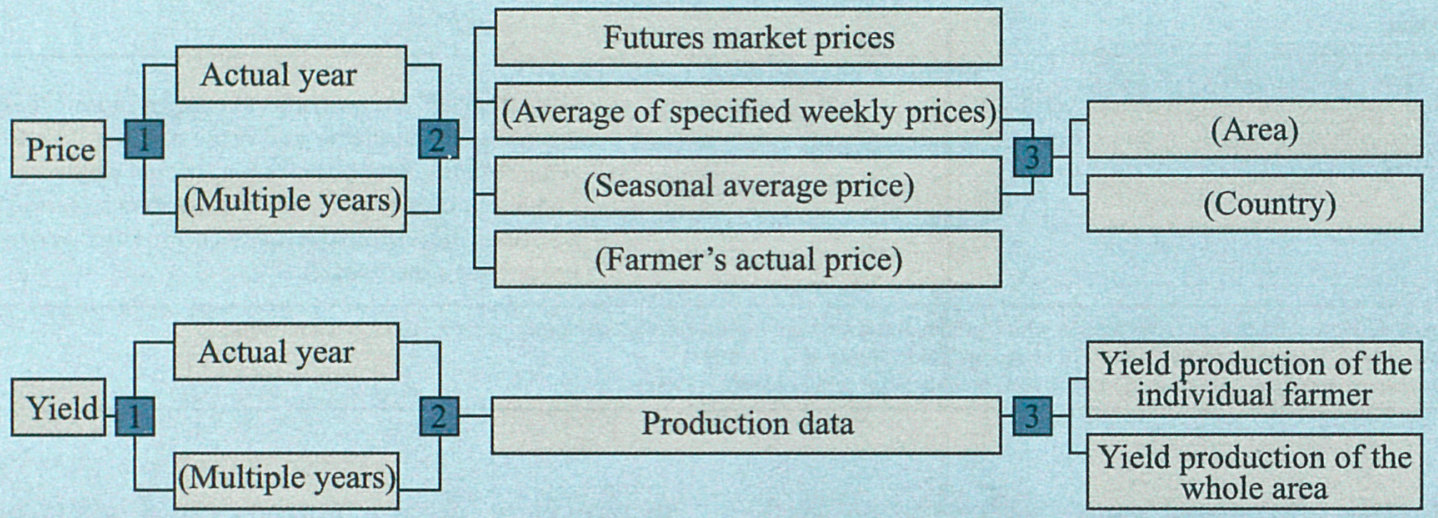

(1) Alternatives which are not recommended are given in brackets.

the same for all farmers in that area (the eventual payment an individual farmer receives depends on the guarantee level chosen).

As Table 11 shows, the advantages and disadvantages shown for both options exactly balance each other.

\subsubsection{Combining insurance coverage and loss assessment}

Every insurance scheme needs to combine one of the insurance coverage options with a form of loss assessment. In combining different options, attention needs to be paid to possible problems of moral hazard and adverse selection.

A combination of individual and area-based concepts in one insurance scheme is likely to result in adverse selection and moral hazard problems. If, for example, insurance coverage is written on area level data but losses are assessed at individual level (which was the practice in the US federal crop insurance programmes until 1981) adverse selection is likely to occur because particular farmers with crop yields lower than area yields will take out insurance; moral hazard is likely to occur because low individual yields do not influence an individual farmer's future coverage.

The group risk plan (GRP), introduced in the US in 1993, is an example of an insurance scheme that uses area (county) data for both insurance coverage and loss assessment. GRP offers insurance on a county's average yield on the premise that, when the county average yield is low, most farmers in the county will suffer losses (Goodwin and Smith, 1995). In 1994, GRP was extended to one third of all counties in the US. The products that can be insured under GRP include barley, corn, cotton, peanuts, grain sorghum, soybeans and wheat.

\subsection{Multi-year versus single year insurance contracts}

In order to prevent a year-to-year variability in participation (fluctuating with the market outlook) farmers would have to participate on a multi-year rather than a year-to-year basis. Farmers could be encouraged to do so through incentives such as premium discounts for multi-year contracts (Vertrees, 1984). With multi-year 
Table 11

Advantages (+) and disadvantages (-) of individually and area-based assessment of yield losses

\begin{tabular}{ll}
\hline Individual & Area-based $\left({ }^{1}\right),\left({ }^{2}\right)$ \\
\hline+ Payments fit individual yield losses & $\begin{array}{l}\text { Farmers may experience farm-level yield losses when area- } \\
\text { yield shortfalls are not sufficient to trigger an indemnity } \\
\text { payment (basis risk) } \\
\text { Area-yield shortfalls are easy to determine }\end{array}$ \\
$\begin{array}{ll}\text { (1) An area is defined as a homogeneous area in which production results are highly correlated (mainly referring to crop commodities). } \\
\left({ }^{2}\right) \text { Halcrow (1949); Barnaby and Skees (1990); Miranda (1991); Skees et al. (1997). }\end{array}$ \\
\hline
\end{tabular}

contracts, it would be essential to have a withdrawal option if a producer leaves agriculture or undertakes a substantial change in production practices.

There are three important issues here. First, why would we want to 'prevent' a year to year fluctuation? It is perfectly rational for a farmer to pull out of a scheme if he/she thinks that the probability of a low return in the coming year is low. Second, if there is symmetric information about the prospects, the premium would be adjusted up or down in line with that information, so farmers hopping in or out of a scheme would be less of a problem. Third, farmers will want to base their decision to insure or not, and how much to insure, on such things as their current net assets. After a series of poor profit years they are more likely to want to buy coverage (i.e. be more risk averse) than after good years when assets and cash reserves are high. To prevent such reasonable adjustments would be most undesirable from an efficiency point of view. Of course, if the insurer wanted to go on writing the same business, to try to maintain profit levels, they might want to look at contracts for multi-year cover, or might offer no-claim bonuses, etc. But there are problems for the insurer in multi-year contracts if the size of risk changes over time, as it surely will for income insurance. In a period of declining incomes they could end up over-exposed.

\subsection{Participation: mandatory or voluntary}

In Section 3.2.3.1 under 'design of an insurance scheme' it was stated that 'any insurance scheme should be voluntary'. However, voluntary insurance programmes often have low participation. An example can be found in US voluntary crop insurance programmes: though the programmes are subsidised, participation is generally low. Skees and Barnett (1994) give three possible reasons that account for the low rates of participation. The first reason is that moral hazard and adverse selection problems often lead to premium rate increases so that premiums become prohibitively high for many producers. The second possible explanation is that producers have come to expect generous government disaster assistance in the event of widespread crop losses; why pay for ex ante crop insurance when you can get it for free ex post? The third possible explanation is that people are typically unable or unwilling to imagine the potential devastation that could be caused by low probability events.

Given the related problems of adverse selection, low participation and human insensitivity to low probability events, it could be suggested that crop insurance programmes would have to be mandatory. However, this option has serious problems as well. Again, the US crop insurance programmes will be used as an example. During the 1980s US farmers received about USD 1.92 in indemnities for every USD 1.00 paid in premiums, but the benefits were not distributed equally. Moral hazard and adverse selection problems for some areas and crops resulted in increased rates of premium so that many low risk farmers could expect to receive far less than a dollar in indemnity payments for each dollar of premiums. Under such conditions, requiring crop insurance for farmers with high debt loans can actually reduce their odds of economic survival (Skees and Barnett, 1994). 


\subsection{Experiences with insurance schemes for agricultural risks}

In countries all over the world both governments and private sector insurance companies have had experience with agricultural insurance schemes. In this section, experiences with crop insurance, mutual insurance for contagious diseases, revenue insurance schemes and income stabilisation accounts are addressed.

\subsubsection{Crop insurance}

In almost every country of the world some form of crop insurance exists. Existing schemes vary according to, among other things, the perils covered and the degree of government involvement. Some examples from European agriculture are discussed below (based on Swiss Re, 1997). US crop insurance schemes are also discussed. This section concludes with an evaluation of public crop insurance programmes following Hazell (1992).

\section{Some European examples}

In Sweden a compulsory crop insurance was in existence between 1961 and 1994, covering all damage caused by natural hazards. The system was financed by collecting a levy on the sales of crop and livestock products. Since 1995, no system of crop insurance exists anymore in Sweden. Instead, the taxation regulations for farmers were changed so that they can build up tax-free reserves in good years which can then be used in years with low income from agricultural activities.

In Italy, agricultural insurance is run by private sector insurance companies, but there is a considerable amount of financial aid by the public sector. Hail is basically the only risk covered. Small-scale experiments are being carried out with frost insurance for grapevines, fruit and artichokes. The premium costs are shared 50/50 between State and farmers (regional authorities may contribute an additional $10 \%$ ).

In France, an agricultural calamity fund exists, which covers crops in the field and livestock in the open. The perils covered are excessive rain, floods and inundation, frost, drought, windstorms, hurricanes, epidemics and parasites. The compensation provided by these funds is financed by an additional premium which applies to all premiums relating to property contracts.

In Spain, agriculture represents a relatively large share of the total economy, resulting in a strong agricultural lobby. It is probably due to this fact that the Spanish system of agricultural insurance is very extensive. There are numerous insurance companies which offer coverage for almost every agricultural risk. These insurers are organised in a pool, which is responsible for administration, claim services and courses for loss adjusters. Centralising these tasks is intended to minimise the organisational costs. Premiums are subsidised by the government (between $20 \%$ and $44 \%$ ). In addition, the State provides reinsurance. In the case of natural catastrophes, the State does not make any disaster payments, since the agricultural insurance scheme covers almost all perils which can possibly threaten income from agricultural activities.

\section{The US crop insurance scheme}

In the US, prior to 1994, the federal government provided two separate programmes: the federal crop insurance programme and ad hoc disaster payments. The Federal Crop Insurance Reform Act of 1994 combined both programmes and provides farmers with a catastrophic coverage level (CAT) for only an administrative fee. The CAT programme provides a coverage level of $50 \%$ of the yield of a farm (based on the farm's actual production history plan) and $60 \%$ of the expected market price. To ensure the widest participation, crop insurance coverage at the CAT level was a requirement to be eligible for any price support or production adjustment programme (from 1996 on, farmers can choose whether they take the CAT insurance or not). Farmers can buy additional coverage under the multiple peril crop insurance scheme (MPCI). Premiums, administrative costs and reinsurance of MPCI are federally subsidised.

In a number of States, crop insurance is not available for all crops (for example, citrus fruits, pears, peppers, plums and flax are non-insurable crops in almost all States). To protect producers of non-insurable crops, the non-insured assistance programme (NAP) was put in place. NAP protection is similar to the catastrophic (CAT) coverage, but, coverage is only available if the area suffers at least a $35 \%$ loss in production.

\section{An evaluation of public crop insurance programmes}

Hazell (1992) analysed the financial performance of public crop insurance programmes in seven countries (for quantitative data see Annex II). He found that, with few exceptions, this performance has been ruinous, both in developed and in developing countries. Hazell states 
that the primary reason for the high cost of public crop insurance schemes is that they invariably attempt to insure risks that are prone to severe moral hazard problems. The moral hazard problem is made worse by the fact that sizeable deductibles (excesses) are rarely incorporated into insurance contracts, and by a common practice of insuring losses assessed as the difference between actual and normal yield, rather than actual losses. The insured normal yields also tend to be set too high.

Another factor in the bad performance of public insurance programmes, according to Hazell, is the incentive problem that arises once the government establishes a pattern of guaranteeing the financial viability of an insurer. If the insurance staff know that any losses will automatically be covered by government, then they have little incentive to pursue sound insurance practices when setting premiums and assessing losses. In fact, they will find it profitable to collude with farmers in filing exaggerated or falsified claims.

Another reason for failures listed by Hazell is that governments undermine public insurers for political reasons. In Mexico the total indemnities paid bore a strong statistical relationship with the electoral cycle, increasing sharply immediately before and during election years and falling off thereafter. In the US, the government has repeatedly undermined the national crop insurer (FCIC) by providing direct assistance to producers in disaster areas. Why should farmers purchase crop insurance against major calamities if they know that farm lobbies can usually apply the necessary political pressure to obtain direct assistance for them in times of need at no financial cost?

Public crop insurers also tend to have high administrative costs. This is partly because they often insure small-scale farmers, but also because crop insurance work is very seasonal and the absence of a well-diversified portfolio means that staff and field equipment are underemployed for significant parts of the year.

\subsubsection{Mutual insurance schemes for contagious diseases}

Losses due to contagious diseases, like losses from droughts and floods, can be very extensive and catastrophic. However, a major distinguishing characteristic of losses from contagious diseases is that farmers collectively can have a big influence on total losses. The way farmers apply preventive measures and observe control measures is crucial in the probability of an outbreak occurring and in the eventual extent of an outbreak. In the Netherlands, this influence of individual farmers on total losses led to the development of mutual insurance schemes.

Mutual insurance schemes are operated by farmers themselves; they decide what losses are indemnified and, as a result, how much premium is to be paid. The role of insurance companies is restricted to that of administrator and reinsurer. An advantage of a mutual insurance scheme is the increased potential for social control. Furthermore, differentiation of premiums and indemnities for high-risk farmers has a sounder basis because it is not the insurance company but colleague farmers who impose these measures. Mutual insurance schemes are discussed in depth in Section 4.6.

In the Netherlands, mutual insurance schemes have been developed for contagious disease outbreaks both in crops (horticulture and potatoes) and livestock (poultry). Studies are being carried out to develop mutual insurance schemes for pigs that insure against losses from classical swine fever, foot-and-mouth disease and swine vesicular disease.

\subsubsection{Revenue insurance}

\section{Canada}

In 1991 Canada introduced the gross revenue insurance plan (GRIP). Though a basic GRIP programme was established, five different formulae were introduced for different provinces of Canada. The costs of the programme were shared by the federal government, provincial governments and farmers; farmers paid only $33 \%$ of the insurance premiums.

The basic GRIP formula was a gross revenue insurance plus crop insurance programme. Basic revenue coverage was offered by establishing a target revenue comprised of individual long-run average yields and a 15year indexed moving average price. Indemnities were equal to the difference between actual farm revenue and the target revenue less any crop insurance indemnities, regardless of whether the farmer was enrolled in crop insurance. However, several provinces developed their own GRIP insurance programme. Major differences from the basic GRIP programme were the area-based approaches in which target revenues are the same for a whole area and in which farmers only receive an indemnity if area revenues fall below the area target revenue. 
Two variations were in place: a commodity-specific area-based approach and an area-based approach which defines a crop portfolio for specific risk regions.

GRIP faced several problems, of which the most important ones will be mentioned here. The first problem concerns the use of a 15-year moving average to establish price levels. When the programme started, commodity prices were low and using a 15 -year moving average ensured high guarantee prices (because of the high prices in the late 1970s that were included in the average). However, prices declined and the use of a moving average turned out to be a short-run remedy for farmers trying to receive high guarantee prices. Another problem was that indemnities were paid on individual yield risks, but premiums were typically based on area averages (for example, all farmers insuring corn paid the same rate) with some adjustment for experience rating. Premiums did not reflect the risks of individuals. Yet another concern about GRIP was the implicit moral hazard associated with switching crop mixes from lowrisk crops to high-risk crops. Moreover, in contravention of the WTO agreements, GRIP was not production neutral (Turvey, 1992). In 1996, GRIP was completely abandoned.

Concerning the Canadian GRIP programme, Skees et al. (1998) state that the programme was costly and interfered with market signals.

\section{United States}

In the US the discussion about 'farm income' insurance began with the Agricultural and Food Act (1981), that mandated a study to examine revenue insurance as a replacement for price and income support programmes. In 1985, the Food Security Act mandated a study to determine the feasibility of using put options to replace price and income support programmes.

Currently, in the US, revenue insurance products are being pilot tested for some major crops. Revenue insurance products are based on the concept of combining price and yield risk protection in one programme that supports expected revenues and that provides downside revenue risk protection. Three insurance products have been introduced: income protection (IP), crop revenue coverage (CRC) and revenue assurance (RA). IP was developed by the US Department of Agriculture (USDA) Office of Risk Management; CRC and RA are private sector initiatives.
IP (introduced in 1996) offers a revenue guarantee based on the crop's expected harvest-time price and the farmer's expected yield. The farmer receives an indemnity if the harvest-time price, multiplied by the farm's actual yield in that year, falls below the guarantee. Because the guarantee is based on the early-season price projection for harvest time, IP protects against declines in actual revenue from expected revenue for a particular season.

CRC (also introduced in 1996) contains two components. The first, similar to IP, offers a revenue guarantee based on price expectations and farmers' expected yields. The second component offers 'replacement coverage', whereby coverage can increase during the season if prices rise. If a producer has a crop shortfall and the price is higher at harvest than the pre-harvest projection, the producer's crop insurance indemnity is paid on the higher harvest-time price, allowing the farmer to buy 'replacement' bushels in the market place. The producer receives the higher of the 'revenue guarantee indemnity' or the 'replacement coverage indemnity'. Because of the added costs of replacement coverage, as well as some other features, CRC premiums are substantially higher, on average, than IP premiums. Premiums in both programmes vary by the coverage level selected (options range from 50 to $75 \%$ ).

The third revenue product, RA (introduced in 1997), is similar to the IP product, but has the additional feature of adjusting the price protection on a local basis (Ackerman, 1997).

\section{Tax-based schemes}

Besides the pilot tests for IP, CRC and RA, pilot tests in which income tax records are used as the source of revenue estimates have also been initiated. Using the tax records, gross revenue less costs of goods purchased for resale is measured. The insured cause of loss is revenue shortfalls provided that the farmer has used accepted farming practices. The tax-based schemes concern farms whose principal crops are non-insurable crops, i.e. NAP crops (see Section 3.7.1). Programmes focus on horticultural crops. Tax-based schemes have been introduced because USDA could not find a practical way to implement the APH (actual production history) for many of the NAP crops. APH refers to the method that is used to determine a farmer's average yield under schemes such as MPCI and CAT. Furthermore, if taxbased schemes work, they potentially minimise transaction costs (Black, personal communication). 


\subsubsection{Income stabilisation accounts}

The net income stabilisation accounts (NISA) programme is a programme that stabilises farmers' income. Currently, such programmes are in place in Canada, Australia and Sweden. For the Swedish programme see Section 3.7.1 under 'some European examples'.

\section{Canada}

The Canadian NISA arrangements subsidise and assist farmers in building savings for low revenue years. This is done by creating farm savings accounts where farmers contribute and receive a dollar-for-dollar match from the government. Farmers are allowed to contribute up to $2 \%$ of eligible sales (computed by summing product sales minus agricultural products purchased and adjusting for farm grown feeds). The farmers are also allowed to make additional contributions, but these are not matched by the government. Account balances are then held in reserve until the farmer experiences a low farm revenue year. The programme can be thought of as a government-subsidised individual savings plan with special withdrawal limitations; withdrawal is allowed when gross margin falls below a five-year average or below a minimum income level. NISA covers most agricultural products except poultry and dairy. The farmer's contribution is taxed in the year it is deposited and the government contribution is taxed in the year it is withdrawn.

NISA can provide substantial risk protection to farmers once account balances have had time to accumulate. Concerning administrative costs, NISA appears less burdensome than, for example, crop insurance, because of the programme's simplicity. Moreover, it provides protection at the farm level rather than individually protecting crop prices and yields. With NISA, problems of moral hazard and adverse selection seem to be much less than with crop and revenue insurance. However, the policy may provide an adverse incentive effect if the policy encourages maximisation of the NISA account which could most easily be accomplished by growing higher risk, higher return crop portfolios (Coble, 1995).

The effect noted by Coble should be seen as a benefit, not a negative feature of the scheme. If any new risksharing instrument is offered and adopted by some farmers, there is almost certainly going to be a compensating shift to a more risky production portfolio. That should be seen as a benefit from a social point of view, since more risk means more expected profit, and society can afford to be risk neutral.

\section{Australia}

The Australian scheme works by allowing farmers to transfer money into income equalisation deposits (which are bonds) in high income years, with the funds so transferred being treated as a deduction from income for assessing income tax. When the bonds are encashed, usually in a low income year, the funds are added to the taxable income in that year. However, given the progressive marginal tax rates, the rate of tax at this time may be zero, or at least lower than the tax saving when the funds were deposited. Obviously, the scheme does not help farmers who are too poor to pay any tax.

\subsection{Need for insurance schemes}

\section{Risk aversion of farmers}

A priori there is no need for insurance. The case for insurance arises only if farmers are sufficiently risk averse that they are willing to forgo some expected income to protect themselves to some degree against the risk of loss. In the absence of moral hazard, adverse selection and government subsidies, the expected cost of buying any insurance contract is negative (any scheme must collect more in premiums than it pays in indemnities, if it is to cover administrative costs and normal profit).

\section{Other risk management strategies}

Insurance is only one among many risk management strategies that farmers can and do use (see Section 3.1). Thus, even though insurance of a particular type may not be available, there may be no need for it to be provided since farmers may be able to get close to the degree of risk protection they want in other ways.

\section{Variability of prices and yields}

Whether, for individual farmers, there is a need for insurance will be influenced by, among other things, the variability of prices and yields. If the variability of prices and yields is low, there is hardly any need for the introduction of an insurance scheme. This is certainly true if the variability is lower than a reasonable deductible or excess (for example $20 \%$ ). 


\section{Price/yield correlation}

Another factor in determining the need for insurance is the price/yield correlation. If the price/yield correlation is strongly negative (i.e. $\mathrm{r}<-0.5$ ):

- there is no need for insurance (low yields are compensated by high prices and vice versa);

- $\quad$ if only yields are insured, the farmer is overcompensated (not efficient);

- if only prices are insured, the farmer is overcompensated (not efficient);

- $\quad$ if farmers require some form of protection, a revenue insurance (price times yield) scheme is the cheapest solution.

If the price/yield correlation is weakly negative or positive (i.e. $\mathrm{r}>-0.5$ ):

- $\quad$ price, yield and revenue insurance schemes make sense;

- if the price variability is low, yield-only insurance would be sufficient;

- $\quad$ if the yield variability is low, price-only insurance (using futures markets) would be sufficient;

- $\quad$ if both yield and price variability are high, price and yield insurance might be necessary to provide sufficient protection. In this case a revenue insurance scheme (price times yield) would be a cheaper solution than two separate (i.e. price and yield) schemes.

Graph 7 presents a framework to discuss the need for insurance schemes. The framework includes both price and yield variability and price/yield correlation. Alternative insurance schemes that fit a particular situation are also listed.

Concerning the multiple peril yield insurance that is shown along with the situation $(\mathrm{HH}, \mathrm{r}<-0.5)$ : the strongly negative correlation would suggest that there is no need for insurance coverage. However, if a farmer has no yields at all (due to a disaster) the farmer does need some form of coverage.

According to the analyses of our data set on European agriculture (see Chapter 5 and Annex IV), the yields of some agricultural commodities are at the low variability side of the framework; others at the high variability side. The same applies for the price variability of com- modities. With further liberalisation, it is to be expected that the variability of prices will increase (compared to current protection circumstances). Concerning the price/yield correlation, our data set does not provide much information (the price data are aggregated data), but, if liberalisation takes place, more commodities are expected to shift to the $r>-0.5$ areas (i.e. closer to $r=0$ which is no correlation), especially commodities where the European production is small when compared to world markets.

\section{Ad hoc support by governments}

Another factor in determining the need for insurance is ad hoc support by governments. If governments step in every time disasters occur, they crowd out any insurance scheme that covers such disasters (Barnett et al., 1998).

\section{Farmer's perception of risk}

A last factor mentioned here is the farmer's perception of risk. With respect to this perception of risks, the following aspects have to be taken into consideration (Camerer and Kunreuther, 1989):

- $\quad$ people tend to underestimate, or even ignore, lowprobability risks;

- $\quad$ people tend to underestimate risks of natural disasters but overestimate man-made risks;

- $\quad$ people are generally optimistic and think that their own risk is lower than the risk for other people;

- farmers believe governments will pay in case of disasters (Hanf, personal communication).

\subsection{Role of governments}

\section{Necessity of government involvement}

If there are farmers who will want to buy insurance for certain risk, then we may assume that commercial providers will step in to offer products. Moreover, given that there are several companies who offer insurance, we would expect that competition between them would ensure that the best and cheapest policies would evolve and become prominent in the market. There is no need for the EU or national governments to do more than regulate the industry to ensure fair trading. 


\section{Graph 7: Scheme to determine the need for insurance, based on price variability, yield variability and price/yield correlation}

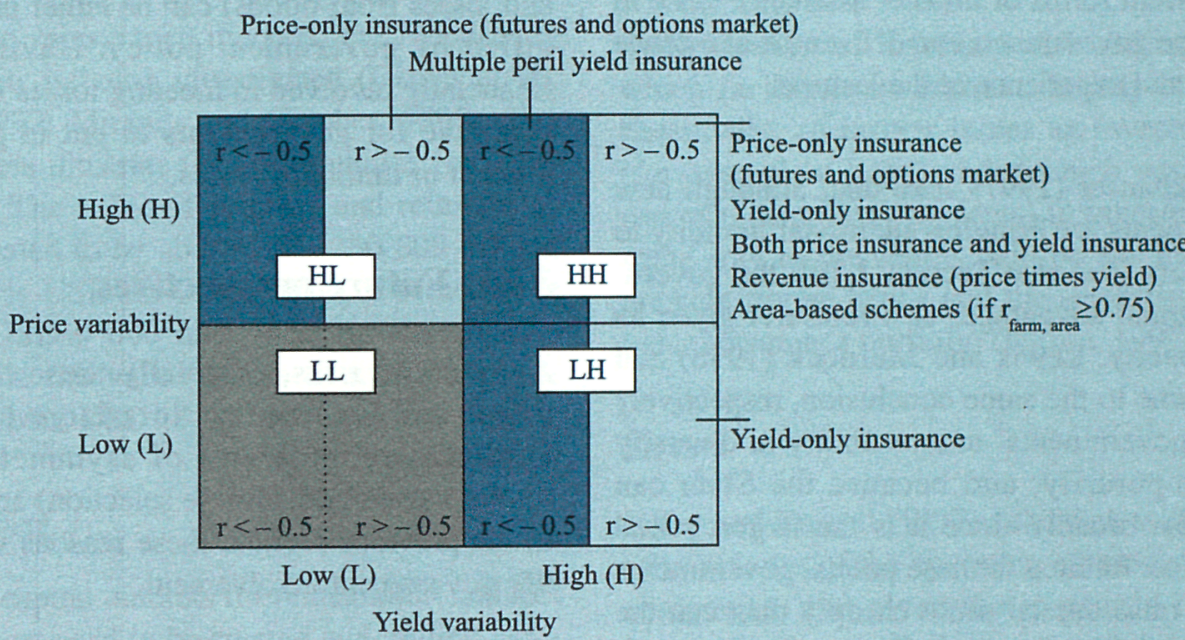

Yield variability

No need for insurance because of strongly negative correlation $(\mathrm{r}<-0.5)$

No need for insurance because of low price and yield variability $(<-20 \%)$

The case for government intervention arises if there is market failure in regard to agricultural insurance. Barnett et al. (1998) state that for the type of risks of interest to this study, market failure can be significant for reasons of (1) human cognitive limitations related to low-probability, high-magnitude, risks, (2) systemic risks and (3) asymmetric information.

The second reason for intervention is that farmers are risk averse and will not allocate resources to maximise expected returns. On the other hand, society can afford to be largely risk indifferent. Therefore there is social benefit to be had, at least in principle, from an intervention that helps farmers move closer to the point of expected profit maximisation.

Besides an active financial role, governments can also fulfil a facilitating role, for example by market development.

\section{If governments are financially involved}

Skees and Barnett (1998) state that, if governments are involved, they should in the first place have as much information as the private sector. They also argue that the government insurance agency should be free from political pressures. Skees and Barnett give the following alternatives for government involvement:

- take all risk and use the private sector to market the insurance;

- $\quad$ provide stop loss and/or quota share reinsurance;

- write and sell stop loss contracts or derivative products (see also Lewis and Murdock (1996) and Cummins, Lewis and Phillips (1996) for multiple peril catastrophe call spreads/excess of loss contracts).

Cutler and Zeckhauser (1997) state that, if governments are involved, they should price their reinsurance at the expected costs:

- to prevent moral hazard of insurance companies;

- to make sure insurance companies have incentives for a sound underwriting policy; and

- $\quad$ to give the right signals to the insured individuals. 


\section{Advantages of government involvement}

Regardless of the exact form of government involvement, we argue that a public-private partnership might be cheaper than current forms of disaster assistance since in such relationships governments can deliver the assistance via the network and experience of the insurers.

Cutler and Zeckhauser (1997) state that, although new financial instruments are bringing additional liquidity to insurance markets (see also Section 3.10), the government has substantial advantages as a reinsurer given its deep credit capacity. Lewis and Murdock (1996) and Priest (1996) come to the same conclusion, respectively because of the governments' unique ability to diversify claims intertemporarily, and because the State can spread risks most broadly since it is the largest social entity in existence. Related to these points, governments may be able to raise capital more cheaply than can the private sector, making reinsurance by government potentially cheaper than private reinsurance.

Cutler and Zeckhauser (1997) also state that governments currently already play the role of natural reinsurer by providing free disaster assistance. Establishing a formal reinsurance system, and thus collecting some money, may be preferable to waiting until the event occurs and spreading the costs more broadly (among all tax payers). Selling insurance in advance of a disaster also makes people more aware of the social costs of their actions and thus limits moral hazard. The latter aspect is also mentioned by Skees et al. (1998) concerning the US CAT policies (see Section 3.7.1).
Cutler and Zeckhauser (1997) argue that another advantage of government involvement is that it may address a moral hazard problem on government behaviour; many catastrophes (for example epidemic disease outbreaks and losses from floods) can be either prevented or magnified by government policy. Having governments financially involved in meeting losses might be the best incentive for governments to put in place policies to prevent or minimise losses.

\subsection{Future perspectives}

Agricultural risks, especially those related to yields, prices and income, are to a large extent systemic. Furthermore, problems of asymmetric information (moral hazard and adverse selection) are likely to occur. In the previous section, these reasons were used to justify government involvement.

In the US, the group risk plan (see Section 3.4.3) was introduced to accommodate the moral hazard and adverse selection problems. However, a problem of the group risk plan (GRP) is that individual farmers may experience yield losses, while the area-yield shortfalls are not sufficient to trigger an indemnity payment (basis risk). GRP only provides effective risk protection in areas in which yields are highly correlated (systemic); not in areas with a number of different topographical features in which risks are much more independent (Skees et al., 1997).

Table 12 summarises the problems mentioned and lists requirements to solve the problems. The last column

Table 12

Problems, requirements and opportunities of insuring agricultural risks

\begin{tabular}{|c|c|c|}
\hline Problems & Requirements to find a solution & Opportunities \\
\hline Systemic risks & More capital in reinsurance markets & Use of capital markets \\
\hline Asymmetric information & $\begin{array}{l}\text { Products based on easily and equally } \\
\text { available information }\end{array}$ & Definition of index products ( $\left.{ }^{(}\right)$ \\
\hline $\begin{array}{l}\text { Insurance of independent risks that remain } \\
\text { after the systemic component } \\
\text { of risks is taken care of }\end{array}$ & $\begin{array}{l}\text { Insurance that provides farm-level } \\
\text { protection for non-systemic, random } \\
\text { yield losses }\end{array}$ & 'Wrap around' products (2) \\
\hline
\end{tabular}


shows opportunities currently being studied and pilot tested in the US.

\subsubsection{Systemic risks}

To add capital to reinsurance markets, the functioning of capital markets is being investigated (Canter et al., 1996; Lamm, 1997; Miranda and Glauber, 1997). The following numbers illustrate the opportunities for using capital markets. The value of primary and reinsurance markets is estimated to be about USD 250000 million (of which there is USD 25000 million of reinsurance and from this USD 9000 million is for catastrophe insurance), while the value of the capital market is estimated to be about USD 19000000 million.

\section{Derivative products}

To mobilise the capital markets for reinsurance, suitable derivative products need to be created and trading commenced. A derivative product is a contract whose value depends on an underlying value. An underlying value can refer to financial and physical goods, but also to an index. Currently, on the Chicago Board of Trade, catastrophe futures contracts and options on these contracts are being traded. The underlying value of the contracts is a loss index established by the property claims services (PCS). If catastrophic losses occur in the Midwest, for example, the PCS index for the Midwest increases and hence also the value of the futures contracts based on this index. Insurance companies in the Midwest would at the same time be confronted with many loss claims. To increase 'reinsurance' capital the insurance companies could sell futures contracts they had bought earlier at a lower value (Geene, 1995).

For insurance companies to use capital markets and derivative products to reinsure agricultural risks, 'agricultural indexes' on which derivatives can be based need to be established. For crop insurance schemes, Miranda and Glauber (1997) propose an area-yield index. Area-yield data are easily and equally available and could be published by an independent organisation. To add reinsurance capital to the insurance company, insurance companies can then trade contracts based on such indices on the exchange markets.

If there is a role for governments in reinsurance, the area-yield reinsurance contracts could also be provided by the government. No asymmetric information problems between governments and private sector insurance companies would exist, because both parties have the same information regarding the area-yield index.

\section{Securitisation}

Securitisation of insurance risk refers to any method which facilitates investment directly in insurance risk. Essentially, an insurer issues an investment instrument (for example a bond) under which payments (coupons and/or redemption payments) to investors are related in some way to the claims paid by the insurer. Examples are catastrophe bonds and the securitisation of an individual insurance portfolio (Lamm, 1997).

\section{Remark}

Jaffee and Russell (1997) state that, with certain tax and other reforms of the operating environment of insurance companies, and given the increased level of support from capital markets, there seems to be no reason why a purely private insurance/capital industry cannot provide catastrophe insurance products.

\subsubsection{Asymmetric information between insurer and farmer}

The use of an area-yield index for reinsurance contracts could also apply to primary insurance contracts (contracts between the insurer and the insured farmer). If insurance contracts are based on an index, both farmers and insurance companies have symmetric information about the basis of the contract, and problems of moral hazard and adverse selection can be reduced significantly. The GRP-product, discussed in Section 3.4.3, approximates such an index-based insurance product: GRP only pays farmers an indemnity if the index, reflecting area yields, falls below the insured level.

\subsubsection{Insurance of independent risks that remain after the systemic component of risk is taken care of}

If insurance companies can reinsure systemic yield risks by means of derivatives and securitisation, and if the asymmetric information problems in yield insurance contracts with farmers are also diminished, private sector initiatives are to be expected concerning the remaining non-systemic, random yield losses. In the US, such products are already being developed as additions to GRP. These 'GRP wrap arounds' only pay if GRP does not pay (Skees et al., 1997). 



\section{Agricultural income insurance in Europe}

Income insurance is a very broad concept. Among other things, it can refer to the use of futures markets to cover price risks, the development of yield insurance to cover quantity risks, or the development of revenue insurance to cover price times yield risks. All options considered in our study need to have the same objective, which is to stabilise a farmer's income, not to provide some structural form of income support for declining agricultural sectors.

Chapter 2 illustrated that European agriculture is not very homogeneous. Differences between countries, areas within countries, sectors and income categories are numerous. Analyses of individual farm data (see Chapter 5) also shows major differences between European farms. Chapter 3 addressed a number of insurance aspects that are important when discussing insurance schemes for agricultural risks. Aspects described include systemic risks, asymmetric information, an analysis of the need for insurance, aspects of government involvement, and the use of derivative markets.

This chapter links the two preceding chapters and provides ideas for a simulation study (Chapter 5) and material for the final conclusions (Chapter 6). Section 4.1 presents a framework to discuss alternative forms of income insurance schemes. Alternatives are discussed in detail in Sections 4.2 to 4.6. This chapter has been partly based on the workshop held in Tilburg on 29 January 1998 (see Annex III).

\subsection{A discussion framework}

\section{Starting points}

The first starting point is that insurance schemes will develop if there is a need (Section 3.8). The second starting point is that government financial involvement is necessary for reasons of market failure and resource allocation (Section 3.9), at least until capital market opportunities are more developed (Section 3.10).

The last point was also brought forward by the participants in the workshop (see Annex III). They argued that governments (national and the European Commission) should play a (limited) financial role in any insurance scheme because (1) governments create rules that influence the size of losses and (2) it would be easier to get reinsurance capacity in the traditional reinsurance markets. Governments could, for example, play the role of 'underwriter of last resort', meaning that governments and the European Commission do not have to step in for every euro of loss, but only if losses are extremely large.

\section{What form of income insurance?}

In Table 13 a comparison is provided of whole-farm income insurance, price insurance, yield insurance and business interruption insurance in terms of problems of asymmetric information and reinsurance. Asymmetric information is regarded as the same as data availability since problems of asymmetric information (i.e. moral hazard and adverse selection) relate to the timely availability of accurate and reliable data. Gross revenue insurance is not mentioned separately in the table since a gross revenue product will be some combination of price and yield insurance. The table is explained in the following sections.

\subsection{Whole-farm income}

Insuring whole-farm income appeals to policy makers because whole-farm (or farm-household) income is the best measure of the welfare of farm families.

\section{Which income?}

In discussing an income insurance scheme, the income measure to be used as a basis for insurance has first to 


\section{Table 13}

Comparison of different insured aspects on problems of asymmetric information and reinsurance, ranging from $--($ bad performance $)$ to $++\left(\right.$ good performance) ${ }^{(1)}$

\begin{tabular}{|c|c|c|c|c|}
\hline \multirow{2}{*}{ Insured aspect } & \multirow{2}{*}{ Insured risks } & \multirow{2}{*}{$\begin{array}{c}\text { Asymmetric information/ } \\
\text { data availability }\end{array}$} & \multicolumn{2}{|c|}{ Reinsurance } \\
\hline & & & Availability & $\begin{array}{c}\text { Ability to deal } \\
\left.\text { with systemic risk ( }{ }^{2}\right)\end{array}$ \\
\hline Whole-farm income & Low income ( $\left.{ }^{3}\right)$ & -- & -- & - \\
\hline Price & All-risk & ++ & -- & 0 \\
\hline Yield & Production risks & & & \\
\hline - individual & & - & - & 0 \\
\hline - area & & + & - & 0 \\
\hline Business interruption & Epidemic disease risks & 0 & -- & - \\
\hline
\end{tabular}

be defined. Annex I shows various commonly used income measures and their components. In choosing an appropriate income basis for the insurance, problems of moral hazard, adverse selection and the related problem of data availability play very important roles. In general, the income measure should not include:

- non-farm income and compensation of employees, because of moral hazard and fraud problems;

- $\quad$ fixed costs (rent and interest) and variable costs (for example feeding costs), because there is too much management by the farmer involved; and

- $\quad$ aspects that are more or less independent of current performance of the farm business, such as depreciation.

Inspection of the measures in Annex I shows that the income measure that remains is farm revenue. A pilot test of income insurance being carried out in the US (see Section 3.7.3) uses gross revenue less costs of goods purchased for resale as the income measure. This income measure is established in the US scheme by using tax returns. The merit of this approach is that farmers seldom overstate their incomes on tax returns, implying that the insurance coverage will never be too high. The insured cause of loss under this 'tax form based revenue insurance' concerns revenue shortfalls, provided that the farmer has used accepted farming practices. In the next section (subsection 'portfolio gross revenue insurance versus farm revenue insur- ance') the tax form based revenue approach is compared with a scheme in which revenues are measured as the sum of gross revenues (price times yield) of different commodities. From that comparison it will be clear that the tax form based approach faces several problems.

\section{Asymmetric information and systemic risk}

Concerning the asymmetric information problems, whole-farm income has a low performance score in Table 13 because of the difficulty in obtaining data for an objective income measure. The score for reinsurance availability is low because of the systemic character of incomes. Concerning the opportunities to deal with the systemic risk problem, the score is also low, because the difficulty in obtaining an objective income measure also implies that it will be difficult to develop derivative products, since such products need to be based on transparent and easily obtainable measures.

\section{Other possibilities for stabilising whole-farm income}

Other possibilities for stabilising whole-farm income include the following.

- Income stabilisation accounts (see Section 3.7.4).

- Different social security eligibility criteria for farmers when incomes are low. This is justifiable since farmers cannot easily leave their farm to 
seek a job, since animals need to be taken care of, crops need to be harvested, etc.

- 'Business continuation insurance' or 'anti-bankruptcy insurance'. Such an insurance scheme could make use of the debt-to-asset ratio of a farm and make payments if this ratio is at the bankruptcy (i.e. catastrophically low) level. Farmers (together with their banks) could establish a farmspecific 'bankruptcy level' and pay a premium according to this level. To prevent moral hazard and adverse selection, accurate data and objectively established asset measures are necessary, trigger levels should always be set very low, and if, after payments, the debt-to-asset ratio stays very low for a long period, banks will eventually stop providing loans. Such 'business continuation insurance' needs further investigation.

\subsection{Gross revenue insurance}

Because of the problems mentioned in the context of whole-farm income insurance (see also the low scores in Table 13), this section discusses the feasibility of gross revenue insurance. Insuring gross revenue (price times yield) is largely a combination of options discussed under price (Section 4.4) and yield (Section 4.5). The same types of commodity can be included and the same types of data are needed. However, some of the effects are different.

In the first place, a gross revenue insurance takes account of the possibility that low yields can be offset by high prices and vice versa. Furthermore, gross revenue is better correlated with farm income than is yield or commodity price, implying that insuring gross revenue is more satisfactory from the point of view of farmers who are seeking to reduce the riskiness of their incomes.

The risk-reducing effect of revenue insurance has been studied by Harwood et al. (1996). They showed for North Carolina that (assuming farmers pay rates that are equal to the expected return from the various risksharing alternatives) the probability of revenue being less than $70 \%$ of the expected level is $23 \%$ if a producer chooses to sell his corn crop at harvest for the local market price, $18 \%$ with either crop insurance or forward contracting and $7 \%$ with revenue insurance (or a combination of crop insurance and forward contracting).
Although some of the effects of gross revenue insurance are different from separate price and yield insurance schemes, the effects described for price and yield insurance of supply response, increased riskiness and resource allocation are the same for revenue insurance.

\section{Commodity-specific versus portfolio}

Gross revenue insurance schemes can be set up per commodity or as a portfolio. Advantages of commodityspecific schemes are as follows.

- Farmers are free to choose which commodities they want to insure and at what levels, given for example the degree of specialisation of the farm and the relative importance of off-farm income. Farmers thus create their own efficient portfolio of risk management strategies. (This argument is also one of several in favour of voluntary insurance schemes.)

- Providers of insurance can focus on activities for which relevant data are available.

Providing portfolio revenue insurance, however, also has some advantages (Trechter, 1984).

- Farm revenue correlates better with farm income than with gross revenue from one or two commodities, implying that insuring farm revenue contributes more to a producer's welfare (which is a function of the net income distribution) than insuring the revenue on a commodity by commodity basis.

- Farm revenue insurance will be cheaper since low revenues from one enterprise are likely to be partly offset by high revenues from another enterprise, as long as they are not perfectly positively correlated. This relates to the basic principle of diversification: aggregating similar independent risks into a single insurance pool reduces the variance of loss.

\section{Portfolio gross revenue insurance versus farm revenue insurance (tax form based approach)}

The differences between a portfolio gross revenue insurance and the tax form based revenue insurance relate to differences in rating and loss assessment methods. In the first scheme (adding gross revenues of different commodities) the 'rating' of the price part can be based on observed futures market prices (not on, for example, a 10-year moving average). In the second 
scheme, however, there is no separate price component and rates can only be based on the distribution of revenues and on average values in previous years. In this field, the Canadian experience with the GRIP scheme (Section 3.7.3) can be mentioned.

Differences also exist in loss assessment. In the first scheme moral hazard can be reduced, at least so far as concerns prices, by the use of observed futures market prices. In the second scheme, serious moral hazard problems can exist as farmers can report very low incomes. This is a problem even though farmers have to prove their losses and even if a farmer's premium rate is (partly) based on his/her own income history.

Besides the rating and moral hazard problems, another problem in the tax form based approach is that insurance companies are likely to face difficulties in getting access to farmers' tax forms.

\section{Remark}

Hennessy et al. (1997) compared the 1990 US farm programme and government-provided revenue insurance programmes. They found that revenue insurance is more efficient because it provides subsidies only when revenue is low and marginal utility is high and it works on the component of the objective function (revenue) that is of greatest relevance to producers.

\subsection{Price}

In Europe, currently, price variability depends to a large extent on the level of price support. Compare, for example, the potato prices and sugar beet prices in Table 8 . Sugar beet prices are supported and potato prices are not. With further liberalisation of agricultural markets in the EU, price variability of products currently supported will tend to rise, though the effect will be less for products in large, highly integrated markets such as exist for grains. Large, well integrated markets are less volatile because of less than perfect correlation in yields in different, widely dispersed, places. Also most livestock product markets can be expected to become highly integrated because of the high value to bulk of these commodities. Potato markets are poorly integrated because potatoes are mostly water and are very perishable which means that transport costs are high relative to the value of the commodity.
Note that some of the observable volatility in world commodity markets is caused by the price support measures in place in the EU and in North America. Farmers in those places do not get the appropriate signals to cut back on production when prices are low, and vice versa, so magnifying price swings. Similarly, for some products, consumers face unchanging prices under price support, regardless of the (world) supply situation. With the eventual removal of these distortions, supply will adjust more quickly to demand shifts, and vice versa, so dampening price swings.

\section{Futures markets}

Price risks can be covered to some degree on futures and options markets (the basis risk cannot be covered). These are efficient markets for systemic price risks (Purcell, 1991; Brealey and Myers, 1996). However, in Europe, the use of these markets is not yet widespread, mainly because of the existence of the common agricultural policy (and other support programmes related to the CAP).

The attention being given to agricultural futures markets in Europe is increasing due to declining agricultural subsidisation (MacSharry and WTO), the specialisation of farms, the introduction of environmental and production rights and the increasing use of automated trade systems (Pennings and Meulenberg, 1995; 1997). The introduction of the single European currency will further stimulate this development. Within Europe, the London Commodity Exchange (LCE) and the Amsterdam Futures Market (ATA) play the most important roles. In London, mainly overseas products are traded (coffee, tea, etc.). In Amsterdam, European products such as potatoes, slaughter pigs and piglets are the main products. Other European futures markets that trade agricultural futures and options are Matif (Marché à Term International de France) and DTB (Deutsche Terminbörse).

The use of futures and options markets can be stimulated by (1) abolishing price support (futures markets can only evolve in a competitive market since they thrive on price uncertainties), (2) educating farmers in the field of futures and options markets and (3) the development of trading requirements (for example quality grading and standard definitions of commodities). 


\section{Price insurance}

Even when futures and options markets are more developed, experience shows that farmers are, in general, reluctant to use them. Learning to use derivative markets requires a substantial investment of time. This overhead appears to be too high for most farmers. On the other hand, an agency such as an insurance company can spread the costs over many clients, making a product based on these markets potentially attractive to farmer clients.

\section{Which price?}

As discussed in Sections 3.4.1 (insurance coverage) and 3.4.2 (loss assessment), an insurance that includes price, should establish prices yearlys and futures market prices would be a good measure of price (though the farmer faces basis risk). For those commodities for which no European futures markets exist, Chicago Board of Trade futures prices or some other transparent prices, such as the Rotterdam harbour prices for grain, might be useful. However, for the latter two cases, research would first be needed to determine the level of basis risk.

\section{Which commodities?}

Commodities for which an objective price measure is available can be included in a price insurance. Attention should be paid in rating the prices from livestock commodities because of the existence of price cycles. However, this aspect is less of a problem when prices are established yearly (as proposed in the previous paragraph), because the stage of the cycle may be reasonably apparent when the insurance contract is written.

Attention should furthermore be paid to speciality products - and smaller volume crops in general — because a small increase in production can have a significant impact on world and domestic prices. Furthermore, speciality commodities have a large number of different varieties which can have very different prices.

\section{Which risks?}

Insuring prices implies an all-risk insurance since price declines cannot be attributed to specific perils.

\section{Asymmetric information and systemic risk}

If the prices to be insured are established in the futures markets, problems of asymmetric information between insurer and insured are reduced (score in Table 13: ++ ). The score for reinsurance availability is low because price risks are highly systemic. The score for possibilities to deal with this systemic risk problem is set at 0 , because, in principle, objective measures for price are available and capital market solutions could develop.

Capital market opportunities may evolve partly in socalled 'over the counter markets', because of the small numbers of suppliers and demanders. In 'over the counter markets' contracts are more specifically based on the needs of both parties.

\section{Effects}

Hedging price risks on futures and options markets reduces risks from price declines within a given year, but provides little or no inter-year income stability. However, forward pricing can improve the efficiency of resource use by reducing price and income uncertainty (Heifner and Wright, 1989). The same would apply for a price insurance scheme as described in this section, since the insurance policy itself would also be based on hedging. The efficiency effects of an insurance scheme that covers price also depends on the costs of the policy.

Hedging prices will produce a supply response, especially if available for only some commodities. The result is likely to be some downward pressure on prices in competitive markets.

New opportunities for hedging prices are also likely to increase the instability of supply and so increase price volatility to some extent. This is because producers who hedge do not face the price decline in periods of higher than normal supply and so have no incentive to make short-term adjustments to production and marketing behaviour. The same is true in periods of short supply.

\section{Remark}

In the US, research has been conducted on the case for subsidised put options as alternatives to price supports (Glauber and Miranda, 1989). They found that, compared to the loan programme (guaranteed minimum prices): (1) decreases or increases in governmental costs depend on the price elasticity of a product; (2) administrative costs may be higher under subsidised puts; and (3) budget uncertainty may be less with subsidised puts. 


\subsection{Yield insurance}

Yield risk in Europe currently varies between a coefficient of variance of $5 \%$ for milk (the Netherlands) and $30 \%$ for potatoes (Baden-Wurtenberg, Germany). However, it is to be expected that yield risks will increase, for example because of stricter rules for the use of fertilisers and medicines. For commodities for which no objective price measures are available, gross revenue insurance is not an option, but yield-only insurance schemes might be feasible.

\section{Which yield: individual versus area-based schemes?}

If homogeneous areas (in which production results are highly correlated) exist for certain commodities, areabased schemes may provide possibilities to reduce moral hazard and adverse selection problems (see also Section 3.4). This is primarily true for crop commodities, because for livestock it is much more complicated to define homogeneous production areas, mainly because much of the livestock is housed under cover.

\section{Which commodities?}

In principle, any commodity can be insured. However, in practice there are special problems in devising yield insurance schemes for intermediate products, livestock commodities and speciality products. For intermediate products, such as maize or young stock on a dairy farm, yields are very difficult to measure. Usually these yields are not recorded in management systems. Livestock commodities in general may cause yield measurement problems as most livestock farms produce output throughout the year (for example a weekly delivery of milk or pigs), or, at the other extreme, have multi-year production cycles. It takes, for example, approximately three years for a heifer to produce a marketable product, a $230 \mathrm{~kg}$ feeder calf. Besides measurement problems there may be some complications in selecting the moment the insurance policy is to be written; there are no clear planting and harvesting times as with crops. Concerning speciality products, there may be a shortage of yield records to rate a yield insurance product accurately.

\section{Which risks?}

We argue that the perils covered in a yield insurance scheme can refer to production risks (such as floods and droughts) that are due to external causes and which have a large impact on the farms' results (catastrophe at farm level). The risks may involve one single farm (incident), but may also involve multiple farms (catastrophe at regional level, i.e. systemic risks).

We furthermore argue that the scheme should be set up as a multiple peril insurance scheme that covers named perils. An all-risk insurance is not advised because:

- $\quad$ it will be easier to obtain reinsurance for a named peril than for an all-risk insurance; and

- $\quad$ in an all-risk insurance, perils unknown at the moment the insurance is written cannot be excluded from insurance.

Epidemic disease risks are not included here. For several reasons these are dealt with separately (see Section 4.6).

\section{Asymmetric information and systemic risks}

Problems of moral hazard and adverse selection are less when the yield insured is area-based. However, areabased schemes are only useful for areas in which yields are well correlated, and mainly for crop commodities. Otherwise, the degree of risk reduction for the individual farmer is likely to be too low to make participation attractive. If individual farm yields are to be insured, deductibles (excesses) and pre- and post-underwriting checks will have to cope with the problems of asymmetric information. Pre-underwriting refers to risk classification of insured farmers. Post-underwriting refers to checking the behaviour of farmers after they have bought the insurance.

Because of the systemic risk in yield insurance, insurance companies may need the support of governments for part of the required reinsurance capacity, at least until opportunities in securitisation and futures and options markets (as discussed in Section 3.10) are more developed.

\section{Effects}

Yield-only insurance is likely to result in a supply response and hence in downward pressure on market prices.

Yield-only insurance will be likely to result in increased riskiness in production and hence in more variable supply and more instability in product prices.

A yield-only insurance scheme for some commodities and not others will affect farmers' resource allocation 
decisions, as is always the case if a new market is opening up. This, however, does not lead to any distortions, as there is distortion only if the prices in that market are not wholly market-determined as is the case if governments subsidise the scheme.

If price/yield correlation is strongly negative, yield-only insurance can lead to overcompensation of the farmer (low yields are already offset by high market prices). On the other hand, if price/yield correlation is weakly negative or positive, yield-only insurance leaves the farmer with a considerable risk (unless price variability is low). The exact effect, however, depends on the price at which a yield shortfall is compensated. This may be either the agreed price at the time the contract is written, or the post-harvest price.

\section{Remarks}

Yield-only insurance partly competes with currently available yield insurance schemes, such as hail insurance.

Yield-only insurance could be replaced by farmers' use of yield options and futures contracts. However, these types of contracts are still in an infant stage.

To reduce revenue variability, farmers could complement yield-only insurance with use of forward contracting or price futures and options.

\subsection{Business interruption}

Epidemic disease risks, both in crop and livestock, are treated separately from production risks such as floods and droughts. One reason is that farmers can affect their own risk from epidemic disease such as classical swine fever, for example by having many animal contacts with other farms and allowing strangers to visit the farm. Moreover, by their actions they can also affect the risks of losses to other farmers. This occurs because, when an epidemic disease is diagnosed, movement restrictions apply in a certain radius around the infected farm.

Epidemic diseases are also treated separately, because governments bear most of the direct losses from an outbreak. Governments are responsible for the control of an epidemic disease and compensate farmers for livestock and crops that need to be destroyed. Farmers are not compensated for any losses that originate from the period their land or buildings are unused. This period can vary between the required minimum number of days and the total period movement restrictions apply (which can be more than half a year if multiple outbreaks occur).

One last reason for treating epidemic disease risk separately is that data concerning epidemic disease outbreaks are rare. In addition, governments from time to time change the legislation affecting the arrangements for disease control, creating more risk for farmers and insurers.

The fact that governments bear the direct losses implies that an insurance scheme needs only to cover consequential losses from business interruption. In the Netherlands, farmers' influence on losses and the lack of data has led to the development of mutual insurance schemes (see also Section 3.7.2). The advantages and disadvantages of such mutual schemes are discussed in the next subsection.

\section{Mutual insurance schemes/funds for epidemic disease risks}

A mutual farm insurance fund is a fund that is operated by farmers themselves. Incentives to prevent losses are central to the success of these funds. For example, participation may be limited to farmers who fulfil certain requirements. Farmers who participate pay a premium to cover administrative costs and reinsurance (i.e. to provide the 'infrastructure'). The fund then indemnifies members against the specified losses. If one member suffers a loss, other members may have to pay a surcharge to fund the indemnity. In mutual insurance funds, the role of insurance companies is restricted to that of administrator and reinsurer. Advantages of using mutual insurance funds for the coverage of epidemic disease losses include the following.

- $\quad$ Surcharges confront farmers directly with losses in a particular year. This is an incentive for farmers to (1) avoid or reduce the risk next year, and/ or (2) to reduce the amount of loss the next time the peril is faced.

- Surcharges reduce the importance of the availability of accurate data.

- Increased potential for social control by members over one another.

- Differentiation of premiums and indemnities for high-risk farmers has a sounder basis because it is 
not an anonymous insurance company but colleague farmers who impose these measures.

- Less severe problems of moral hazard and adverse selection because of farmers' familiarity with each other's production circumstances.

- Because most of the money to pay for losses (surcharges) is collected after the loss instead of being paid 'up front' in the form of premiums, farm capital is not reduced unless there is a loss.

In setting up a mutual insurance fund the following points should be borne in mind.

- Money to pay for losses is gathered a posteriori, which results in farmers being confronted with both losses and potentially large surcharges in the same year. This is why many Lloyds 'names' went broke recently. They invested the capital needed to meet surcharges they had guaranteed to pay in various assets, some of which depreciated. Therefore, they could not raise the promised amounts when called upon to do so (i.e. it can be very risky to be a member of such a fund).

- Mutuals should be organised regionally (homogeneous areas), because otherwise many of the advantages will disappear. However, regionally organised funds face the risk that all farmers in the fund face losses at the same time since the mutual fund covers risks that have systemic characteristics. In such a case other mutuals, possibly from other European countries, could step in. For this is to be effective, it is essential that mutuals agree on transparency about their accounts. This is especially important if governments provide financial backup in the form of reinsurance.

\section{Asymmetric information and systemic risk}

For losses from business interruption the scores for a mutual fund in respect of asymmetric information and data availability in Table 13 are set at 0 , because of farmers' familiarity with each other's production circumstances and the use of surcharges. The score for reinsurance availability is low because traditional reinsurance markets are, in general, reluctant to reinsure epidemic disease risks. The score for ability to deal with systemic risks is low, because research in the field of a 'livestock index' has only just started.

\section{Remark}

Mutual funds work well for ' $0 / 1$ ' risks (for example a farm is or is not infected with classical swine fever). For risks such as droughts, losses are much more difficult to determine and surcharges could be perceived as unfair. For example, if the trigger yield is set at $70 \%$ of normal yields, a farmer with yields of $65 \%$ of the normal quantity receives a payment (that is financed by surcharges for all farmers), while a farmer with a yield of $71 \%$ does not get a payment (while he has to pay a surcharge). If mutuals are to be used to cover risks other than epidemic disease, solutions might be found whereby group members decide that payments are also made to the farmer whose yield is $71 \%$. A system with more than one trigger level (and corresponding levels of indemnity payments) may handle this problem. 


\section{Data analysis and simulation}

\subsection{Introduction}

In the previous chapter it was suggested that income insurance in European agriculture can be introduced either as gross revenue insurance schemes for commodities for which objective price measures are available, or as yield-only insurance for those commodities for which such price measures are not available. In this chapter, a panel-data set with yield and price data is analysed and used as a basis for simulation. The simulation model is used to illustrate the effect of yield-only and gross revenue insurance schemes on the stability of the individual farmer's income. Implications for insurers are also discussed.

The simulation model can, in principle, be used to analyse many combinations of insurance schemes (variations in deductible, indemnities, commodities, etc.). However, given the limited time available for this study, only some important concepts and assumptions will be evaluated. This is done for illustrative purposes only, i.e. to show major effects of the schemes.

Section 5.2 discusses the materials and methods used. In Sections 5.3 and 5.4 yield-only and gross revenue insurance schemes are illustrated respectively. Section 5.5 concludes with a further underpinning of the major research question, namely whether an insurance scheme is a feasible instrument to achieve income stability in the future, in the light of the results of the simulations.

\subsection{Materials and methods}

\subsubsection{Data analysis}

In discussing insurance schemes, it is essential to have available individual farm data, because aggregated data from large areas would hide individual farm yield fluctuations. A large panel data set, containing individual farm yield data from the period 1989-95 (FADN
Information European Commission), is analysed. The data set includes annual data from six EU countries (Denmark, France, Germany (BRD), Greece, Italy and the Netherlands) and six agricultural commodities (wheat, potatoes, sugar beet, beef, milk and piglets). The total data set covers 49 regions and about 13000 farms. For each region calculations are made for the individual farms and for the group of farms as a whole. In both cases the average yield and the coefficient of variance $(\mathrm{CV})$ of yields are calculated. Annex IV gives an overview of the data. Because of the limited number of years, no trend effects are calculated.

Because gross revenue insurance schemes also include prices, price data are analysed as well (Eurostat, 1997). These price data refer to prices at country level, not to farm-gate prices. Furthermore, for potatoes and pigs, prices on the Amsterdam Exchange Market are analysed (1986-96). The latter are presented in Annex IV (last table). The other price data are shown in Section 5.3.1 (Table 16).

\subsubsection{Monte Carlo simulation}

\section{Introduction}

As its name implies, simulation is a method of analysing a problem situation by creating a model of the situation that can then be manipulated by modifying the input. In our study we used the @RISK simulation package from Palisade. The @RISK computer package brings advanced modelling and risk analysis to Excel worksheets (Palisade, 1997). In the simulation, risk is quantified using a probability density function (PDF) or a cumulative distribution function (CDF). Such functions are mathematical devices for presenting the quantified risk for a variable. @RISK uses these functions to describe uncertain values and to present results.

A major sampling technique in @RISK is Monte Carlo sampling. Monte Carlo sampling refers to the tradi- 
tional technique for using random numbers to sample from a PDF (Hardaker et al., 1997). Monte Carlo sampling techniques are entirely random. That is, any given sample may fall anywhere within the range of the input distribution. Samples, of course, are more likely to be drawn in areas of the PDF which have higher probabilities of occurrence. With enough iterations, Monte Carlo sampling will produce stable and reliable results.

Sampling is used in @ RISK simulation to generate possible values from PDFs or CDFs. These sets of possible values are then used to evaluate the Excel worksheet. Sampling is the process by which values are randomly drawn from input PDFs or CDFs. Because of this, sampling is the basis for the hundreds or thousands of "what if'scenarios@RISK calculates for the worksheet. Each set of samples represents a possible combination of input values that could occur. Sampling in a simulation is done repetitively - with one sample drawn every iteration from each input PDF or CDF. Again, with enough iterations, the sampled values will become distributed in a manner which approximates the combination of input PDFs or CDFs. The statistics of the sampled distribution - mean, standard deviation and higher moments - will approximate the true statistics that were input for the distributions.

The risk analyses are usually followed by a so-called sensitivity analysis. In a sensitivity analysis, the values of the parameters and assumptions used in the analysis are systematically varied to determine whether and how the outcome changes.

\section{Our simulation model}

The simulation model we developed in our study is a very straightforward model that can be used to illustrate the main principles of insurance schemes and the effect such schemes have on the stability of farmers' incomes. We define income as net return to labour and management. Graph 8 shows the various components of the net return to labour and management.

In the simulation model, variation of the net return to labour and management is caused by variation in yields and prices (no cost information is available).

Simulation is carried out for individually based schemes (not area-based schemes) and for crop commodities

\section{Graph 8: Net return to labour and management}

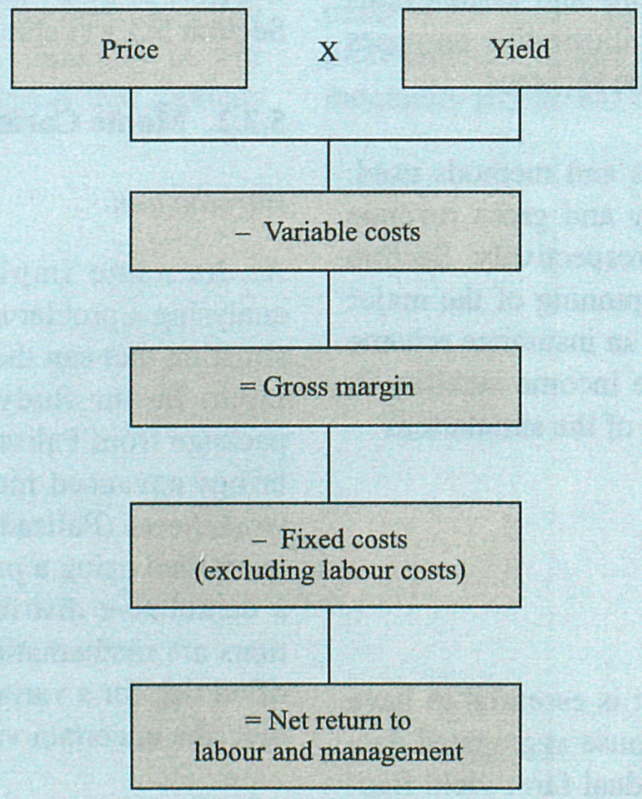


(potatoes, wheat and sugar beet) only. This is because, in the case of the livestock commodities available in the data set on yields (milk, beef and pigs), the variation in milk yields is modest (with the exception of certain regions in Italy and Greece) which reduces the need for and impact of insurance schemes, while for beef and pigs only gross production values (GPV) are available. These values are measures of production, but include growth of animals and livestock purchases which cause considerable fluctuations (which in fact are artificial) in these production measures. This means that they are not a good basis for insurance schemes.

For the simulation of yields, the simulation model uses CDFs that are directly derived from the data set discussed in the previous section. For the simulation of prices, PDFs are used. For all calculations 500 @RISK iterations are carried out. Background information on the simulation of the effect of insurance is provided in Annex V.

\subsection{Yield-only insurance}

In a yield-only insurance, yield fluctuations are insured. Yield shortfalls (minus the deductible/excess) are indemnified at a certain price. Section 5.3.1 shows the data that are selected from the large panel data set to illustrate the yield-only insurance. Section 5.3.2 dis- cusses the implications of individually based yield-only insurance schemes for individual farmers. This is first done using only the data from the panel data set and then by adding catastrophic events to the data. The latter is done, because the occurrence of catastrophic events is likely to be under-represented in the seven-year data set.

Section 5.3.3 illustrates the implications of yield-only insurance schemes for insurers. First the loss ratio (i.e. the ratio between indemnities paid and premiums received) is discussed. Then two important factors affecting the variation of the loss ratio are discussed: the number of insured farmers and the type of risk insured (independent versus systemic risks). The last part of the section illustrates the concept of reinsurance and the possible financial role the European Commission could play (as 'underwriter of last resort'). The role of the European Commission is illustrated both in a situation where the European Commission backs up insurance per commodity and in a situation where the European Commission only steps in if a so-called 'solidarity fund' cannot pay the losses. The solidarity fund is a fund to which all insurers transfer part of their premium receipts.

\subsubsection{Results from data analysis}

Table 14 shows the commodities and regions that are selected to illustrate a yield-only insurance. The

Table 14

Yield data: commodities and regions selected for illustration of yield-only insurance

\begin{tabular}{|c|c|c|c|c|}
\hline & \multicolumn{3}{|c|}{ Total group of farms } & \multirow{3}{*}{$\begin{array}{c}\text { CV within } \\
\text { farms (1) } \\
(\%)\end{array}$} \\
\hline & $n$ & Average yield & CV (1) & \\
\hline & & $(100 \mathrm{~kg} / \mathrm{ha})$ & $(\%)$ & \\
\hline \multicolumn{5}{|l|}{ Potatoes } \\
\hline The Netherlands & 43 & 423 & 22.4 & 12.2 \\
\hline Baden-Württemberg (D-BRD) & 44 & 234 & 41.3 & 29.5 \\
\hline Denmark & 24 & 289 & 37.5 & 26.6 \\
\hline \multicolumn{5}{|l|}{ Wheat } \\
\hline Makedonia-Thraki (EL) & 284 & 31 & 33.4 & 25.6 \\
\hline Pays de la Loire (F) & 104 & 59 & 24.9 & 17.8 \\
\hline Piemonte (I) & 107 & 48 & 26.4 & 20.0 \\
\hline \multicolumn{5}{|l|}{ Sugar beet } \\
\hline Marche (I) & 255 & 420 & 26.9 & 21.1 \\
\hline Makedonia-Thraki (EL) & 65 & 710 & 25.0 & 18.6 \\
\hline Picardie (F) & 112 & 644 & 16.6 & 12.4 \\
\hline
\end{tabular}


Table 15

Yield data expressed relative to farm averages

\begin{tabular}{|c|c|c|c|c|c|}
\hline & \multicolumn{4}{|c|}{ Total group of farms } & \multirow{2}{*}{$\begin{array}{c}\text { CV within } \\
\text { farms }\left({ }^{1}\right) \\
(\%)\end{array}$} \\
\hline & $\begin{array}{l}\text { Mean } \\
(\%)\end{array}$ & $\begin{array}{l}\text { Min. } \\
(\%)\end{array}$ & $\begin{array}{l}\text { Max. } \\
\text { (\%) }\end{array}$ & $\begin{array}{c}\text { CV (') } \\
(\%)\end{array}$ & \\
\hline \multicolumn{6}{|l|}{ Potatoes } \\
\hline The Netherlands & 100 & 53 & 151 & 13.1 & 12.2 \\
\hline Baden-Württemberg (D-BRD) & 100 & 22 & 234 & 31.6 & 29.5 \\
\hline Denmark & 100 & 27 & 190 & 29.1 & 26.6 \\
\hline \multicolumn{6}{|l|}{ Wheat } \\
\hline Makedonia-Thraki (EL) & 100 & 14 & 231 & 28.3 & 25.6 \\
\hline Pays de la Loire (F) & 100 & 20 & 175 & 19.4 & 17.8 \\
\hline Piemonte (I) & 100 & 17 & 187 & 22.1 & 20.0 \\
\hline \multicolumn{6}{|l|}{ Sugar beet } \\
\hline Marche (I) & 100 & 14 & 230 & 23.2 & 21.1 \\
\hline Makedonia-Thraki (EL) & 100 & 41 & 183 & 19.8 & 18.6 \\
\hline Picardie (F) & 100 & 29 & 151 & 13.3 & 12.4 \\
\hline
\end{tabular}

symbol $n$ represents the number of farms that are in the data set for a specific region and commodity. Average yields and the variability of yields are calculated for the group as a whole. The CV is used as a measure of variability and is defined as the standard deviation divided by the mean. The last column gives an insight into the variability of yields within farms.

Table 14 shows that the variability of yields within farms is much lower than the variability of yields for the total group of farms. This is due to the fact that the $\mathrm{CV}$ of the total group represents not only the $\mathrm{CV}$ of yield within farms (as a result of good and bad production years) but also the CV of yields between farms (as a result of high versus low producing farms).

For the calculation of premiums for an individual farmer, not only data from that individual farm are needed, but from a larger group of farms (see Graph 5). In such a way production circumstances of the area are included in the calculations. However, the data of the total group of farms not only represents the effect of farms that encounter good/bad years but also the effect of high/low producing farms (variation between farms). For this reason the absolute data are converted to relative data by expressing the data of each individual farmer relative to his farm average. After doing this, the CVs of yields for groups as a whole are decreased sig- nificantly. The CVs within farms, of course, stay the same. Table 15 shows the data of the total group expressed relative to farm averages.

The yield data underlying Table 15 are used to estimate the CDFs for the simulation model. Table 16 shows the means and CVs of the price data on potatoes, wheat and sugar beet.

Table 16 shows that in all countries the CV of prices is highest for potatoes and lowest for sugar beet (with the exception of Greece in which the CV of wheat is lowest). For use in the @ RISK simulation model the price data underlying Table 16 are first expressed in a relative way (because yields are also expressed relatively). These relative data are then reflected by lognormal PDFs. Lognormal distributions seem appropriate to reflect price distributions.

\subsubsection{Implications for individual farmers: simulation results}

\subsubsection{Assumptions}

To illustrate the impact of yield-only insurance schemes for individual farmers, the following assumptions have been made (those marked with an asterisk are explained in Annex V). See Annex V for the formulae used. 
Table 16

Commodity prices (1986-95) for potatoes, wheat and sugar beet

\begin{tabular}{|c|c|c|c|c|c|c|}
\hline & \multicolumn{2}{|c|}{ Potatoes } & \multicolumn{2}{|c|}{ Wheat } & \multicolumn{2}{|c|}{ Sugar beet } \\
\hline & $\begin{array}{c}\text { Mean } \\
\text { (ECU/100 kg) }\end{array}$ & $\begin{array}{l}\text { CV (') } \\
(\%)\end{array}$ & $\begin{array}{c}\text { Mean } \\
\text { (ECU/100 kg) }\end{array}$ & $\begin{array}{c}\mathrm{CV}\left({ }^{1}\right) \\
(\%)\end{array}$ & $\begin{array}{c}\text { Mean } \\
\text { (ECU/100 kg) }\end{array}$ & $\begin{array}{c}\mathrm{CV}\left({ }^{(}\right) \\
(\%)\end{array}$ \\
\hline B & 7.1 & 46.1 & 15.6 & 12.5 & 4.0 & 4.6 \\
\hline DK & 16.1 & 34.0 & 16.0 & 9.7 & 3.9 & 7.3 \\
\hline D & 12.3 & 26.9 & 16.4 & 11.8 & 4.1 & 5.6 \\
\hline EL & 22.4 & 22.4 & 16.4 & 6.5 & 4.8 & 11.1 \\
\hline$E$ & 17.3 & 20.8 & 19.4 & 7.3 & .5 .4 & 4.1 \\
\hline$F$ & 9.4 & 38.1 & 15.8 & 10.5 & 3.3 & 7.1 \\
\hline IRL & - & - & 14.5 & 8.4 & 4.8 & 4.4 \\
\hline 1 & 22.5 & 18.2 & 20.1 & 9.8 & 5.6 & 2.8 \\
\hline L & 15.8 & 18.0 & 15.0 & 10.9 & - & - \\
\hline NL & 9.7 & 41.6 & 15.7 & 10.5 & 4.7 & 7.1 \\
\hline$P$ & 15.2 & 21.7 & 24.2 & 21.9 & 4.5 & 4.6 \\
\hline FIN & 23.2 & 19.6 & 41.6 & 27.1 & 8.4 & 17.9 \\
\hline$S$ & 17.8 & 26.5 & 16.2 & 16.7 & 3.9 & 12.2 \\
\hline UK & 14.2 & 38.6 & 15.6 & 6.6 & 4.3 & 6.2 \\
\hline
\end{tabular}

Source: Eurostat (1997).

- Guarantee level* $=80 \%$ tines the farm's average yield

(i.e. deductible $=20 \%$ )

- $\quad$ Election percentage $*=90 \%$, i.e. yield shortfalls are indemnified at $90 \%$ of the market price

- Variable costs

$=1$; same for all regions and commodities

- $\quad$ Fixed costs

$=0$; same for all regions and commodities

\section{Remarks}

To avoid moral hazard, yield shortfalls are indemnified at $90 \%$ of the market price. In such a way, farmers always have an incentive to produce the highest yield possible, even if yields fall below the guarantee level.

\subsubsection{Results based on historical data (1989-95)}

Based on the historical data, Table 17 shows the implications of yield-only insurance for individual farmers by comparing the variability of the net return (NR) to labour and management with and without insurance. The term ' $<50 \%$ ' represents the probability of net returns less than $50 \%$ of the average net return. The loss costs are the basis for determining the premium. If, for example, the average yield of a potato farmer in the Netherlands is $30000 \mathrm{~kg} / \mathrm{ha}$ and the election price is $0.06 \mathrm{ECU} / \mathrm{kg}$, the premium is $0.5 \% * 30000 * 0.06 \mathrm{ECU}$ $=9 \mathrm{ECU} / \mathrm{ha}$.

Table 17 shows that the yield-only insurance reduces the $\mathrm{CV}$ of the net return to labour and management. The reduction varies from $0.3 \%$ for potatoes in the Netherlands to $18 \%$ for wheat in Makedonia-Thraki. Furthermore, the chances of outcomes less than $50 \%$ of the average net return are reduced in all cases, except for potatoes in the Netherlands. The latter is due to the fact that in the Netherlands the price variability for potatoes is much larger than the yield variability.

\subsubsection{Results based on historical data (1989-95) extended with catastrophic events}

The results presented in Table 17 are based on the seven-year data of the panel data set on yields (FADN Information European Commission). These yield data may not sufficiently represent the occurrence of catastrophic events. For an individual farmer a catastrophic event is defined as an event that results in extremely 
Table 17

Effect of yield-only insurance for individual farmers (500@RISK iterations)

\begin{tabular}{|c|c|c|c|c|c|}
\hline & \multicolumn{2}{|c|}{ No insurance } & \multicolumn{3}{|c|}{ With insurance } \\
\hline & CV NR (') & $<50 \%\left({ }^{2}\right)$ & CV NR ins $^{(1)}$ & $<50 \%\left({ }^{3}\right)$ & Loss costs \\
\hline \multicolumn{6}{|l|}{ Potatoes } \\
\hline The Netherlands & 48.4 & 11 & 48.3 & 11 & 0.5 \\
\hline Baden-Württemberg (D-BRD) & 44.8 & 9 & 41.9 & 5 & 4.3 \\
\hline Denmark & 44.1 & 9 & 41.5 & 6 & 4.3 \\
\hline \multicolumn{6}{|l|}{ Wheat } \\
\hline Makedonia-Thraki (EL) & 29.1 & 4 & 23.8 & 0 & 3.9 \\
\hline Pays de la Loire (F) & 22.7 & 2 & 20.0 & 0 & 1.7 \\
\hline Piemonte (I) & 25.0 & 2 & 21.7 & 0 & 2.4 \\
\hline \multicolumn{6}{|l|}{ Sugar beet } \\
\hline Marche (I) & 23.5 & 1 & 20.7 & 0 & 1.9 \\
\hline Makedonia-Thraki (EL) & 25.1 & 1 & 23.2 & 0 & 1.6 \\
\hline Picardie (F) & 17.6 & 0 & 16.5 & 0 & 0.5 \\
\hline $\begin{array}{l}\text { (1) Coefficient of variance }(\mathrm{CV}):(\mathrm{sc} \\
\text { (2) Frequency }(\%) \text { of } \mathrm{NR} \text { less than } 5 \\
\text { (3) Frequency }(\%) \text { of } \mathrm{NR}_{\text {ins }} \text { less than }\end{array}$ & NR. & & & & \\
\hline
\end{tabular}

low yields (approaching zero). Examples of the type of catastrophic events this study refers to are floods and droughts. To simulate the occurrence of catastrophic events at the farm level, a Poisson distribution is introduced in the model. The Poisson distribution is typically used to represent situations in which a number of individual events occur in a given unit of time. For each region and commodity it is assumed that farmers are, on average, confronted with a catastrophic event every two-year period. Furthermore, it is assumed that if such an event occurs the yield of a farmer decreases by $70 \%$ if one catastrophic event occurs, by $85 \%$ if two such events occur and by $90 \%$ and $95 \%$ if the farm is confronted with 3 or 4 catastrophic events in a certain year. This is really a worst-case situation. The variability of the net return to labour and management and the effect of a yield-only insurance under such circumstances are shown in Table 18.

Table 18 shows that the $\mathrm{CV}$ of the net return to labour and management is much higher than in Table 17 as are the loss costs. As catastrophic events occur, the yieldonly insurance reduces the variability of net return to labour and management by $10 \%$ (the Netherlands) to $34 \%$ (Picardie). Comparing the $<50 \%$ frequencies in Table 18 with and without insurance, showns that the frequency of outcomes less than $50 \%$ of the average net return to labour and management is much lower with insurance. Because of the possibility of very low yields (due to the occurrence of catastrophes) and because of the deductibles (both in yield and price) the $<50 \%$ frequencies are not reduced to zero. As an illustrative example, Graph 9 shows the CDF of the relative net return to labour and management (with and without insurance) for a sugar beet farmer in Marche (Italy).

The expected value of the net return to labour and management is the same for the curve with and without insurance. If a farmer is indifferent to risk, he will be indifferent between the two options since he will base his choice on the expected value. Risk-averse farmers prefer the situation with insurance, with the preference positively correlated with the degree of risk-aversion (Hardaker et al., 1997).

\subsubsection{Implications for insurers: simulation results}

\subsubsection{Loss ratio}

The loss ratio of an insurance company represents the ratio between indemnities paid and premiums received. If insured farmers pay a premium that is based on loss costs (see Annex V) premiums are actuarially sound and the ratio is, in the long run, equal to 1 (assuming zero profit and no administrative and reinsurance costs). The loss ratio of an insurer for the insurance of a specific commodity $\mathrm{c}$ is defined as: 
Table 18

Effect of yield-only insurance with the occurrence of catastrophes (500 @RISK iterations)

\begin{tabular}{|c|c|c|c|c|c|}
\hline & \multicolumn{2}{|c|}{ No insurance } & \multicolumn{3}{|c|}{ With insurance } \\
\hline & CV NR $\left({ }^{1}\right)$ & $<50 \%\left({ }^{2}\right)$ & CV NR ${ }_{\text {ins }}\left({ }^{1}\right)$ & $<50 \%\left({ }^{3}\right)$ & Loss costs \\
\hline \multicolumn{6}{|l|}{ Potatoes } \\
\hline The Netherlands & 76.6 & 33 & 68.7 & 24 & 12.2 \\
\hline Baden-Württemberg (D-BRD) & 73.0 & 34 & 63.3 & 24 & 10.7 \\
\hline Denmark & 68.4 & 31 & 58.4 & 19 & 9.9 \\
\hline \multicolumn{6}{|l|}{ Wheat } \\
\hline Makedonia-Thraki (EL) & 60.9 & 33 & 48.5 & 10 & 12.5 \\
\hline Pays de la Loire (F) & 56.7 & 34 & 43.9 & 11 & 12.2 \\
\hline Piemonte (I) & 57.1 & 33 & 44.4 & 12 & 10.2 \\
\hline \multicolumn{6}{|l|}{ Sugar beet } \\
\hline Marche (I) & 56.8 & 33 & 41.9 & 1 & 9.1 \\
\hline Makedonia-Thraki (EL) & 57.3 & 32 & 43.0 & 8 & 11.8 \\
\hline Picardie (F) & 53.8 & 35 & 35.6 & 2 & 10.3 \\
\hline $\begin{array}{l}\text { (1) Coefficient of variance (CV): (sd } \\
\text { (2) Frequency (\%) of NR less than } 5 \\
\left({ }^{3}\right) \text { Frequency (\%) of } \mathrm{NR}_{\text {ins }} \text { less than }\end{array}$ & $\begin{array}{l}\text { ge NR. } \\
\text { rage NR be }\end{array}$ & & & & \\
\hline
\end{tabular}

Graph 9: Net return to labour and management (with and without insurance) for a sugar beet farmer in Marche (Italy)

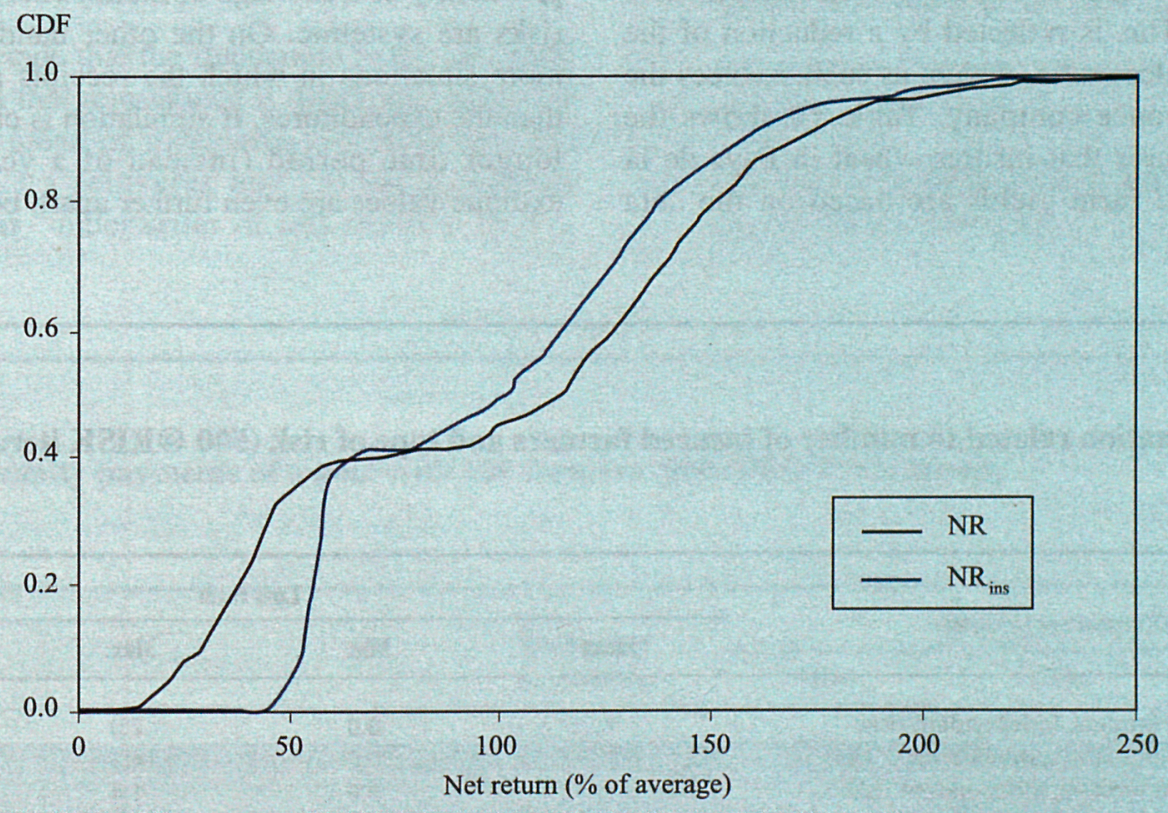




$$
L R_{c, t}=\frac{\sum_{f=1}^{F} I_{f, c, t}}{\sum_{f=1}^{F} P R_{f, c, t}}
$$

with:

$$
\begin{aligned}
L R_{c, t}= & \begin{array}{l}
\text { loss ratio of insurer for commodity } c \text { in } \\
\text { year } t
\end{array} \\
I_{f, c, t}= & \begin{array}{l}
\text { indemnity for farmer } f \text { and commodity } c \\
\text { in year } t
\end{array} \\
P R_{f, c, t}= & \begin{array}{l}
\text { premium paid by farmer } f \text { for commodity } \\
c \text { in year } t
\end{array} \\
F \quad= & \begin{array}{l}
\text { total number of insured farmers in the } \\
\text { pool }
\end{array}
\end{aligned}
$$

\subsubsection{Factors that influence the variation of the loss ratio}

Though, in the long run, the loss ratio equals one, the variability of the ratio depends on (1) the number of insured farms and (2) the type of risks insured (independent versus systemic risks).

\section{Number of insured farmers}

The more farmers are insured, the more the risks are spread among the farmers (pooling of risk or economies of size in risk). This is reflected by a reduction of the variability of the loss ratio, which, as such, reduces the risk for an insurance company. Table 19 shows the effect for an insurer that insures wheat in Pays de la Loire. Individual farm yields are based on the data explained in Section 5.3.2.2 (i.e. historical data extended with catastrophic events). The effect of the number of insured farmers becomes most clear in the situation of independent risks (see rows 1 and 3 in Table 19): the variability of the loss ratio is decreased from 40 to 14 .

\section{Independent versus systemic risks}

The catastrophic events in this study often involve a lot of farms at the same time. Such so-called systemic risks result in an increase in the variability of the loss ratio of an insurer because claims are not equally spread over time. Table 19 shows the effect of the type of risk insured. The systemic character of risks is simulated assuming a correlation of yields between farmers of 0.8 .

Table 19 shows that the type of risks insured has a large impact on the variability of the loss ratio. In case of the pool of 100 farms, the CV of the loss ratio is eight times higher when systemic risks are insured (compare 111 versus 14).

To illustrate the effect of the type of risks insured on the receipts (premiums) and expenditures (indemnities) of an insurer, Graph 10 shows the cumulative distribution function of premiums $(\mathrm{P})$ minus indemnities (I) for the case of 100 insured farmers.

As Graph 10 shows with the long tail to the left, the

\begin{tabular}{|c|c|c|c|c|}
\hline & \multicolumn{4}{|c|}{ Loss ratio } \\
\hline & Mean & Min. & Max. & $\mathrm{CV}$ \\
\hline Insurance pool of 10 farmers, independent risks & 1 & 0.0 & 2.0 & 40 \\
\hline Insurance pool of 10 farmers, systemic risks & 1 & 0.0 & 4.1 & 111 \\
\hline Insurance pool of 100 farmers, independent risks & 1 & 0.6 & 1.4 & 14 \\
\hline Insurance pool of 100 farmers, systemic risks & 1 & 0.0 & 4.0 & 111 \\
\hline
\end{tabular}
probability of a shortage of money (i.e. P - I) is larger if risks are systemic. On the other hand, there are also more situations in which the receipts are much larger than the expenditures. If simulation is carried out over a longer time period (instead of a yearly basis) the extreme values are even further apart, because there is a

Table 19

Loss ratio: fluctuation related to number of insured farmers and type of risk (500 @ RISK iterations) 


\section{Graph 10: CDF of premiums received (P) minus indemnities paid (I) for wheat in Pays de la Loire (insurance pool of $\mathbf{1 0 0}$ farmers)}

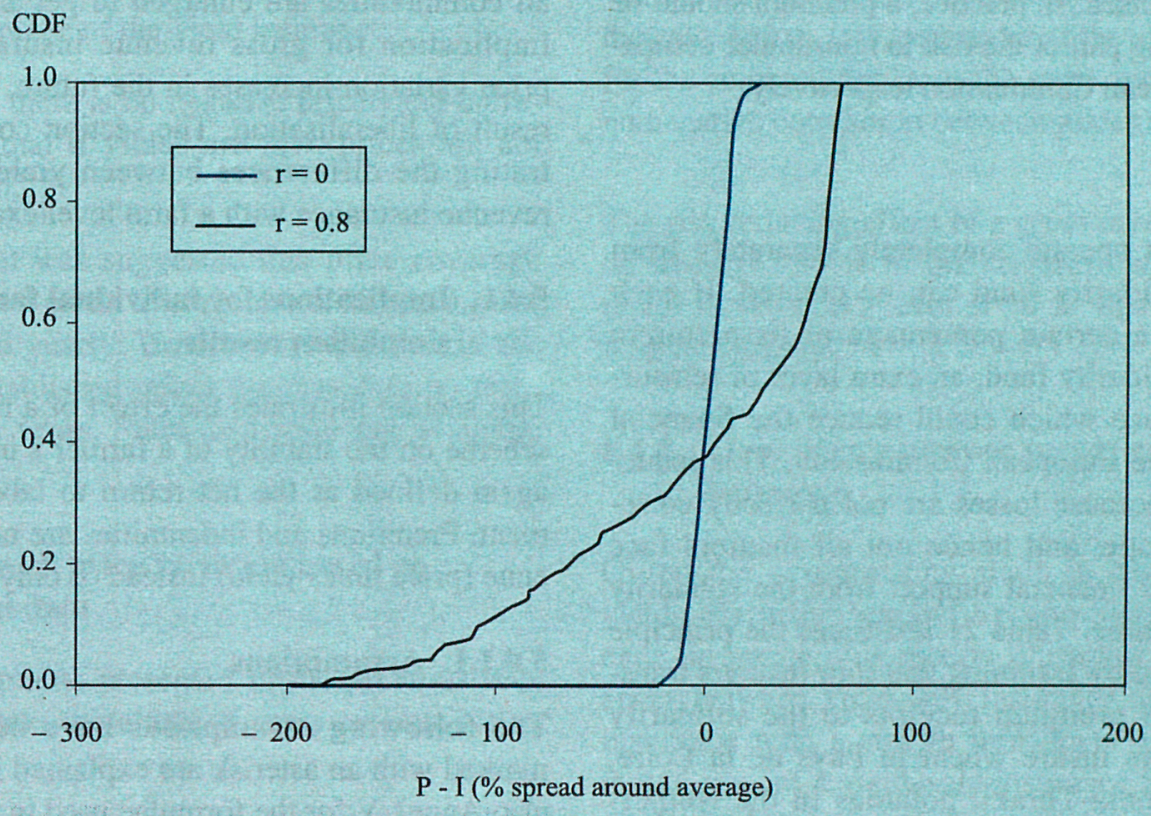

possibility of having a number of 'loss years' or 'no loss years' in a row.

\subsubsection{Reinsurance}

Insurers may decide that the fluctuation in the loss ratio is too large and that reinsurance is necessary. Table 20 illustrates the spread of indemnity payments over (1) the insurer, (2) a reinsurer and (3) the European Commission (as 'underwriter of last resort'). In this example the following assumptions are made on an annual basis, taking the loss ratio of the insurance pool of 100 farmers (last row Table 19) as a starting point:

- $\quad$ insurer is responsible for loss ratio below 2;

- $\quad$ reinsurance company takes loss ratio between 2 and 3.5;

- the European Commission gives a guarantee to pay for losses above 3.5 .

Table 20

Spread of indemnity payments of a pool with 100 farmers (500 @RISK iterations)

\begin{tabular}{lcrrr}
\hline & & & \multicolumn{3}{c}{ Amount of payments (EUR) } \\
\cline { 4 - 6 } & Frequency of & & Min. & Max. \\
\hline Insurer & 84 & 5293 & 0 & 12885 \\
Reinsurer & 22 & 999 & 0 & 9664 \\
European Commission & 2 & 44 & 0 & 3144 \\
\hline
\end{tabular}


Table 20 shows that the insurer takes the major part of the losses (both in frequency and in amount of payments). Payments by the European Commission are restricted to $2 \%$ of the cases and to a maximum that is only $25 \%$ of that of the insurer itself. In practice, a premium should be paid for transferring part of the risk to reinsurance companies and the European Commission respectively.

\section{Solidarity fund}

If insurers do not operate completely separately from each other, a solidarity fund can be created. If each insurer transfers a certain percentage of its premium receipts to the solidarity fund, an extra layer of reinsurance is put in place which could reduce the financial involvement of the European Commission. This reduction takes place because losses are not perfectly correlated within Europe, and hence not all insurers face shortage and need financial support from the solidarity fund at the same time. Table 21 illustrates the principle of a solidarity fund by assuming that four insurers transfer $15 \%$ of their premium receipts to the solidarity fund. The insurers insure wheat in Pays de la Loire, wheat in Makedonia-Thraki, potatoes in the Netherlands and potatoes in Baden-Württemberg.

Table 21 shows that the frequency and the average amount of payments by the European Commission is reduced significantly.

\subsection{Gross revenue insurance}

In a gross revenue insurance scheme both low prices and low yields can trigger a payment. A prerequisite for such a scheme to work properly is an objective measure for price, for example futures markets prices. This section illustrates the implications of gross revenue insur-

ance schemes for individual farmers. This is first done using the CVs of yields and prices from historical data (assuming that the price data underlying Table 16 are objective measures of price); then the CVs of prices of all commodities are enlarged to get an insight into the implication for gross revenue insurance schemes of price variation increases in the future, for example as a result of liberalisation. The section concludes by illustrating the differences between yield-only and gross revenue insurance with a farm level example.

\subsubsection{Implications for individual farmers: simulation results}

This section illustrates the effect of a revenue insurance scheme on the stability of a farmer's income. Income is again defined as the net return to labour and management. Premiums and indemnities are now based on revenue (price times yield) instead of only yield.

\subsubsection{Assumptions}

The following assumptions have been made (those marked with an asterisk are explained in Annex V). See also Annex V for the formulae used in the calculations.

- Guarantee level* ${ }^{*}=80 \%$ times the farm's average revenue (i.e. deductible $=20 \%$ )

- Election percentage* $=90 \%$, i.e. $90 \%$ of the revenue shortfalls ( $>$ deductible) are indemnified

- Variable costs

- $\quad$ Fixed costs
$=1$; same for all regions and commodities

$=0$; same for all regions and commodities

Table 21

Payments of the European Commission (EC) to four insurers with and without the existence of a solidarity fund (500@RISK iterations)

\begin{tabular}{|c|c|c|c|c|}
\hline & \multirow{2}{*}{$\begin{array}{c}\text { Frequency of } \\
\text { EC payments (\%) }\end{array}$} & \multicolumn{3}{|c|}{ Amount of payments (EUR) } \\
\hline & & Mean & Min. & Max. \\
\hline Without solidarity fund & 8.0 & 329 & 0 & 16568 \\
\hline With solidarity fund & 0.4 & 22 & 0 & 10348 \\
\hline
\end{tabular}




\section{Remarks}

To make the comparison between yield-only and gross revenue insurance as clear as possible, the election percentage for the gross revenue insurance is set equal to the election percentage of the yield insurance.

It is assumed that there is no negative price/yield correlation, implying that if yields are low, prices are not automatically high.

In Section 3.4.1 it was suggested that price coverage should not be based on an average price, but on a price that is established yearly. However, simulation in the field of yearly established prices requires data on price variability within years. Such data were not available for this study.

\subsubsection{Results with price variation based on historical data}

Given the assumptions presented in the previous section, Table 22 shows the effect of gross revenue insurance schemes.

For the 'no insurance' situation, results are the same as presented in Table 17 (yield-only insurance). However, the 'with insurance' situation shows higher loss costs, but also a greater reduction effect, varying from $8 \%$ for sugar beet in Picardie to $19 \%$ for wheat in MakedoniaThraki.

\subsubsection{Results with increased price variation}

Table 23 shows the effect of gross revenue insurance schemes if the $\mathrm{CV}$ of potato, wheat and sugar beet prices were to rise to $50 \%$ (which is an extreme example). In the calculations it is assumed that the average price level for the commodities stays the same and that there is still no negative correlation between prices and yields.

The risk reducing effect of a gross revenue insurance is, on average, $14 \%$ in the situation where the CVs of prices increase to a level of $50 \%$. Loss costs are higher than in Table 22.

\subsubsection{Yield-only insurance versus gross revenue insurance}

Given the assumptions made in Section 5.3.2.1 on yield-only insurance and Section 5.4.1.1 on gross revenue insurance, this section illustrates the major differences between yield-only insurance and gross revenue insurance with a simple farm-level example. Assume that in case of a yield-only insurance the situation for a particular farmer is as follows:

$$
\begin{aligned}
& \text { - } \text { average yield }=1000 \\
& \text { - } \text { guarantee level }=800 \text { (i.e. deductible }=20 \% \text { ) } \\
& \text { - } \text { election price } \quad=90 \% \text { market price. }
\end{aligned}
$$

\begin{tabular}{|c|c|c|c|c|c|}
\hline & \multicolumn{2}{|c|}{ No insurance } & \multicolumn{3}{|c|}{ With insurance } \\
\hline & CV NR $\left({ }^{1}\right)$ & $<50 \%\left({ }^{2}\right)$ & CV NR ${ }_{\text {ins }}\left({ }^{1}\right)$ & $<50 \%\left({ }^{3}\right)$ & Loss costs \\
\hline \multicolumn{6}{|l|}{ Potatoes } \\
\hline The Netherlands & 48.4 & 11 & 41.9 & 0 & 7.0 \\
\hline Baden-Württemberg (D-BRD) & 44.8 & 9 & 38.7 & 0 & 7.1 \\
\hline Denmark & 44.1 & 9 & 36.9 & 0 & 8.2 \\
\hline \multicolumn{6}{|l|}{ Wheat } \\
\hline Makedonia-Thraki (EL) & 29.1 & 4 & 23.7 & 0 & 4.0 \\
\hline Pays de la Loire (F) & 22.7 & 2 & 19.2 & 0 & 2.0 \\
\hline Piemonte (I) & 25.0 & 2 & 21.3 & 0 & 2.5 \\
\hline \multicolumn{6}{|l|}{ Sugar beet } \\
\hline Marche (I) & 23.5 & 1 & 20.6 & 0 & 1.8 \\
\hline Makedonia-Thraki (EL) & 25.1 & 1 & 22.2 & 0 & 2.0 \\
\hline Picardie (F) & 17.6 & 0 & 16.2 & 0 & 0.7 \\
\hline \multicolumn{6}{|c|}{$\begin{array}{l}\text { (1) Coefficient of variance (CV): (sd/mean)* } 100 \text {. } \\
\text { (2) Frequency (\%) of NR less than } 50 \% \text { of the average NR. } \\
\text { (3) Frequency }(\%) \text { of } \mathrm{NR}_{\text {ins }} \text { less than } 50 \% \text { of the average NR before insurance. }\end{array}$} \\
\hline
\end{tabular}

Table 22

Effect of gross revenue insurance for individual farmers (500 @RISK iterations) 
Table 23

Effect of gross revenue insurance with increased CV for prices (500@RISK iterations)

\begin{tabular}{|c|c|c|c|c|c|}
\hline & \multicolumn{2}{|c|}{ No insurance } & \multicolumn{3}{|c|}{ With insurance } \\
\hline & CV NR ( $\left.{ }^{1}\right)$ & $<50 \%\left({ }^{2}\right)$ & CV NR ${ }_{\text {ins }}\left({ }^{1}\right)$ & $<50 \%\left({ }^{3}\right)$ & Loss costs \\
\hline \multicolumn{6}{|l|}{ Potatoes } \\
\hline The Netherlands (NL) & 58.2 & 16 & 50.4 & 0 & 8.9 \\
\hline Baden-Württemberg (D-BRD) & 64.6 & 20 & 55.7 & 0 & 11.8 \\
\hline Denmark (DK) & 60.8 & 20 & 51.6 & 0 & 11.7 \\
\hline \multicolumn{6}{|l|}{ Wheat } \\
\hline Makedonia-Thraki (EL) & 61.3 & 17 & 52.0 & 0 & 10.3 \\
\hline Pays de la Loire (F) & 56.6 & 18 & 48.3 & 0 & 10.1 \\
\hline Piemonte (I) & 57.5 & 17 & 48.7 & 0 & 10.0 \\
\hline \multicolumn{6}{|l|}{ Sugar beet } \\
\hline Marche (I) & 63.8 & 23 & 54.4 & 1 & 10.6 \\
\hline Makedonia-Thraki (EL) & 66.7 & 22 & 57.2 & 0 & 9.5 \\
\hline Picardie (F) & 72.3 & 25 & 62.2 & 4 & 9.4 \\
\hline $\begin{array}{l}\text { (1) Coefficient of variance (CV): (s } \\
\text { (2) Frequency (\%) of NR less than } 5 \\
\text { (3) Frequency (\%) of } \mathrm{NR}_{\text {ins }} \text { less thar }\end{array}$ & $\begin{array}{l}\text { verage NR } \\
\text { average } \mathrm{N}\end{array}$ & ance. & & & \\
\hline
\end{tabular}

And in case of a gross revenue insurance:

- average market price $=10$

- $\quad$ average gross revenue $=10000$

(= average yield times average price)

- guarantee level $=8000$

(i.e. deductible $=20 \%$ )

- election percentage $\quad=90 \%$.
Table 24 shows the indemnity payments of both insurance schemes for two different market situations (high versus low market price).

Table 24 shows that, because gross revenue insurance schemes are triggered by reductions in gross revenue instead of yield, the eventual revenue for the farmer is much closer to his average with a gross revenue insurance than with a yield-only insurance scheme. For example, in the situation with a high market price, while the yield insurance indemnifies the farmer for his yield loss, the high price has already compensated the income loss.

Table 24

Indemnity payments under yield-only and gross revenue insurance: an example

\begin{tabular}{cccccc}
\hline & Actual circumstances & & & \multicolumn{2}{c}{ Indemnity payments } \\
\cline { 1 - 2 } \cline { 5 - 6 } Market price & Yield & Gross revenue & & Yield-only insurance & Gross revenue insurance \\
\hline 20 & 500 & 10000 & & 5400 (i.e. $(800-500) * 90 \% * 20)$ & 0 (actual revenue $>$ guarantee level) \\
\hline 2 & 500 & 1000 & & 540 (i.e. $(800-500) * 90 \% * 2)$ & 6300 (i.e. $(8000-1000) * 90 \%)$ \\
\hline
\end{tabular}




\subsection{Discussion}

The simulation model aimed to illustrate the effects of yield-only and gross revenue insurance schemes on the stability of the individual farmer's income. Though the model set up was very straightforward, the main principles of insurance have been demonstrated, i.e. the calculation of net return to labour and management (with and without insurance), the $\mathrm{CV}$ of the net return to labour and management (with and without insurance), the premiums based on the loss costs, the calculation of indemnity payments and the effect of the number of insured farmers and the type of risks insured on the variation of the loss ratio.

Simulation results show that yield-only and gross revenue insurance schemes are able to reduce the volatility of farmers' income, though the exact effect for a specific commodity depends on the variability of prices, the number and size of catastrophic events, the size of the deductible (excess), the price at which yield shortfalls are indemnified and the price taken into consideration to establish the revenue guarantee level. In all cases the risk of getting (catastrophically) low outcomes, which can put farmers out of business, is removed. 



\section{Conclusions, discussion, recommendations and further research}

In the US, income insurance studies already have a long history, starting in 1981 with the Agricultural and Food Act. Only recently were the first income insurance products introduced, the so-called income protection, revenue assurance and crop revenue coverage products. In Europe, this study is the first in this field. This chapter summarises the conclusions from this study (mainly based on Chapter 4). The conclusions are then discussed in view of the general conditions European income insurance schemes need to fulfil. The chapter concludes with recommendations and suggestions for further research.

\subsection{Main conclusions}

In discussing the feasibility of an income insurance scheme for European agriculture, two questions are central: (1) is it possible to develop a scheme that is attractive to commercial insurers and (2) will such schemes appeal to farmers?

\subsubsection{Is it possible to develop a scheme that is attractive to commercial insurers?}

Insurers will offer some form of income insurance if they can make a profit by doing so without exposing themselves to unbearable risk. This implies that serious problems of adverse selection, moral hazard and systemic risk have to be solved in the design of any income insurance scheme for it to be viable for the insurer.

\section{Asymmetric information}

Asymmetric information exists when the would-be insured knows more about the risk being insured than does the insurer. Such asymmetry of information can lead to unacceptable problems for the insurer of adverse selection and moral hazard.

To prevent problems of asymmetric information an income insurance scheme should ideally cover only:
- $\quad$ accidental and unintentional losses - when losses can be influenced by the behaviour of the insured, problems of moral hazard are likely to arise;

- $\quad$ income measures for which proper risk classification and rate making is possible - this requires the availability of sufficient and reliable data; and

- $\quad$ losses that are determinable and measurable - for a proper loss assessment, the amount of loss and the issue of whether the loss is caused by an insured event need to be unambiguous.

In practice, all these conditions may not be fully satisfied, yet it may still be possible to develop a workable income insurance scheme attractive to insurers. For example, moral hazard problems of management influence on the outcome of the insured event can be minimised by such measures as use of deductibles/excesses or no-claims bonuses, as is done in vehicle accident insurance.

The severity of problems of asymmetric information depends to a large degree on the income measure insured. The pros and cons of different measures are reviewed below.

\section{Whole-farm income insurance}

Insuring whole-farm income as such is not possible because it includes aspects such as farm operating costs and inventories, which are strongly influenced and easily manipulated by the insured farmer. Furthermore, in calculating premium rates, sufficient data on wholefarm incomes calculated in an acceptable and consistent way may not be available.

\section{Whole-farm gross revenue insurance}

Insurance for the gross revenue earned from a combination of several commodities on a farm is only feasible if the revenues from each of the commodities substan- 
tially fulfil the requirements listed below for commodity gross revenue insurance. If there are only a few commodities for which these conditions are met, wholefarm gross revenue insurance is not possible, although commodity-specific gross revenue insurance may be feasible, as discussed below.

\section{Commodity gross revenue insurance}

Insuring gross revenue earned from production of a given commodity implies insuring the product of the price and yield of that commodity. For insurers to set adequate premiums, they need information on the joint distribution of prices and yields. Since prices and yields may not be stochastically independent, the information requirements to derive the full joint distribution are considerable. An extra difficulty arises if the nature of the stochastic dependency changes over time, e.g. as a result of market liberalisation.

In addition to issues of jointness, problems of asymmetric information arise in relation to the marginal distributions of the price and yield components, as discussed below.

\section{Yields}

Yields calculated on an area basis (rather than individual farm or field yields) cannot be influenced much by the individual farmer and could, therefore, be a good basis for insurance if the area yields can be measured reliably. Furthermore, for reasons of basis risk for farmers contemplating buying insurance, area-yield data can only be used in insurance contracts in areas where yields are highly correlated across farms.

If individual farm yields are to be used, insurance instruments such as deductibles (excesses), no-claim bonuses, monitoring the behaviour of individual farmers (good farming practices), and the monitoring of crops just before or at harvest time, are necessary to reduce the moral hazard problem inherent to the use of farm-level data.

With respect to livestock commodities, insurance against low yields is likely to face problems. The following points relate to individual farm yields, not to area yields; area yields would not be an option for most livestock because, in the case of intensively reared livestock at least, yield variations are not caused to any large degree by environmental factors affecting many farms in an area.
- $\quad$ Fluctuations in livestock yields are generally less than in crop yields. The fluctuations that do occur, especially for intensive livestock, are much more a management issue than for crops (for which weather-related events cause part of the fluctuation), implying extra difficulties of moral hazard for the would-be insurer.

- Most livestock commodities do not have a clear 'harvesting' time, as with crops. Livestock farms either produce output throughout the year (e.g. piglets) or have a multi-year production cycle (e.g. beef cattle). Moreover, the timing of 'harvesting' for some livestock systems is quite flexible. Both aspects may allow insured farmers to manipulate the timing of sales in order to make a claim on the insurer. There are also likely to be related complications in selecting the moment the insurance policy is to be written and in determining the period in the future to which it is to apply.

\section{Prices}

For price insurance two prices are essential: the strike price, i.e. the price that triggers a payment, and a measure of the actual price on which the amount of any indemnity payment can be based. At the moment the insurance contract is written, the level of the strike price must be agreed. To prevent adverse selection, insurers need reliable data to establish an accurate strike price and a related premium rate. In this regard, the following aspects are important.

- Due to the existence of price cycles (especially with respect to livestock commodities), insurers should use as much actual market information as possible, possibly extended with some historical price data. Futures markets may be helpful instruments.

- Price cycles are a reason for reconsidering the level of strike prices each year.

- If commodities are not reasonably uniform and a wide variety of different grades (and different prices) exist, the establishment of strike prices may be difficult.

After having set the strike price for a specific commodity of a certain grade, insurers need a good measure of the actual price of the commodity of a certain grade at harvest or sale time. Realised prices by individual farmers are likely to be problematical since they are too 
much influenced by the management of the insured. Observed spot market prices can be useful for wellfunctioning markets with a good reporting system. Well-functioning markets are those with a high degree of market integration, meaning that prices for the same commodity in different places are closely similar. For this to happen price information needs to be public.

\section{Business interruption insurance for specific diseases}

Where a form of income insurance is not feasible for certain disease risks, as could be the case for e.g. classical swine fever and foot-and-mouth disease, a specific disease risk insurance for catastrophic losses may still be possible. In this report, regionally organised mutual insurance funds are proposed to deal with such disease risks. Losses covered in this regard will mainly refer to losses from business interruption.

A mutual farm insurance fund is a fund that is operated by farmers themselves. Incentives to prevent losses are central to the success of these funds. Farmers who participate pay a premium to cover administrative costs and reinsurance (i.e. to provide the infrastructure). The fund then indemnifies members against the specified losses. If one member suffers a loss, other members may have to pay a surcharge to fund the indemnity. In mutual insurance funds, the role of insurance companies is restricted to that of administrator and reinsurer. With respect to asymmetric information problems, the advantages of using mutual insurance funds are that moral hazard is reduced due to farmers' familiarity with each other's production circumstances and that the availability of reliable data is less important because of the use of surcharges (i.e. accurate premiums need not to be set beforehand). The latter is especially useful since epidemic disease outbreaks are rare events for which data are seldom available.

Mutual insurance funds should be organised regionally to make best use of the farmers familiarity with each other's production circumstances. Regionally organised funds face the risk that all farmers in the fund face losses at the same time (since the mutual covers risks that have systemic characteristics). To deal with such problems, a pool of individual mutuals could be organised (possibly at European level), since at such level risks will be more or less independent.

\section{Systemic risk}

Regardless of the exact form(s) of income insurance, the risks covered (i.e. production risks, epidemic disease risks such as classical swine fever, and price risks) refer to risks that are to some extent systemic. This implies that sufficient traditional reinsurance capacity may not be available. For this reason, and because capital market opportunities are not (yet) widely developed, some form of public-private partnership may well be necessary for insurers to enter this income insurance market. There are two main ways (or a combination of the two) in which governments might become involved: (1) they could agree to provide reinsurance coverage to insurance companies at zero costs, or (2) they could do so at fully commercial rates. Both alternatives have pros and cons.

\section{Governments provide reinsurance at zero costs}

Arguments in favour of this option include the following.

- Governments already provide free disaster relief. An insurance system in which governments provide reinsurance is likely to be more efficient than disaster relief. Disaster relief is very ad hoc and often involves problems of 'who receives the money'. There are also considerable administrative costs incurred in setting up special agencies to organise and provide the disaster relief. By providing reinsurance, governments can use the experience and capacity of insurance companies which are experienced in dealing with moral hazard and adverse selection and have the capacity to handle large numbers of claims.

- $\quad$ Although free reinsurance is a form of subsidy and therefore a potential source of economic distortion, a case can be made that some subsidy is appropriate to correct for the market failure inherent in farmers' risk aversion. Society as a whole may be assumed to be more or less risk indifferent so far as farm income risks are concerned (because the risks are negligible when spread nationally, across all members of society). It is socially preferable that farmers allocate their resources almost to the point where expected marginal costs and expected marginal returns are equal. Because risk-averse farmers will generally stop short of the social optimum, a small subsidy, embodied in reinsurance, may be socially beneficial. 
- Having the government financially involved may address a moral hazard problem in government behaviour; many catastrophes (for example epidemic disease outbreaks and losses from floods) can be either prevented or magnified by government policy. Having governments financially responsible for some losses might be an incentive for them to put into place appropriate hazard management policies.

\section{Governments provide reinsurance at fully commercial rates}

Arguments in favour of this option are summarised below.

- Governments can potentially provide reinsurance cheaper than private market reinsurers can. Governments have substantial advantages because of their deep credit capacity and their unique position as the largest social entity in a country. These advantages enable them to diversify claims intertemporally and to spread risks broadly.

- $\quad$ Provided that governments charge for providing reinsurance at rates that will cover costs, some of these functions will be taken over by the private sector as capital and commodity markets deepen (privatising the market).

\section{Comments on both options}

The following comments apply to both options.

- Moral hazard of insurance companies can be prevented if governments reinsure only part of the risks underwritten by the insurers.

- Reinsurance agreements between governments and insurers can be based on a stop loss and/or a quota share basis. Since governments have no experience in the reinsurance market, rent seeking behaviour by insurers is to be minimised by ensuring that both governments and insurance companies have the same information about insured risks and size of losses.

- Free disaster relief will reduce the incentives for farmers to buy insurance. In cases where governments provide reinsurance at zero costs, political pressure to provide free disaster relief will be less.

\subsubsection{Will income insurance schemes appeal to farmers?}

The reason why farmers may be willing to buy a form of income insurance is that they are risk averse. They are therefore willing to pay a premium to avoid losses, especially catastrophic losses that threaten the survival of the farm business. Although it is possible to make some theoretical estimates, the exact amount of money farmers are willing to pay for specific forms of income insurance cover can only be established by pilot testing.

Besides the level of risk aversion of farmers and the exact form of the insurance, other factors that influence the extent to which schemes will appeal to farmers are the availability of other risk management strategies, the variability of yields and prices, the price/yield correlation, the ad hoc support provided by governments in case of disasters, and farmers' perception of risks.

If governments subsidise income insurance to some extent, the likelihood that insurers will set premiums at levels that farmers will find attractive will be higher. On the other hand, the availability of other forms of subsidy that give farmers higher and more stable incomes, such as price support schemes, reduces the chances that farmers will want to buy commercial income insurance.

Another factor of importance is the level of risk reduction provided by an insurance scheme. Our simulation study showed that the chance of receiving low incomes is less in the case of gross revenue insurance than in case of yield-only insurance. The exact effect for a specific commodity, however, depends on the variability of the price of the commodity, the number and size of catastrophic events, the size of the deductible (excess), the price at which yield shortfalls are indemnified, the price taken into consideration to establish the revenue guarantee level and the stochastic dependency between yields and prices.

From a farmer's point of view, forms of income insurance that cover losses at a higher level of aggregation (i.e. gross revenue insurance as opposed to yield-only insurance) will be more appealing since such schemes are closer to whole-farm income, and, hence, to the welfare of a farm family. 


\subsection{European Commission's conditions for income insurance schemes}

The European Commission stated that an income insurance scheme should fulfil at least the following five requirements.

1. Interference/disturbance with markets should be kept to a minimum.

Comments. As long as insurance products are priced according to the risks covered, no market interference occurs. This implies either that schemes should not be subsidised or, if subsidised, the level should be no more than governments currently pay for disaster relief in agriculture.

2. Income insurance schemes need to be in compliance with WTO agreements.

Comments. As long as subsidies are minimal and public-private relationships are transparent, no problems are to be expected.

3. Any income insurance scheme needs to be developed in such a way that it can be run by the private sector without, in principle, government involvement.

Comments. Due to the systemic character of risks covered, traditional reinsurance capacity is not likely to be sufficiently available, which implies that such schemes are unlikely to come into being unless governments are involved to some degree, at least until capital market opportunities are more developed.

4. An income insurance scheme may not be used to finance or compensate a long-term sector decline.

Comments. If insurance contracts are established on a yearly basis, this will not occur. (For some commodities such as beef, a somewhat longer time horizon may be appropriate and acceptable).

5. Income insurance schemes must be applicable to both the northern and the southern European countries.

Comments. The schemes proposed are in principle applicable to the whole European Union, provided that data are available. Each country, however, will have to determine to what extent there is a need for a form of income insurance. If there is a need, and schemes can be devised that are attractive to both insurers and significant numbers of farmers, they will develop, although perhaps only with some official assistance in the early stages.

\subsection{Recommendations and further research}

If a form of income insurance is introduced in Europe, it is recommended that the following points be observed.

- Only aspects for which 'moral hazard' and 'adverse selection' can be dealt with adequately should be included in a scheme.

- Gross revenue insurance should only be considered for crop - not for livestock - commodities.

- Insurance should start with true market commodities, i.e. commodities for which no price support is available.

- If governments provide reinsurance (at zero costs, at fully commercial rates, or as a combination of these two options) they should only reinsure part of the risks underwritten by insurers.

- Before wide introduction, some pilot tests should first be carried out. In pilot tests the interest of farmers in insurance schemes that cover systemic risks such as floods, droughts and epidemic diseases can become clear, as well as the interest of insurance companies in setting up mutual insurance funds for such schemes. In setting up pilot tests it is crucial for later implementation that governments are involved to no more than the necessary minimum extent, using transparent rules for such aspects as stop losses, i.e. from the beginning there should be no asymmetric information between insurers and governments.

Since the time available for this study was short (only nine months) and it was the first study in this field in a European context, further research should be carried out on the following aspects, among others.

- More statistical analyses of data, for example with respect to:

— joint distributions of prices and yields;

- correlations between individual and area yields;

- price variability within years;

- the opportunities to use for example, Chicago Board of Trade futures and commodity prices or Rotterdam harbour prices as measures of insurable price.

- More simulation studies to cover a broader range of insurance topics, for example with respect to 
the effect of area-based insurance schemes and the impact of the availability and uptake of new insurance products on the overall risk management strategies adopted by farmers.

- The availability of accurate data on which to base insurance premiums and indemnities.
- More generally, possibilities to replace publicfunded risk management programmes with more market-based solutions. This includes the development of futures and options markets to cover price risks, the reinsurance of systemic risks and more market-based agreements with governments if they provide financial back-up. 


\section{References}

Ackerman, K., 'Statement Before the Senate Agriculture, Nutrition and Forestry Committee', in Hearing on the Federal Crop and Revenue Insurance Program, Washington DC, 1997.

Anderson, D. R., 'All Risks Rating within a Catastrophe Insurance System', J. Risk and Insurance, Vol. 43, 1976, pp. 629-651.

Barnaby, G. A. and Skees, J. R., 'Public Policy for Catastrophic Yield Risk: an Alternative Crop Insurance Program', Choices, second quarter 1990, pp. 7-9.

Barnett, B. J., Skees, J. R. and Black, J. R., New Risk/New Alternatives: Farming With a Lower Safety Net, forthcoming book, 1998.

Borch, K. H, Economics of Insurance, Advanced textbooks in economics, Vol. 29, Elsevier Science Publishers, Amsterdam, 1990.

Brealy, R. A. and Myers, S .C., Principles of Corporate Finance, McGraw-Hill, New York, 1996.

Camerer, C. F. and Kunreuther, H., 'Decision Processes for Low Probability Events: Policy Implications', J. Policy Analysis and Management, Vol. 8, 1989, pp. 565-592.

Canter, M. S., Cole, J. B. and Sandor, R. L., 'Insurance Derivatives: A New Asset Class for the Capital Markets and a New Hedging Tool for the Insurance Industry', J. Derivatives, Winter 1996, pp 89-104.

Chambers, R. G., 'Insurability and Moral Hazard in Agricultural Insurance Markets', Am. J. Agr. Econ., Vol. 71, 1989, pp. 604-616.

Coble, K. H., 'An Examination of Income Stabilisation Accounts as an Alternative to Current US Farm Programs', Work. Pap., ERS/USDA, December 1995.
Cummins, J. D., Lewis, C. M. and Phillips, R. D., 'Pricing Excess-of-Loss Reinsurance Contracts against Catastrophic Loss', Work. Pap., Centre for Risk Management and Insurance Research, Georgia State University, 1996.

Cutler, D. M. and Zeckhauser, R. J., 'Reinsurance For Catastrophes and Cataclysms', Work. Pap., NBER, Cambridge, February 1997.

European Commission, Agriculture in the European Union, Report 1994, Office for Official Publications of the European Communities, Luxembourg, 1995.

Eurostat, Agriculture - Statistical Yearbook 1997, Statistical Office of the European Communities, Luxembourg, 1997.

Folmer, C., Keyzer, M. A., Merbis, M. D., Stolwijk, H. J. J., and Veenendaal, P. J. J., The Common Agricultural Policy Beyond the Mac Sharry Reform, Elsevier Science Publishers, Amsterdam, 1995.

Geene, A., Financial Innovations for Reinsuring Natural Catastrophes; the Solution for the Capacity Shortage on the Reinsurance Market? Master thesis, Interpolis, Tilburg, the Netherlands, 1995 (in Dutch).

Glauber, J. W. and Miranda, M. J., 'Subsidised Put Options as Alternatives to Price Supports', USDA, ERS, 1989.

Goodwin, B. K. and Smith, V. H., The Economics of Crop Insurance and Disaster Aid, AEI Press, Washington DC, 1995.

Halcrow, H. G., 'Actuarial Structures for Crop Insurance', J. of Farm Econ., Vol. 31, May 1949 pp. 418-43. 
Hardaker, J. B., Huirne, R. B. M. and Anderson, J. R., Coping with Risk in Agriculture, CAB International, Wallingford, UK, 1997.

Harwood, J., Heifner, D., Coble, K. and Perry, J., 'Strategies for a New Risk Management Environment', Ag. Outlook, October 1996, pp. 24-30.

Hazell, P. B. R., 'The Appropriate Role of Agricultural Insurance in Developing Countries', J. of International Development, Vol. 4, 1992, 567-581.

Heifner, R. G. and Wright, B. H., 'Potential for Substituting Farmers' Use of Futures and Options for Farm Programs', USDA, ERS, 1989.

Hennessey, D. A., Babcock, B. A. and Hayes, D. J., 'Budgetary and Producer Welfare Effects of Revenue Insurance', Amer. J. Agr. Econ, Vol. 79, August 1997, pp. 1024-34.

Hoogh, J. de, and Silvis H. J. (eds.), EULandbouwpolitiek van Binnen en van Buiten, Wageningen Press, Wageningen, The Netherlands, 1994 (in Dutch).

Jaffee, D. W. and Russell, T., 'Catastrophe Insurance, Capital Markets, and Uninsurable Risks', J. Risk and Insurance, Vol. 64, 1997, pp. 205-30.

Lamm, R. M., 'The Catastrophe Reinsurance Market: Gyrations and Innovations Amid Major Structural Transformation', Bankers Trust Research, February 3, 1997.

LEI (Agricultural Economics Research Institute), Dutch Agriculture on the European Scoreboard, The Hague, 1996 (in Dutch).

LEI/CBS (Agricultural Economics Research Institute and Statistics Netherlands), Agricultural and Horticultural Data 1997, The Hague, 1997.

Lewis, C. M. and Murdock, K. C., 'The Role of Government Contracts in Discretionary Reinsurance Markets for Natural Disasters', J. Risk and Insurance Vol. 63, 1996, pp. 567-597.

Miranda, M. J., 'Area Yield Insurance Reconsidered', Am.J. Agr. Econ., Vol. 73, 1991, pp. 233-242.
Miranda, M. J. and Glauber, J. W., 'Systemic Risk, Reinsurance, and the Failure of Crop Insurance Markets', Amer.J.Agr. Econ., Vol. 79, 1997, pp. 206-15.

National GRIP Committee, Report on the Future GRIP Program Design, Canada, 1992.

Palisade, @RISK Users Guide, Risk Analysis and Simulation Add-in for Excel, Palisade Corporation, 31 Decker Rd, Newfield, NY 14867, 1997.

Pennings, J. M. E. and Meulenberg. M.T.G., 'De Opkomst van Agrarische Termijnmarkten', Econ. Stat. Ber., Vol. 80, 1995, pp. 1105-1107 (in Dutch).

Pennings, J. M. E. and Meulenberg, M. T. G., 'Grondstoffentermijnmarkten: Ontwikkelingen en Innovaties', Bedrijfskunde, Vol. 69, 1997, pp. 81-86 (in Dutch).

Priest, G. L., 'The Government, the Market, and the Problem of Catastrophic Loss', J. Risk and Insurance, Vol. 12, 1996, pp. 219-237.

Purcell, W. D., Agricultural Futures and Options: Principles and Strategies, Maxwell Macmillan International, New York, 1991.

Rejda, G. E., Principles of Risk Management and Insurance, Harper Collins Publishers, New York, 1992.

Skees, J. R. and Barnett. B. J., 'Agricultural Insurance Alternatives: Can They Work in Taiwan?', in Tweeten, L. and Hsu, H. (eds.), Changing Trade Environment after WTO: a Case Study of Taiwan, Council of Agriculture Executive, Yuan, 1994.

Skees, J. R. and Barnett, B. J., 'New Solutions for Risk Sharing in the Farm and Food System', submitted to Rev. of Agr. Econ., 1998.

Skees, J. R., Black, J. R. and Barnett, B. J., 'Designing and Rating an Area Yield Crop Insurance Contract', Am.J. Agr. Econ., Vol. 79, 1997, pp. 430-438.

Skees, J. R., Harwood, J., Somwaru, A. and Perry, J., 'The Potential for Revenue Insurance Policies in the South', J. Agr. and Appl. Econ., Vol. 30, July 1998, pp. 47-61.

Strain, R. W. (ed.), Reinsurance, Strain Publishing and Seminars, Athens, Texas, 1980. 
Swiss Re., Climate Change and Risks for Agriculture: Management Implications for the Insurance Industry, Masters Thesis completed at Swiss Re by W. Ortloff, Depart. Prod. Management and Environm. Econ., University of Düsseldorf, 1997.

Trechter, D. D., An Economic Analysis of Farm Revenue Insurance, Dissertation, Dept. Agr. Econ., Michigan State University, 1984.

Turvey, C. G. 'An Economic Analysis of Alternative Farm Revenue Insurance Policies', Can. J Agr. Econ., Vol. 40, 1992, pp. 403-426.
US Income Task Force (Farm Income Protection Insurance Task Force), Farm Income Protection Insurance: a Report to the United States Congress, Washington DC, 1983.

Vertrees, J. G., 'A Case for Farm Income Insurance?', in Risk Analysis for Agricultural Production Firms: Concepts, Information Requirements and Policy Issues, Proceedings of a seminar sponsored by Southern Regional Project S-180, 'An economic Analysis of Risk Management Strategies for Agricultural Production Firms', New Orleans, Louisiana, 25-28 March, 1984. 



\section{Annexes}





\section{Annex I}

\section{Income measures}

Graph 11: Schematic presentation of value-added and income (Eurostat, 1997)






\section{Annex II}

\section{Financial performance of agricultural insurance programmes}

Hazell (1992) analysed the financial performance of public crop insurance programmes in seven countries (both developing and developed countries). This annex provides quantitative information from these analyses.

Table 25 gives an overview of the financial performance of seven agricultural insurance programmes. The symbol $A$ indicates average administration costs, $I$ indicates average indemnities, and $P$ indicates the average amount of premiums collected from farmers. To be financially solvent an insurance company must satisfy $(A+I) / P<1$. As Table 25 shows, this ratio is typically much larger than 1.0. The ratio $I / P$ expresses the indemnities as a ratio of premiums collected, and is often called the loss ratio. The ratio $A$ / $P$ expresses the administration costs as a proportion of the total premiums collected.

Table 25

Financial performance of seven agricultural insurance programmes

\begin{tabular}{|c|c|c|c|c|}
\hline Country (insurer) & Period & I/ P & $A / P$ & $(A+I) / P$ \\
\hline Brazil (Proagro) & $1975-81$ & 4.29 & 0.28 & 4.57 \\
\hline Costa Rica (INS) & $1970-89$ & 2.26 & 0.54 & 2.80 \\
\hline India (CCIS) & $1985-89(1)$ & 5.11 & - & - \\
\hline \multirow[t]{2}{*}{ Japan (agriculture) } & $1947-77$ & 1.48 & 1.17 & 2.60 \\
\hline & $1985-89\left({ }^{2}\right)$ & 0.99 & $3.57\left({ }^{3}\right)$ & 4.56 \\
\hline Mexico (Anagsa) & $1980-89$ & 3.18 & 0.47 & 3.65 \\
\hline Philippines (PCIC) & 1981-89 & 3.94 & 1.80 & 5.74 \\
\hline US (FCIC) & $1980-90$ & 1.87 & 0.55 & 2.42 \\
\hline \multicolumn{5}{|c|}{$\begin{array}{l}\text { (') Not including the } 1989 \text { rabi season. } \\
\text { (2) Paddy only. } \\
\text { (3) Administration cost data based on } 1989 \text { only. }\end{array}$} \\
\hline
\end{tabular}



in European agriculture

\section{Introduction}

Income insurance is a very broad concept that can refer to (inter alia) the use of futures markets to cover price risks, the development of yield insurance to cover quantity risks, or the development of revenue insurance to cover price times yield risks. All options need to have the same objective, which is to stabilise income, not to provide some structural form of income support for declining agricultural sectors.

The goal of the workshop was to discuss the idea of different types of income insurance schemes with an extensive group of selected people to see whether certain concepts of income insurance might be feasible and practical. And, if so, for which commodities and risks, and in what form. The workshop was held in Tilburg at Interpolis headquarters on 29 January 1998.

\section{Participants in the workshop}

Twenty people participated in the workshop. The participants represented the organisations and countries shown in Table 26.

\section{Methods}

The total workshop consisted of five sections:

- before the workshop, participants were asked to complete a questionnaire;

- workshop-part 1: income measures, levels of measurement, insurance coverage, loss assessment;

- workshop-part 2: problems and pitfalls: moral hazard, adverse selection, systemic risks;

- workshop-part 3: role of the European Commission and governments, reinsurance, conditions for insurance schemes;

- workshop-part 4: insurable commodities and risks, definition of total insurance concepts.

Each part of the workshop was set up as follows:

- $\quad$ short introduction;

- $\quad$ questionnaire (in which participants could always chose a commodity they were familiar with);

- group discussion;

- $\quad$ possibility to revise answers given in the questionnaire.

Table 26

\section{Participants}

\begin{tabular}{lccccc}
\hline & The Netherlands & Belgium & France & Germany & Sweden \\
\hline & 2 & 1 & 3 & 1 & 1 \\
Insurance company & 4 & 1 & & & \\
Reinsurance company & 2 & 1 & & \\
Bank & 1 & 1 & & \\
\hline Others & & & & \\
\hline
\end{tabular}


In each questionnaire people were asked to indicate their preferences on a Likert scale. For example:

Importance of price risk for crop commodities

\begin{tabular}{ccccc}
\hline $\begin{array}{c}\text { Not } \\
\text { Important }\end{array}$ & & & $\begin{array}{c}\text { Very } \\
\text { important }\end{array}$ \\
\hline 1 & 2 & 3 & 4 & 5 \\
\hline
\end{tabular}

\section{Results of the questionnaire (preceding the workshop)}

Fifteen participants in the workshop completed and returned the questionnaire.

From the questionnaire it was clear that currently most farmers already use a mix of risk management strategies. However, all participants in the workshop indicated that there is a need for new risk management strategies in their country. Underlying factors causing that need (in order of importance):

- $\quad$ specialisation of farms;

- liberalisation of the European agricultural markets;

- $\quad$ increased attention of consumers to food safety and quality.

In the questionnaire we also asked if the need for new risk management strategies would be the same all over Europe. This question was answered positively by $60 \%$ and negatively by $40 \%$ of the participants. From the last group all persons indicated that in countries with a high degree of specialisation and concentration the need for new risk management strategies is higher. Countries mentioned here were the Netherlands, Denmark, Ireland, France and the United Kingdom.

\section{Workshop-part 1: income measures, levels of measurement, insurance coverage, loss assessment}

\section{Income measures}

Concerning the income measures, two important aspects are the availability of data and the fraud sensitivity of these data. In general, the participants indicated that the more aggregated the income measure, the less available data are and the more sensitive they are to fraud. Related to this, most participants prefer yield and gross revenue as income measure.

\section{Level of measurement}

Concerning the level of measurement (commodity, portfolio or farm) in general, the commodity level is preferred.

\section{Insurance coverage and loss assessment}

Concerning the loss assessment, two rather striking aspects were that:

- $\quad$ some participants prefer a multiple year loss observation period;

- $\quad$ area-based loss assessment (area as trigger) is not very popular.

\section{Workshop-part 2: problems and pitfalls: moral hazard, adverse selection, systemic risks}

From this part, it was clear that the problems of moral hazard, adverse selection and systemic risks cannot be discussed in a general way; they differ too much among:

- $\quad$ compulsory/non-compulsory schemes;

- $\quad$ risks included (for example hail versus epidemic diseases);

- $\quad$ income measure used.

\section{Workshop-part 3: role of the European Commission and governments, reinsurance, conditions for insurance schemes}

\section{Role of the European Commission and governments}

Insurance companies tend to agree on the statement that if the European Commission and governments are not financially involved, no form of income insurance will be feasible. Consistent with this, insurance companies think it is relevant that the European Commission and governments provide reinsurance and subsidise administration and delivery costs. Reinsurance companies prefer a facilitating and regulatory role for the European Commission and governments. Banks do not score high on any role for the European Commission and governments, but see some role in providing reinsurance. 


\section{Reinsurance}

Banks and insurance and reinsurance companies:

- $\quad$ are not very confident that traditional reinsurance markets can provide sufficient capacity for the risks considered in the workshop, i.e. risks that have systemic characteristics;

- think that, of the financial market products, CAT bonds provide bigger opportunities than CAT futures;

- think that the European Commission and governments can be a partner in reinsurance, especially via a stop loss agreement.

The following aspects were also discussed:

- for a number of risks the European Commission and governments need to be involved because they make the rules (for example control measures for foot-and-mouth disease);

- a maximum, i.e. quota, of reinsurance capacity per country avoids high-risk countries receiving a lot of extra capital.

\section{Conditions for income insurance schemes}

Both banks and insurance and reinsurance companies agree on the following aspects:

- a scheme is only feasible if it has low administration costs;

- the feasibility of a scheme does not depend on the inclusion of speciality products;

- $\quad$ a scheme should be in compliance with WTO rules;

- income insurance should not be used to finance or compensate long-term sector declines;

- a scheme should be developed in such a way that it can be run by the private sector, without, in principle, government involvement.

Banks and insurance and reinsurance companies have different views on the following items:

- reinsurance companies think it is important that governments stop ad hoc disaster assistance;

- reinsurance companies don't think part of a scheme needs to be compulsory to be feasible;

- $\quad$ insurance companies think a scheme is only feasible if it is applied to all EU countries.

\section{Workshop-part 4: insurable commodities and risks, definition of total insurance concepts}

\section{Insurable commodities}

Participants in the workshop were asked to give their views on the insurability of a number of commodities. In general, the estimated feasibility of some form of coverage is higher for crop commodities than for livestock commodities. Forage crops are an exception because very often these crops are intermediate products (used on the farm to feed livestock), and as a consequence they are very difficult to measure.

\section{Insurable risks}

The participants in the workshop indicated that the feasibility of some form of income insurance for price risks is not very high.

\section{Total concepts}

For several commodities the participants of the workshop indicated a 'total setting' of an income insurance scheme. Commodities most frequently referred to were: livestock in general, milk, pigs, crops in general, cereals, potatoes and tomatoes. The preferred settings of insurance schemes for these commodities did not differ a lot among participants. A remarkable aspect was the frequent reference to mutual schemes. An advantage of a mutual insurance scheme is that the availability of data for rating the scheme is less important, because of the possibility of a surcharge. Furthermore, in a mutual scheme there is more social control among insured farmers which will reduce abuse of the insurance.

\section{Summary of the workshop}

The main conclusion of the workshop can be summarised 'as the one-size-fits-all principle does not apply', meaning that it is not possible to develop one form of income insurance that is applicable to all EU countries, commodities and risks. A few examples will illustrate the problems.

\section{Differences among countries:}

- $\quad$ need for new risk management strategy (specialisation, concentration, part-time farming);

- data availability (existence of bookkeeping system, possibility of fraud); 
Income insurance in European agriculture

- $\quad$ existence of large areas with the same production circumstances in which production results are correlated, and thus area-based schemes could be set up.

Differences among commodities:

- commodities that have price cycles (for example pigs) - multi-year insurance schemes?

- intermediate products — how to measure the yield?
Other aspects agreed upon:

- $\quad$ it is very important to stimulate farmers' use of futures and options markets (task for farmers' organisations and banks);

- in general, it is very important to have sufficient and reliable data, both for properly rating an insurance scheme and for a proper indemnification;

- the feasibility of income insurance schemes would increase if the insurance tax were abolished. 


\section{Annex IV}

\section{Data analysis of European agriculture: farm yield data and price data}

\section{Source}

FADN Information European Commission

\section{Countries included}

The following EU countries are included in the data set:

- Denmark

- France

- $\quad$ Germany (BRD)

- Greece

- Italy

- The Netherlands

All countries are subdivided into a number of regions (with the exception of the Netherlands and Denmark which are each regarded as one region).

\section{Time period}

For all countries except Greece the data refer to the time period 1989-95 (seven years); for Greece the data refer to $1989-94$.

\section{Commodities included}

Potatoes (100 kg/ha)

Sugar beet $(100 \mathrm{~kg} / \mathrm{ha})$

Wheat $(100 \mathrm{~kg} / \mathrm{ha})$
Milk (100 kg/cow)

Beef (GPV in ECU/LU)

Pig (GPV in ECU/LU)

Table 27

Explanation of livestock unit (LU)

Value of one animal in LU

\begin{tabular}{|lll|} 
Beef & Fattening calves & 0.4 \\
& Other cattle $<1$ year & 0.4 \\
& Male cattle $1-<2$ year & 0.6 \\
& Female cattle $1-<2$ year & 0.6 \\
& Male cattle $>=2$ years & 1.0 \\
& Breeding heifers & 0.8 \\
& Heifers for fattening & 0.8 \\
& Dairy cows & 1.0 \\
& Cull dairy cows & 1.0 \\
\hline \multirow{3}{*}{ Pigs } & Other cows & 0.8 \\
& Piglets & \\
& Breeding sows & 0.027 \\
\hline & Pigs for fattening & 0.5 \\
\hline & Other pigs & 0.3 \\
\hline
\end{tabular}

\section{Coefficient of variance (CV)}

The coefficient of variance is used as a measure for variability and is defined as:

(standard deviation divided by the mean)*100. 
Table 28

Agricultural data by region

\begin{tabular}{|c|c|c|c|}
\hline \multicolumn{3}{|c|}{ Total group of farms } & $\mathrm{CV}$ within \\
\hline$n$ & $\begin{array}{c}\text { Average yield } \\
\text { (100 kg/ha) }\end{array}$ & $\begin{array}{l}\mathrm{CV} \\
(\%)\end{array}$ & $\begin{array}{c}\text { farms } \\
(\%)\end{array}$ \\
\hline
\end{tabular}

Denmark (1989-95)

\begin{tabular}{|lrrrr|}
\hline Potatoes $(100 \mathrm{~kg} / \mathrm{ha})$ & 24 & 289 & 37.5 & 26.6 \\
\hline Sugar beet $(100 \mathrm{~kg} / \mathrm{ha})$ & 77 & 483 & 17.4 & 12.7 \\
Wheat $(100 \mathrm{~kg} / \mathrm{ha})$ & 233 & 73 & 20.9 & 13.9 \\
Milk $(100 \mathrm{~kg} / \mathrm{cow})$ & 190 & 63 & 15.2 & 6.2 \\
Beef (GPV in ECU/LU) & 236 & 489 & 124.1 & 31.6 \\
\hline Pig (GPV in ECU/LU) & 203 & 1262 & 38.8 & 18.3
\end{tabular}

France (1989-95)

\section{Alsace}

Potatoes $(100 \mathrm{~kg} / \mathrm{ha}) \quad 6 \quad 265$

Sugar beet $(100 \mathrm{~kg} / \mathrm{ha})$

Wheat (100 kg/ha)

Milk (100 kg/cow)

Beef (GPV in ECU/LU)

Pig (GPV in ECU/LU)

$\begin{array}{rr}18 & 6 \\ 56 & 64 \\ 22 & 739 \\ 38 & 1327\end{array}$

$\begin{array}{rrr}265 & 30.2 & 26.5 \\ 610 & 21.4 & 15.8 \\ 64 & 16.1 & 11.1 \\ 53 & 30.2 & 10.6 \\ 739 & 313.1 & 34.5 \\ 327 & 60.3 & 34.4\end{array}$

\section{Aquitaine}

Potatoes $(100 \mathrm{~kg} / \mathrm{ha}) \quad 19$

Sugar beet $(100 \mathrm{~kg} / \mathrm{ha})$

Wheat (100 kg/ha)

Milk (100 kg/cow)

Beef (GPV in ECU/LU)

Pig (GPV in ECU/LU)

$\begin{array}{rrrr}19 & 182 & 68.0 & 17.5 \\ - & - & - & - \\ 35 & 47 & 27.1 & 19.2 \\ 50 & 51 & 29.9 & 13.0 \\ 134 & 543 & 100.5 & 75.2 \\ 29 & 1230 & 60.1 & 35.6\end{array}$

\section{Auvergne}

Potatoes $(100 \mathrm{~kg} / \mathrm{ha})$

Sugar beet $(100 \mathrm{~kg} / \mathrm{ha})$

Wheat $(100 \mathrm{~kg} / \mathrm{ha})$

Milk (100 kg/cow)

Beef (GPV in ECU/LU)

Pig (GPV in ECU/LU)

230

60.1

35.6

Basse-Normandie

Potatoes (100 kg/ha)

Sugar beet $(100 \mathrm{~kg} / \mathrm{ha})$

Wheat (100 kg/ha)

Milk (100 kg/cow)

Beef (GPV in ECU/LU)

Pig (GPV in ECU/LU)

$\begin{array}{rr}- & - \\ - & - \\ 49 & 5 \\ 71 & 4 \\ 120 & 58 \\ 15 & 127\end{array}$

$\begin{array}{|ccc|}- & - & - \\ - & - & - \\ 51 & 29.3 & 16.4 \\ 43 & 28.3 & 14.2 \\ 589 & 86.5 & 32.4 \\ 271 & 76.6 & 56.1\end{array}$

\section{Bourgogne}

Potatoes (100 kg/ha)

Sugar beet $(100 \mathrm{~kg} / \mathrm{ha})$

Wheat $(100 \mathrm{~kg} / \mathrm{ha})$

Milk (100 kg/cow)

Beef (GPV in ECU/LU)

Pig (GPV in ECU/LU)

$\begin{array}{ll}- & - \\ 39 & \\ 44 & 637 \\ - & \end{array}$

$\begin{array}{rrr}- & - & - \\ - & - & - \\ 64 & 22.7 & 13.9 \\ 48 & 25.7 & 12.2 \\ 637 & 144.7 & 32.3\end{array}$

\section{Bretagne}

Potatoes (100 kg/ha)

Sugar beet $(100 \mathrm{~kg} / \mathrm{ha})$

Wheat $(100 \mathrm{~kg} / \mathrm{ha})$

Milk (100 kg/cow)

Beef (GPV in ECU/LU)

Pig (GPV in ECU/LU)

$\begin{array}{lr}- & - \\ - & - \\ 19 & 57 \\ - & - \\ - & 665\end{array}$

-
-
57
-
665
-

\begin{tabular}{ll}
- & - \\
- & - \\
22.4 & 14.5 \\
- & - \\
62.0 & 28.2 \\
\hline
\end{tabular}

$\begin{array}{rr}- & - \\ - & - \\ 78 & 62 \\ 82 & 58 \\ 102 & 520 \\ 69 & 1119\end{array}$

$\begin{array}{rrr}- & - & - \\ - & - & - \\ 62 & 20.9 & 15.6 \\ 58 & 19.9 & 8.3 \\ 520 & 101.3 & 35.1 \\ 1119 & 34.9 & 18.1\end{array}$


Data analysis of European agriculture: farm yield data and price data

Centre

$\begin{array}{lrrrr}\text { Potatoes }(100 \mathrm{~kg} / \mathrm{ha}) & - & - & - & - \\ \text { Sugar beet }(100 \mathrm{~kg} / \mathrm{ha}) & - & - & - & 22.3 \\ \text { Wheat }(100 \mathrm{~kg} / \mathrm{ha}) & 158 & 64 & 32 & 30.0 \\ \text { Milk }(100 \mathrm{~kg} / \mathrm{cow}) & 21 & 62 & 755 & 141.4 \\ \text { Beef (GPV in ECU/LU) } & 6 & 865 & 48.6 & 36.6 \\ \text { Pig (GPV in ECU/LU) } & & 27.0 & \end{array}$

Champagne-Ardenne

Potatoes (100 kg/ha)

Sugar beet $(100 \mathrm{~kg} / \mathrm{ha})$

$\begin{array}{rr}- & \\ 46 & 692 \\ 131 & 70 \\ 47 & 50 \\ 72 & 485\end{array}$

$\begin{array}{rll}- & - & - \\ 692 & 17.1 & 11.3 \\ 70 & 21.1 & 10.9 \\ 50 & 24.3 & 11.0 \\ 485 & 95.2 & 39.9\end{array}$

Milk (100 kg/cow)

Beef (GPV in ECU/LU)

Pig (GPV in ECU/LU)

Corse

Potatoes (100 kg/ha)

Sugar beet $(100 \mathrm{~kg} / \mathrm{ha})$

Wheat (100 kg/ha)

Milk (100 kg/cow)

Beef (GPV in ECU/LU)

Pig (GPV in ECU/LU)

\section{Franche-Comté}

Potatoes (100 kg/ha)

Sugar beet $(100 \mathrm{~kg} / \mathrm{ha})$

Wheat (100 kg/ha)

Milk (100 kg/cow)

Beef (GPV in ECU/LU)

Pig (GPV in ECU/LU)

\section{Haute-Normandie}

Potatoes (100 kg/ha)

Sugar beet $(100 \mathrm{~kg} / \mathrm{ha})$

Wheat (100 kg/ha)

Milk (100 kg/cow)

Beef (GPV in ECU/LU)

Pig (GPV in ECU/LU)

\section{île-de-France}

Potatoes (100 kg/ha)

Sugar beet $(100 \mathrm{~kg} / \mathrm{ha})$

Wheat (100 kg/ha)

Milk (100 kg/cow)

Beef (GPV in ECU/LU)

Pig (GPV in ECU/LU)

-
-
-
5
-

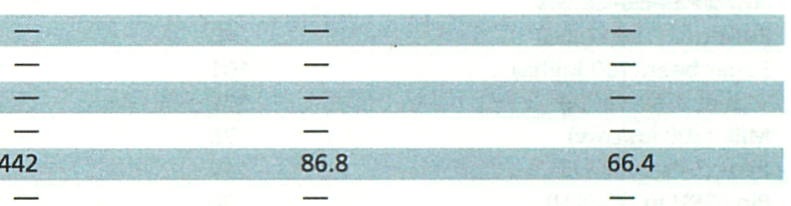

Languedoc-Roussillon

Potatoes (100 kg/ha)

Sugar beet $(100 \mathrm{~kg} / \mathrm{ha})$

Wheat (100 kg/ha)

Milk (100 kg/cow)

Beef (GPV in ECU/LU)

Pig (GPV in ECU/LU)

-
-
27

$\begin{array}{rll}- & - & - \\ - & - & - \\ 53 & 23.9 & 16.5 \\ 51 & 20.4 & 10.4 \\ 393 & 99.0 & 27.5\end{array}$

\section{Limousin}

Potatoes (100 kg/ha)

Sugar beet $(100 \mathrm{~kg} / \mathrm{ha})$

Wheat (100 kg/ha)

Milk (100 kg/cow)

Beef (GPV in ECU/LU)

Pig (GPV in ECU/LU)

-

$\begin{array}{ll}- \\ - \\ 35 & 472 \\ 32 & \end{array}$

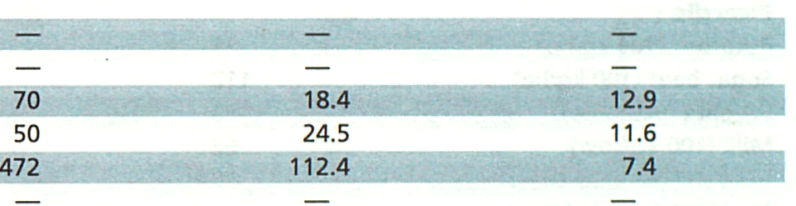



$2+32$


Income insurance in European agriculture

Lorraine

Potatoes (100 kg/ha) -

Sugar beet $(100 \mathrm{~kg} / \mathrm{ha})$

Wheat (100 kg/ha)

Milk (100 kg/cow)

Beef (GPV in ECU/LU)

Pig (GPV in ECU/LU)

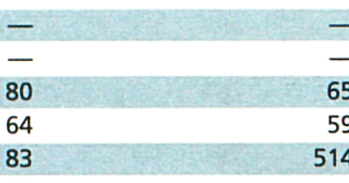

Midi-Pyrenées

Potatoes $(100 \mathrm{~kg} / \mathrm{ha})$

Sugar beet $(100 \mathrm{~kg} / \mathrm{ha})$

Wheat $(100 \mathrm{~kg} / \mathrm{ha})$

Milk (100 kg/cow)

Beef (GPV in ECU/LU)

Pig (GPV in ECU/LU)

83

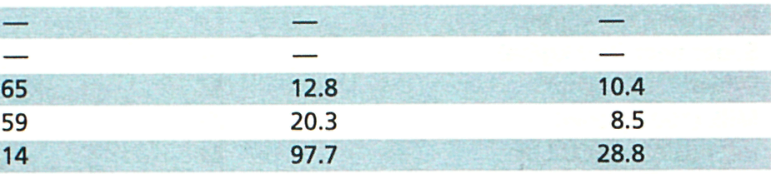

Nord/Pas-de-Calais

Potatoes (100 kg/ha)

Sugar beet $(100 \mathrm{~kg} / \mathrm{ha})$

Wheat (100 kg/ha)

Milk (100 kg/cow)

Beef (GPV in ECU/LU)

Pig (GPV in ECU/LU)

$\begin{array}{rr}- & - \\ - & 46 \\ 67 & 43 \\ 101 & 607 \\ 15 & 1296\end{array}$

$\begin{array}{rcc}- & - & - \\ - & - & - \\ 46 & 27.0 & 19.2 \\ 43 & 29.7 & 13.2 \\ 607 & 93.8 & 40.7 \\ 1296 & 95.3 & 41.5\end{array}$

Pays de la Loire

Potatoes (100 kg/ha)

Sugar beet (100 kg/ha)

Wheat $(100 \mathrm{~kg} / \mathrm{ha})$

Milk (100 kg/cow)

Beef (GPV in ECU/LU)

Pig (GPV in ECU/LU)

$\begin{array}{rrrr}48 & 317 & 27.5 & 21.8 \\ 101 & 647 & 15.6 & 11.3 \\ 140 & 77 & 16.1 & 11.0 \\ 78 & 58 & 20.5 & 11.3 \\ 117 & 640 & 225.4 & 35.2 \\ 30 & 1124 & 40.2 & 31.3\end{array}$

\section{Picardie}

Potatoes (100 kg/ha)

Sugar beet $(100 \mathrm{~kg} / \mathrm{ha})$

Wheat (100 kg/ha)

Milk (100 kg/cow)

Beef (GPV in ECU/LU)

Pig (GPV in ECU/LU)

Poitou-Charentes

Potatoes (100 kg/ha)

Sugar beet $(100 \mathrm{~kg} / \mathrm{ha})$

Wheat $(100 \mathrm{~kg} / \mathrm{ha})$

Milk (100 kg/cow)

Beef (GPV in ECU/LU)

Pig (GPV in ECU/LU)

$\begin{array}{rr}- & - \\ - & - \\ 104 & 59 \\ 88 & 55 \\ 135 & 644 \\ 9 & 1882\end{array}$

$\begin{array}{rrr}- & - & - \\ - & - & - \\ 59 & 24.9 & 17.8 \\ 55 & 26.6 & 10.4 \\ 644 & 116.7 & 30.3 \\ 882 & 130.9 & 43.9\end{array}$

\section{Provence-Alpes-Côte d'Azur}

Potatoes (100 kg/ha)

Sugar beet (100 kg/ha)

Wheat $(100 \mathrm{~kg} / \mathrm{ha})$

Milk (100 kg/cow)

Beef (GPV in ECU/LU)

Pig (GPV in ECU/LU)

$\begin{array}{rrrr}19 & 356 & 27.2 & 23.5 \\ 112 & 644 & 16.6 & 12.4 \\ 138 & 78 & 12.3 & 9.4 \\ 62 & 60 & 20.7 & 11.4 \\ 88 & 620 & 119.9 & 33.1\end{array}$

\section{Rhônes-Alpes}

Potatoes (100 kg/ha)

Sugar beet $(100 \mathrm{~kg} / \mathrm{ha})$

Wheat $(100 \mathrm{~kg} / \mathrm{ha})$

Milk (100 kg/cow)

Beef (GPV in ECU/LU)

Pig (GPV in ECU/LU)

) -

$-$

$\begin{array}{lr}- & - \\ - & - \\ 57 & 58 \\ 18 & 47 \\ 47 & 588 \\ - & -\end{array}$

$\begin{array}{rcc}- & - & - \\ - & - & - \\ 58 & 20.3 & 14.0 \\ 47 & 37.7 & 14.6 \\ 588 & 80.4 & 37.5 \\ - & - & -\end{array}$

$\begin{array}{ccc}- & - & - \\ - & - & - \\ 40 & 28.0 & 4.15 \\ - & - & - \\ 301 & 72.1 & 51.3 \\ - & - & -\end{array}$




\section{Baden-Württemberg}

Potatoes (100 kg/ha)

Sugar beet $(100 \mathrm{~kg} / \mathrm{ha})$

Wheat $(100 \mathrm{~kg} / \mathrm{ha})$

Milk (100 kg/cow)

Beef (GPV in ECU/LU)

Pig (GPV in ECU/LU)

$\begin{array}{rr}44 & 234 \\ 33 & 558 \\ 131 & 58 \\ 135 & 45 \\ 140 & 495 \\ 88 & 1615\end{array}$

$\begin{array}{rrr}234 & 41.3 & 29.5 \\ 558 & 19.7 & 15.1 \\ 58 & 23.2 & 14.0 \\ 45 & 20.9 & 9.9 \\ 495 & 103.7 & 26.0 \\ 615 & 340.2 & 31.2\end{array}$

Bayern

Potatoes (100 kg/ha)

Sugar beet $(100 \mathrm{~kg} / \mathrm{ha})$

Wheat (100 kg/ha)

Milk (100 kg/cow)

Beef (GPV in ECU/LU)

Pig (GPV in ECU/LU)

$\begin{array}{rrrr}29 & 280 & 34.3 & 19.4 \\ 41 & 586 & 16.8 & 11.8 \\ 75 & 61 & 21.7 & 13.3 \\ 74 & 48 & 17.6 & 7.6 \\ 85 & 707 & 129.2 & 23.3 \\ 70 & 1834 & 93.8 & 33.6\end{array}$

Hessen

\begin{tabular}{lrrrr}
\hline Potatoes $(100 \mathrm{~kg} / \mathrm{ha})$ & 34 & 212 & 40.9 & 25.1 \\
Sugar beet $(100 \mathrm{~kg} / \mathrm{ha})$ & 35 & 545 & 15.7 & 12.0 \\
Wheat $(100 \mathrm{~kg} / \mathrm{ha})$ & 136 & 60 & 20.3 & 11.4 \\
Milk $(100 \mathrm{~kg} / \mathrm{cow})$ & 117 & 54 & 18.6 & 9.3 \\
Beef (GPV in ECU/LU) & 132 & 444 & 53.0 & 33.2 \\
Pig (GPV in ECU/LU) & 112 & 1218 & 29.4
\end{tabular}

\section{Niedersachsen}

Potatoes $(100 \mathrm{~kg} / \mathrm{ha}) \quad 84$

Sugar beet $(100 \mathrm{~kg} / \mathrm{ha})$

Wheat $(100 \mathrm{~kg} / \mathrm{ha})$

Milk (100 kg/cow)

Beef (GPV in ECU/LU)

Pig (GPV in ECU/LU)

$\begin{array}{rrrr}84 & 314 & 25.9 & 18.4 \\ 108 & 512 & 17.7 & 11.0 \\ 132 & 71 & 22.2 & 14.7 \\ 278 & 60 & 18.0 & 8.2 \\ 320 & 579 & 107.2 & 30.8 \\ 232 & 1402 & 93.6 & 25.3\end{array}$

\section{Nordrhein-Westfalen}

\begin{tabular}{lrrrr}
\hline Potatoes $(100 \mathrm{~kg} / \mathrm{ha})$ & 18 & 291 & 39.3 & 23.3 \\
\hline Sugar beet $(100 \mathrm{~kg} / \mathrm{ha})$ & 65 & 571 & 13.9 & 19.3 \\
Wheat $(100 \mathrm{~kg} / \mathrm{ha})$ & 137 & 68 & 18.6 & 13.7 \\
Milk $(100 \mathrm{~kg} / \mathrm{cow})$ & 116 & 58 & 129.5 & 3.4 \\
Beef (GPV in ECU/LU) & 160 & 987 & 41.8 & 1.8 \\
Pig (GPV in ECU/LU) & 143 & 1492 & 19.8
\end{tabular}

\section{Rheinland-Pfalz}

Potatoes $(100 \mathrm{~kg} / \mathrm{ha})$

Sugar beet $(100 \mathrm{~kg} / \mathrm{ha})$

Wheat (100 kg/ha)

Milk (100 kg/cow)

Beef (GPV in ECU/LU)

Pig (GPV in ECU/LU)

$\begin{array}{rrrr}21 & 200 & 38.8 & 24.1 \\ 12 & 506 & 16.8 & 13.1 \\ 61 & 53 & 21.7 & 14.7 \\ 104 & 51 & 20.8 & 9.1 \\ 18 & 415 & 66.3 & 32.5 \\ 46 & 1334 & 53.0 & 35.4\end{array}$

\section{Saarland}

Potatoes (100 kg/ha)

Sugar beet $(100 \mathrm{~kg} / \mathrm{ha})$

Wheat $(100 \mathrm{~kg} / \mathrm{ha})$

Milk (100 kg/cow)

Beef (GPV in ECU/LU)

$\mathrm{Pig}$ (GPV in ECU/LU)

$\begin{array}{rr}- & \\ - & \\ 5 & 52 \\ 5 & 373 \\ 5 & 1032 \\ 4 & \end{array}$

$\begin{array}{rll}- & - & - \\ - & - & - \\ 52 & 26.6 & 17.5 \\ 54 & 14.0 & 10.0 \\ 373 & 39.1 & 31.2 \\ 1032 & 61.0 & 34.5\end{array}$

Schleswig-Holstein

Potatoes $(100 \mathrm{~kg} / \mathrm{ha})$

Sugar beet $(100 \mathrm{~kg} / \mathrm{ha})$

Wheat (100 kg/ha)

Milk (100 kg/cow)

Beef (GPV in ECU/LU)

Pig (GPV in ECU/LU)

$\begin{array}{rr}- & - \\ 16 & 465 \\ 63 & 7 \\ 109 & 57 \\ 123 & 50 \\ 35 & 148\end{array}$

$\begin{array}{rrr}- & - & - \\ 465 & 16.4 & 13.0 \\ 72 & 19.0 & 12.1 \\ 57 & 15.9 & 7.7 \\ 501 & 132.4 & 27.8 \\ 483 & 35.0 & 18.8\end{array}$


Income insurance in European agriculture

Greece (1989-94)

Ipiros-Peloponissos-Nissi loniou

Potatoes (100 kg/ha)

Sugar beet $(100 \mathrm{~kg} / \mathrm{ha})$

Wheat (100 kg/ha)

Milk (100 kg/cow)

Beef (GPV in ECU/LU)

Pig (GPV in ECU/LU)

$\begin{array}{rrrr}65 & 182 & 46.6 & 15.6 \\ - & - & - & - \\ 29 & 34 & 22.6 & 17.5 \\ 9 & 39 & 31.9 & 16.5 \\ 128 & 480 & 255.7 & 44.9\end{array}$

Makedonia-Thraki

Potatoes (100 kg/ha)

Sugar beet $(100 \mathrm{~kg} / \mathrm{ha})$

Wheat $(100 \mathrm{~kg} / \mathrm{ha})$

Milk (100 kg/cow)

Beef (GPV in ECU/LU)

Pig (GPV in ECU/LU)

\begin{tabular}{rrrr}
26 & 313 & 38.1 & 23.4 \\
65 & 711 & 25.0 & 18.6 \\
284 & 31 & 33.4 & 25.6 \\
101 & 33 & 31.9 & 16.6 \\
23 & 591 & 77.3 & 50.2 \\
\hline
\end{tabular}

Sterea Ellas-Nissi Egaeou-Kriti

Potatoes $(100 \mathrm{~kg} / \mathrm{ha}) \quad 26$

Sugar beet (100 kg/ha)

Wheat (100 kg/ha)

Milk (100 kg/cow)

Beef (GPV in ECU/LU)

Pig (GPV in ECU/LU)

\section{Thessalia}

Potatoes (100 kg/ha)

Sugar beet $(100 \mathrm{~kg} / \mathrm{ha})$

Wheat (100 kg/ha)

Milk (100 kg/cow)

Beef (GPV in ECU/LU)

Pig (GPV in ECU/LU)

\begin{tabular}{lrcc}
26 & 211 & 44.3 & 23.3 \\
-17 & - & - & - \\
21 & 33 & 25.1 & 17.9 \\
37 & 25 & 41.0 & 26.2 \\
\hline
\end{tabular}

Italy (1989-95)

\section{Abruzzo}

Potatoes $(100 \mathrm{~kg} / \mathrm{ha})$

Sugar beet $(100 \mathrm{~kg} / \mathrm{ha})$

Wheat (100 kg/ha)

Milk (100 kg/cow)

Beef (GPV in ECU/LU)

Pig (GPV in ECU/LU)

$5 \quad 21$

212

34

6

212
701
29
43
658

$\begin{array}{rrr}2 & 48.1 & 42.6 \\ 01 & 22.1 & 17.9 \\ 29 & 36.0 & 31.1 \\ 43 & 19.9 & 15.8 \\ 8 & 129.5 & 51.6\end{array}$

\section{Alto-Adige}

Potatoes (100 kg/ha)

Sugar beet $(100 \mathrm{~kg} / \mathrm{ha})$

Wheat (100 kg/ha)

Milk (100 kg/cow)

Beef (GPV in ECU/LU)

Pig (GPV in ECU/LU)

\section{Emilia-Romagna}

Potatoes (100 kg/ha)

Sugar beet $(100 \mathrm{~kg} / \mathrm{ha})$

Wheat (100 kg/ha)

Milk (100 kg/cow)

Beef (GPV in ECU/LU)

Pig (GPV in ECU/LU)

$\begin{array}{lr}- & - \\ - & \\ 18 & 42 \\ 21 & 41 \\ 41 & 1343 \\ - & \end{array}$

\begin{tabular}{rrr}
- & - & - \\
- & - & - \\
42 & 23.5 & 17.6 \\
41 & 26.7 & 17.0 \\
343 & 131.5 & 45.7 \\
\hline
\end{tabular}

\section{Friuli-Venezia}

Potatoes (100 kg/ha)

Sugar beet $(100 \mathrm{~kg} / \mathrm{ha})$

Wheat $(100 \mathrm{~kg} / \mathrm{ha})$

Milk (100 kg/cow)

Beef (GPV in ECU/LU)

Pig (GPV in ECU/LU)

$\begin{array}{ll}- & - \\ - & \\ 29 & 447\end{array}$

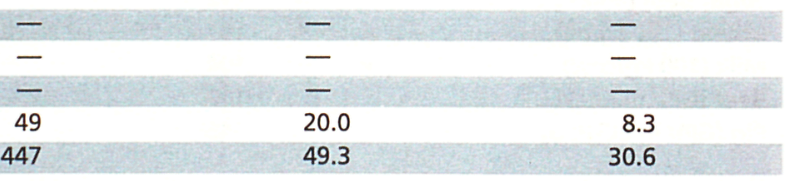

$\begin{array}{lrrr}- & - & - & - \\ 22 & 520 & 30.2 & 25.6 \\ 26 & 59 & 23.9 & 19.2 \\ 25 & 60 & 21.4 & 11.6 \\ 29 & 672 & 157.6 & 72.6 \\ - & - & - & -\end{array}$

- 
Liguria

$\begin{array}{lrrrr}\text { Potatoes }(100 \mathrm{~kg} / \mathrm{ha}) & 17 & 140 & 56.6 & 27.3 \\ \text { Sugar beet }(100 \mathrm{~kg} / \mathrm{ha}) & - & - & - & 24.2 \\ \text { Wheat }(100 \mathrm{~kg} / \mathrm{ha}) & 7 & 38 & 30.8 & 16.8 \\ \text { Milk }(100 \mathrm{~kg} / \mathrm{cow}) & 21 & 33 & 106.7 & 21.4 \\ \text { Beef (GPV in ECU/LU) } & 42 & 676 & 46.0\end{array}$

Beef (GPV in ECU/LU)

Pig (GPV in ECU/LU)

\section{Marche}

Potatoes $(100 \mathrm{~kg} / \mathrm{ha})$

Sugar beet $(100 \mathrm{~kg} / \mathrm{ha})$

Wheat (100 kg/ha)

Milk (100 kg/cow)

Beef (GPV in ECU/LU)

Pig (GPV in ECU/LU)

-
25
12
22
14
27

$\begin{array}{rr}- & - \\ 255 & 420 \\ 122 & 47 \\ 22 & 33 \\ 144 & 1222 \\ 27 & 1998\end{array}$

$\begin{array}{rll}- & - & - \\ 420 & 26.9 & 21.1 \\ 47 & 22.8 & 10.8 \\ 33 & 27.6 & 13.1 \\ 222 & 96.7 & 37.0 \\ 998 & 52.8 & 33.5\end{array}$

Molise

Potatoes $(100 \mathrm{~kg} / \mathrm{ha})$

Sugar beet $(100 \mathrm{~kg} / \mathrm{ha})$

Wheat (100 kg/ha)

Milk (100 kg/cow)

Beef (GPV in ECU/LU)

Pig (GPV in ECU/LU)

\begin{tabular}{cccc}
- & - & - & - \\
16 & 578 & 19.1 & 15.8 \\
-12 & - & - & - \\
16 & 39 & 16.0 & 10.8 \\
\hline
\end{tabular}

\section{Piemonte}

Potatoes (100 kg/ha)

Sugar beet $(100 \mathrm{~kg} / \mathrm{ha})$

Wheat (100 kg/ha)

Milk (100 kg/cow)

Beef (GPV in ECU/LU)

Pig (GPV in ECU/LU)

$\begin{array}{rr}8 & 270 \\ - & - \\ 107 & 48 \\ 90 & 39 \\ 189 & 1156 \\ 4 & 1259\end{array}$

$\begin{array}{rrr}270 & 59.1 & 26.0 \\ - & - & - \\ 48 & 26.4 & 20.0 \\ 39 & 47.2 & 19.9 \\ 156 & 141.9 & 49.2 \\ 259 & 50.1 & 22.7\end{array}$

\section{Toscana}

Potatoes (100 kg/ha)

Sugar beet $(100 \mathrm{~kg} / \mathrm{ha}$ )

Wheat (100 kg/ha)

Milk (100 kg/cow)

Beef (GPV in ECU/LU)

Pig (GPV in ECU/LU)

\section{Trentino}

Potatoes (100 kg/ha)

Sugar beet $(100 \mathrm{~kg} / \mathrm{ha})$

Wheat (100 kg/ha)

Milk (100 kg/cow)

Beef (GPV in ECU/LU)

Pig (GPV in ECU/LU)

$\begin{array}{rrrr}- & - & - & - \\ - & - & - & - \\ 10 & 44 & 24.0 & 19.4 \\ 15 & 35 & 38.8 & 24.9 \\ 27 & 1147 & 108.2 & 51.3\end{array}$

\section{Umbria}

Potatoes (100 kg/ha)

Sugar beet (100 kg/ha)

Wheat (100 kg/ha)

Milk (100 kg/cow)

Beef (GPV in ECU/LU)

Pig (GPV in ECU/LU)

$\begin{array}{lr}- & - \\ - & - \\ 6 & 4 \\ 6 & 35\end{array}$

$\begin{array}{ccc}- & - & - \\ - & - & - \\ - & - & - \\ 44 & 17.5 & 12.1 \\ 357 & 55.0 & 50.0\end{array}$

Valle d'Aosta

Potatoes (100 kg/ha)

Sugar beet (100 kg/ha)

Wheat $(100 \mathrm{~kg} / \mathrm{ha})$

Milk (100 kg/cow)

Beef (GPV in ECU/LU)

Pig (GPV in ECU/LU)

$\begin{array}{rrrc}- & - & - & - \\ - & - & - & - \\ 175 & 49 & 20.4 & 13.6 \\ 24 & 42 & 20.6 & 13.2 \\ 132 & 1287 & 134.2 & 37.8 \\ 86 & 1910 & 48.3 & 29.5\end{array}$

$\begin{array}{rrrc}6 & 200 & 38.3 & 34.2 \\ - & - & - & - \\ - & - & - & - \\ 122 & 32 & 21.2 & 16.7 \\ 119 & 670 & 148.5 & 110.1 \\ 3 & 3817 & 53.5 & 48.2\end{array}$


Income insurance in European agriculture

Veneto

Potatoes (100 kg/ha)

Sugar beet $(100 \mathrm{~kg} / \mathrm{ha})$

Wheat $(100 \mathrm{~kg} / \mathrm{ha})$

Milk (100 kg/cow)

Beef (GPV in ECU/LU)

Pig (GPV in ECU/LU)

$\begin{array}{lr}- & - \\ - & - \\ - & 42 \\ 10 & 388\end{array}$

$\begin{array}{ccc}- & - & - \\ - & - & - \\ - & - & - \\ 42 & 22.5 & 13.7 \\ 388 & 45.1 & 35.1 \\ - & - & -\end{array}$

The Netherlands (1989-95)

\begin{tabular}{llccc}
\hline Potatoes $(100 \mathrm{~kg} / \mathrm{ha})$ & 43 & 423 & 22.4 & 12.2 \\
Sugar beet $(100 \mathrm{~kg} / \mathrm{ha})$ & 38 & 624 & 16.9 & 11.8 \\
Wheat $(100 \mathrm{~kg} / \mathrm{ha})$ & 29 & 82 & 15.9 & 10.2 \\
Milk $(100 \mathrm{~kg} / \mathrm{cow})$ & 62 & 67 & 16.8 & 4.9 \\
Beef $(\mathrm{GPV}$ in ECU/LU) & 74 & 2662 & 1297 & 38.6 \\
Pig (GPV in ECU/LU) & 34 & 1461 & 26.6 & 19.9 \\
\hline
\end{tabular}

Price data (Amsterdam Exchange Market)

\begin{tabular}{lrrr}
\hline & Time period & Average price & CV (\%) \\
\hline Potatoes & $1986-96$ & $13.7(\mathrm{ECU} / 100 \mathrm{~kg})$ & 49.9 \\
Pig meat & $1989-94$ & $1.26(\mathrm{ECU} / \mathrm{kg})$ & 16.8 \\
\hline
\end{tabular}




\section{Annex V}

\section{Simulation of the effect of insurance}

This annex provides background information on Chapter 5 'Data analysis and simulation'. The concept of loss costs is explained and the formula for the calculation of premiums, indemnities and net return to labour and management, both for yield-only and gross revenue insurance schemes, are described.

\section{Definitions}

Loss costs: basis for premium.

Guarantee level: level that triggers a payment $=100 \%$ minus deductible $=$ coverage level.
Election percentage: for a yield-only insurance: percentage of a price against which yield shortfalls ( $>$ deductible) are indemnified; for a gross revenue insurance: percentage of revenue shortfalls ( $>$ deductible) that are indemnified.

\section{More on loss costs}

The loss costs are expressed as a percentage and reflect the amount of premium that is required to offer an actuarially sound insurance programme (excluding administrative costs and profits). Loss costs can be calculated by multiplying the percentage frequency and the percentage severity (US income task force, 1983). For a crop yield insurance these are defined as follows.

\section{Graph 12: PDF for wheat farmers in Makedonia-Thraki}

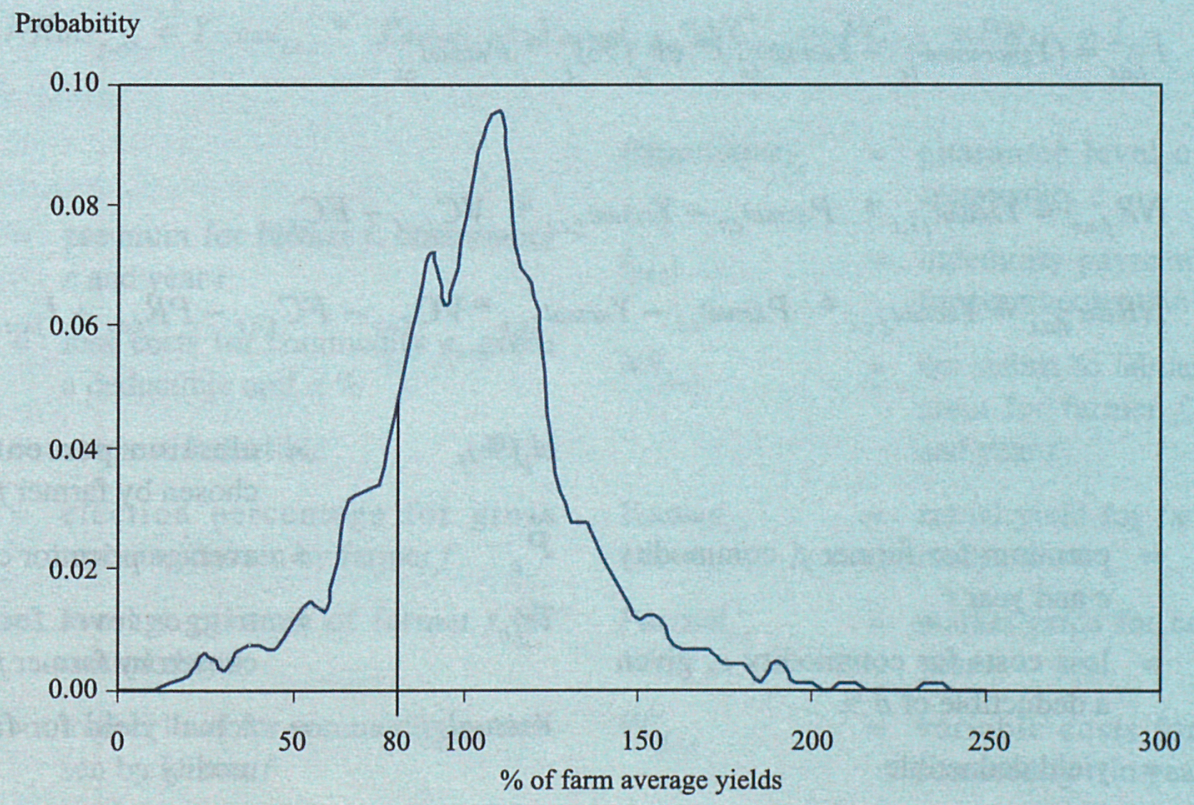


- $\quad$ Percentage frequency: the probability of an insurance company having to indemnify insured farmers. The percentage frequency is calculated from the number of times crop yields fall below the guarantee level.

- Percentage severity: if the guarantee level is set at, for example, $80 \%$ of average farm yields, and actual yields are $60 \%$ of this average, the percentage severity is $20 \%$.

\section{Loss costs: an example for yield-only insurance}

Graph 12 shows the probability distribution function (PDF) of individual yield data of 284 wheat farms in Makedonia-Thraki (EL) expressed relative to the farm averages. If the guarantee level is assumed to be $80 \%$, the area at the left hand side of $80 \%$ (see line in graph) represents the loss costs (i.e. percentage frequency (here $21.4 \%$ ) times the average percentage severity (here $18 \%$ ) $=3.9 \%$ ). Every wheat farmer who buys insurance in Makedonia-Thraki pays a premium that is based on the loss costs of $3.9 \%$. The eventual premium depends on the farmer's average yield of wheat, the coverage level and the election price.

\section{Remark}

Expressing farm yield data relative to farm averages and then calculating the loss costs, excludes effects from low/high producing farms. Differences in yield variation within farms are still present in the data. Insurance companies could differentiate premiums between farmers with a high versus a low yield variation. However, when data refer to only a few years, the farmer with a small variation in yields might just have been lucky a number of years in a row.

\section{Yield-only insurance}

Premiums for yield-only insurance are calculated using the formula:

$$
\begin{aligned}
& P R_{f, c, t}=L C(d \%)_{c} * \bar{Y}_{f, c} * e l_{p}(\%)_{f} * \bar{P}_{c} \\
& T r_{f, c}=\text { Yactual }_{f, c}<Y_{\text {guarantee }_{f, c}}
\end{aligned}
$$

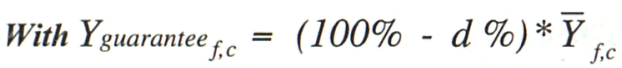

$$
\begin{aligned}
& I_{f, c, t}=\left(Y_{\text {guarantee }}-Y_{f, c} \text { actual }_{f, c}\right) * e l_{p}\left(\%_{f} * P_{a c t u a l}\right. \\
& N R_{f, c, t}=Y_{\text {actual }_{f, c, t}} * P_{a_{c t u a l}, t}-Y_{\text {actual }_{f, c, t}} * V C_{f, c, t}-F C_{f, c, t} \\
& \operatorname{NRins}_{f, c, t}=\text { Yactual }_{f, c, t} * P_{\text {actual }_{c, t}}-\text { Yactual }_{f, c, t} * V C_{f, c, t}-F C_{f, c, t}-P R_{f, c, t}+I_{f, c, t}
\end{aligned}
$$

With:

$$
P R_{f, c, t}
$$$$
L C_{c}
$$

$d \%$

$\bar{Y}_{f, c}$

$$
e l_{p}(\%)_{f}
$$

$=$ premium for farmer $f$, commodity $c$ and year $t$

$=$ loss costs for commodity $c$, given a deductible of $d \%$

$=$ yield deductible

$=$ average yield of farmer $f$ for commodity $c$

$$
\begin{aligned}
& \bar{P}_{c} \\
& \operatorname{Tr}_{f, c}
\end{aligned}
$$

Yactual $_{f, c}$

Yguarante $_{f, c}$
= election percentage for price, chosen by farmer $f$

$=$ average price for commodity $c$

$=$ trigger level for commodity $c$, chosen by farmer $f$

$=$ actual yield for farmer $f$ of commodity $c$

$=$ guarantee level of farmer $f$ for commodity $c$ 


$$
\begin{aligned}
& I_{f, c, t} \quad=\text { indemnity payments for farmer } f \quad \operatorname{NRins}_{f, c, t} \\
& \text { for commodity } c \text { in year } t \\
& N R_{f, c, t}=\text { net return to labour and manage- } \\
& P R_{f, c, t}=L C(d \%)_{c} * e l_{r}(\%)_{f} * \bar{R}_{f, c} \\
& \operatorname{Tr}_{f, c}=\text { Ractual }_{f, c}<{\text { R } \text { guarantee }_{f, c}} \\
& \text { With } \text { Ruarantee }_{f, c}=(100 \%-d \%) * \bar{R}_{f, c} \\
& I_{f, c, t}=e l_{r}(\%)_{f} *\left(\text { Rguarantee }_{f, c}-\text { Ractual }_{f, c}\right) \\
& N R_{f, c, t}=\text { Yactual }_{f, c, t} * P_{\text {actual }_{c, t}}-\text { Yactual }_{f, c, t} * V C_{f, c, t}-F C_{f, c, t} \\
& \text { NRins }_{f, c, t}=\text { Yactual }_{f, c, t} * P_{\text {actual }_{c, t}}-Y_{\text {actual }_{f, c, t}} * V C_{f, c, t}-F C_{f, c, t}-P R_{f, c, t}+I_{f, c, t}
\end{aligned}
$$

\begin{tabular}{|c|c|c|c|}
\hline$P R_{f, c, t}$ & & $\begin{array}{l}\text { premium for farmer } f \text {, commodity } \\
c \text { and year } t\end{array}$ & $I_{f, c, t}$ \\
\hline$L C(d \%)_{c}$ & $=$ & $\begin{array}{l}\text { loss costs for commodity } c \text {, given } \\
\text { a deductible omf } d \%\end{array}$ & $N R_{f, c, t}$ \\
\hline$d \%$ & $=$ & revenue deductible & \\
\hline$e l_{r}(\%)_{f}$ & $=$ & $\begin{array}{l}\text { election percentage for gross } \\
\text { revenue, chosen by farmer } f\end{array}$ & Yactual $_{f, c}$ \\
\hline $\bar{R}_{f, c}$ & $=$ & $\begin{array}{l}\text { average revenue of farmer } f \text { for } \\
\text { commodity } c\end{array}$ & Pactual $_{c, t}$ \\
\hline$T r_{f, c}$ & $=$ & $\begin{array}{l}\text { trigger level for commodity } c \text {, cho- } \\
\text { sen by farmer } f\end{array}$ & $V C_{f, c, t}$ \\
\hline Ractual $_{f, c}$ & & $\begin{array}{l}\text { actual revenue for farmer } f \text { of com- } \\
\text { modity } c\end{array}$ & $F C_{f, c, t}$ \\
\hline
\end{tabular}

\section{Remark}

\section{Gross revenue insurance}

$=$ net return to labour and management for farmer $f$, commodity c and year $t$, with insurance

In the simulation model the $e l_{p}(\%)_{f}$ is set smaller than 1 (i.e. at $90 \%$ ) to avoid moral hazard: if the price at which yield shortfalls are indemnified is always lower than the actual market price, farmers always have an incentive to produce the highest yield possible even if

With:
$=$ guarantee level of farmer $f$ for commodity $c$

$=$ indemnity payments for farmer $f$ for commodity $c$ in year $t$

$=$ net return to labour and management for farmer $f$, commodity $c$ and year $t$

$=$ actual yield for farmer $f$ of commodity $c$

$=$ market price for commodity $c$ in year $t$

$=$ variable costs for farmer $f$ for commodity $c$ in year $\mathrm{t}$

$=$ fixed costs for farmer $f$ for commodity $c$ in year $\mathrm{t}$ 

NRins $_{\mathrm{f}, \mathrm{c}, \mathrm{t}}=$ net return to labour and manage- ment for farmer $f$, commodity $c$ and year $t$, with insurance

\section{Remarks}

To make the comparison between yield-only and gross revenue insurance as clear as possible, the $e l_{r}(\%)_{f}$ level is set at the same level as the $e l_{p}(\%)_{f}$ level.
It is assumed that there is no negative price/yield correlation, implying that if yields are low, prices are not automatically high.

In Section 3.4.1 it was suggested that price coverage should not be based on an average price, but on a price that is established yearly. However, simulation in the field of yearly established prices requires data on price variability within years. Such data were not available in this study. 


\section{List of contents of European Economy}

\section{Basic editions}

\section{1, November 1978}

- Annual Economic Report 1978-79

- Annual Economic Review 1978-79

\section{2, March 1979}

- European Monetary System

- Texts of the European Council of 4 and 5 December 1978

\section{3, July 1979}

- Short-term economic trends and prospects

- The European monetary system

- Commentary

- Documents

\section{4, November 1979}

- Annual Economic Report 1979-80

- Annual Economic Review 1979-80

\section{5, March 1980}

- Short-term economic trends and prospects

- Adaptation of working time

\section{6, July 1980}

- Short-term economic trends and prospects Borrowing and lending instruments looked at in the context of the Community's financial instruments

\section{7, November 1980}

- Annual Economic Report 1980-81

- Annual Economic Review 1980-81

\section{8, March 1981}

- Economic trends and prospectsThe Community's borrowing and lending operations recent developments

\section{9, July 1981}

- Fifth medium-term economic policy programme - The main medium-term issues: an analysis

\section{0, November 1981}

- Annual Economic Report 1981-82 - Annual Economic Review 1981-82
11, March 1982

- Economic trends and prospects - Unit labour costs in manufacturing industry and in the whole economy

\section{2, July 1982}

- Documents relating to the European monetary system

\section{3, September 1982}

- The borrowing and lending activities of the Community in 1981

\section{4, November 1982}

- Annual Economic Report 1982-83 - Annual Economic Review 1982-83

\section{5, March 1983}

- Economic trends and prospects - Budgetary systems and procedures - Industrial labour costs - Greek capital markets

\section{6, July 1983}

- Business investment and the tax and financial environment - Energy and the economy: a study of the main relationships in the countries of the European Community - The foreign trade of the Community, the United States and Japan

\section{7, September 1983}

- The borrowing and lending activities of the Community in 1982

\section{8, November 1983}

- Annual Economic Report 1983-84 - Annual Economic Review 1983-84

\section{9, March 1984}

- Economic trends and prospects - Industrial labour costs - Medium-term budget balance and the public debt - The issue of protectionism 


\section{0, July 1984}

- Some aspects of industrial productive performance in the European Community: an appraisal - Profitability, relative factor prices and capital/labour substitution in the Community, the United States and Japan, 1960-83 - Convergence and coordination of macroeconomic policies: some basic issues

\section{1, September 1984}

- Commission report to the Council and to Parliament on the borrowing and lending activities of the Community in 1983

\section{2, November 1984}

- Annual Economic Report 1984-85

- Annual Economic Review 1984-85

\section{3, March 1985}

- Economic trends and prospects 1984-85

\section{4, July 1985}

- The borrowing and lending activities of the Community in 1984

\section{5, September 1985}

- Competitiveness of European industry: situation to date - The determinants of supply in industry in the Community - The development of market services in the European Community, the United States and Japan - Technical progress, structural change and employment

\section{6, November 1985}

- Annual Economic Report 1985-86 - Annual Economic Review 1985-86

\section{7, March 1986}

- Employment problems: views of businessmen and the workforce - Compact: a prototype macroeconomic model of the European Community in the world economy

\section{8, May 1986}

- Commission report to the Council and to Parliament on the borrowing and lending activities of the Community in 1985

\section{9, July 1986}

- Annual Economic Review 1986-87

\section{0, November 1986}

- Annual Economic Report 1986-87

\section{1, March 1987}

- The determinants of investment Estimation and simulation of international trade linkages in the Quest model

\section{2, May 1987}

- Commission report to the Council and to Parliament on the borrowing and lending activities of the Community in 1986

\section{3, July 1987}

- The economic outlook for 1988 and budgetary policy in the Member States Economic trends in the Community and Member States

\section{4, November 1987}

- Annual Economic Report 1987-88

\section{5, March 1988}

- The economics of 1992

\section{6, May 1988}

- Creation of a European financial area

\section{7, July 1988}

- Commission report to the Council and to Parliament on the borrowing and lending activities of the Community in 1987

\section{8, November 1988}

- Annual Economic Report 1988-89

\section{9, March 1989}

- International trade of the European Community

\section{0, May 1989}

- Horizontal mergers and competition policy in the European Community 


\section{1, July 1989}

- The borrowing and lending activities of the Community in 1988 - Economic convergence in the Community: a greater effort is needed

\section{2, November 1989}

- Annual Economic Report 1989-90

\section{3, March 1990}

- Economic transformation in Hungary and Poland

\section{4, October 1990}

- One market, one money

\section{5, December 1990}

- Stabilisation, liberalisation and devolution

\section{6, December 1990}

- Annual Economic Report 1990-91

\section{7, March 1991}

- Developments on the labour-market in the Community - Quest: a macroeconomic model for the countries of the European Community as part of the world economy

\section{8, September 1991}

- Fair competition in the internal market: Community State aid policy - The ecu and its role in the process towards monetary union

49, 1993

- Reform issues in the former Soviet Union

\section{0, December 1991}

- Annual Economic Report 1991-92

\section{1, May 1992}

- The climate challenge: economic aspects of the Community's strategy for limiting $\mathrm{CO}_{2}$ emissions

\section{2,1993}

- The European Community as a world trade partner

\section{3, 1993}

- Stable money, sound finances: Community public finance in the perspective of EMU

\section{4,1993}

- Annual Economic Report for 1993

\section{5,1993}

- Broad economic policy guidelines and convergence report

\section{6,1994}

- Annual Economic Report for 1994

\section{7, 1994}

- Competition and integration - Community merger control policy

\section{8, 1994}

- 1994 Broad economic policy guidelines Report on the implementation of macrofinancial assistance to third countries

59, 1995

- Annual Economic Report for 1995

60, 1995

- 1995 Broad economic policy guidelines

61, 1996

- Annual Economic Report for 1996

62, 1996

- 1996 Broad economic policy guidelines

63, 1997

- Annual Economic Report for 1997

64, 1997

- 1997 Broad economic policy guidelines

65, 1998

- Commission's recommendation concerning the third stage of economic and monetary union - Convergence report 1998 Growth and employment in the stabilityoriented framework of EMU 
66, 1998

- 1998 Broad economic policy guidelines

67, 1999

- 1999 Annual Economic Report

\section{Reports and studies}

\section{$1-1993$}

- The economic and financial situation in Italy

\section{2-1993}

- Shaping a market economy legal system

\section{3-1993}

- Market services and European integration: the challenges for the 1990s

\section{4-1993}

- The economic and financial situation in Belgium

\section{5-1993}

- The economics of Community public finance

\section{6-1993}

- The economic and financial situation in Denmark

\section{1-1994}

- Applying market principles to government borrowing - Growth and employment: the scope for a European initiative

\section{2-1994}

- The economic and financial situation in Germany

\section{3-1994}

- Towards greater fiscal discipline

\section{4-1994}

- EC agricultural policy for the 21 st century

\section{5-1994}

- The economics of the common agricultural policy (CAP)

\section{6-1994}

- The economic interpenetration between the EU and Eastern Europe

\section{7-1994}

- The economic and financial situation in Spain

\section{1-1995}

- The economic and financial situation in the Netherlands

\section{2-1995}

- Report on the implementation of macrofinancial assistance to third countries in 1994

\section{3-1995}

- Performance of the European Union labour market

\section{4-1995}

- The impact of exchange-rate movements on trade within the single market

\section{1-1996}

- The economic and financial situation in Ireland - Ireland in the transition to EMU

\section{2-1996}

- The CAP and enlargement economic effects of the compensatory payments

\section{3-1996}

- Ageing and pension expenditure prospects in the Western world

\section{4-1996}

- Economic evaluation of the internal market

\section{1-1997}

- The economic and financial situation in Portugal in the transition to EMU

\section{2-1997}

- The CAP and enlargement - Agrifood price developments in five associated countries

\section{3-1997}

- The European Union as a world trade partner 


\section{4-1997}

- The welfare state in Europe: challenges and reforms

\section{$5-1997$}

- Towards a common agricultural and rural policy for Europe

\section{6-1997}

- The joint harmonised EU programme of business and consumer surveys

\section{1-1998}

- Getting environmental policy right - The rational design of European environmental policy from an economic perspective

\section{2-1998}

- The economic and financial situation in Austria

\section{3-1998}

- Income benefits for early exit from the labour market in eight European countries:

a comparative study

\section{1-1999}

- The economic and financial situation in Finland

\section{Special editions}

Special issue 1979

- Changes in industrial structure in the European economies since the oil crisis 1973-78 - Europe: its capacity to change in question

\section{Special edition 1990}

- The impact of the internal market by industrial sector: the challenge for the Member States

\section{Special edition No 1/91}

- The economics of EMU

\section{Special edition No 2/91}

- The path of reform in Central and Eastern Europe

\section{Special edition No $1 / 92$}

- The economics of limiting $\mathrm{CO}_{2}$ emissions 



\section{ORDER FORM}

European Economy

Price annual subscription (two issues and three reports per year): EUR 112

\section{European Economy + Supplements A, B and C}

Price combined annual subscription: EUR 190

Name and address:

Date:

Signature:

\section{ORDER FORM}

Supplements to 'European Economy'

Series A - Economic trends

Price annual subscription (11 issues per year): EUR 46

Series B - Business and consumer survey results Price annual subscription (11 issues per year): EUR 46

Series C-Economic reform monitor

Price annual subscription ( 4 issues per year): EUR 24

Complete series of supplements:

EUR 90

Name and address:

Date:

Signature:

\section{ORDER FORM}

\section{European Economy}

ISSN 0379-0991

Number

of copies:

Price annual subscription (two issues and three reports per year): EUR 112

\section{European Economy + Supplements A, B and C}

Price combined annual subscription: EUR 190

Name and address:

Date: 
Office des

publications officielles

des Communautés européennes

L-2985 Luxembourg

Office des

publications officielles

des Communautés européennes

L-2985 Luxembourg

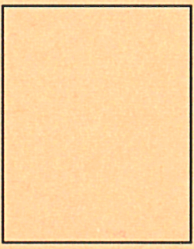

Office des

publications officielles

des Communautés européennes

L-2985 Luxembourg 


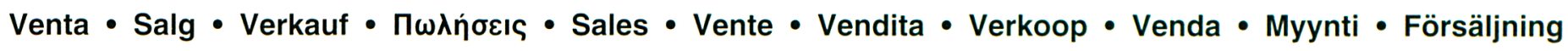

\section{BELGIQUE/BELGIË}

Jean De Lannoy

Avenue du Roi 202/Koningslaan 202 B-1190 Bruxelles/Brussel

Fax (32-2) 5380841

E-mail: jean.de.lannoy@infoboard.be

URL: http://www.jean-de-lannoy.be

La librairie europeeenne/

De Europese Boekhandel

Rue de la Loi 244/Wetstraat 244

B-1040 Bruxelles/Brussel

Tél. (32-2) 2952639
Fax (32-2) 7350860

E-mail: mail@libeurop be

URL: http://www.libeurop.be

Moniteur belge/Belgisch Staatsblad

Rue de Louvain 40-42/Leuvenseweg 40-42

B-1000 Bruxelles/Bruss

Fax (32-2) 5110184

DANMARK

J. H. Schultz Information A/S

Herstedvang 10-12

DK-2620 Albertslund

TIf. (45) 43632300
Fax (45) 43631969

Fax (45) 43631969

E-mail: schultz@schultz.dk

DEUTSCHLAND

Bundesanzeiger Verlag GmbH

Vertriebsabteilung

Amsterdamer Straße 192

Tel. (49-221)

Tel. (49-221) 976680
Fax $(49-221) 97668278$

E-Mail: vertrieb@bundesanzeiger.de

URL: http://www.bundesanzeiger.de

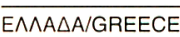

G. C. Eleftheroudakis SA

International Bookstore

Panepistimiou 17

GR-10564 Athina
Tel. (30-1) 33141 80/1/2/3/4/5

Fax (30-1) 3239821

E-mail: elebooks@netor.gr

ESPAÑA

Boletin Oficial del Estado

Trafalgar, 27

Tel. (34) 915382111 (Libros),

(34) 915382111 (Libros)
913841715 (Suscrip.)

Fax (34) 915382121 (Libros)

913841714 (Suscrip.)

E-mail: clientes@ @om.boe.

Mundi Prensa Libros, SA

Castelló, 37

E-28001 Madrid

Tel. (34) 914363700

E-mail: libreria@mundiprensa.es

E-mL: htp:/www mundiprensa.es

\section{FRANCE}

Journal officiel

Service des publications des $\mathrm{CE}$

F-75727 Paris Cedex 15

Tèl. (33) 140587731

URL: http://www.journal-officiel.gouv.fr

\section{IRELAND}

Government Supplies Agency

Publications Section

4-5 Harco
Dublin 2

Tel. (353-1) 6613111
Fax (353-1) 4752760

\section{ITALIA}

Via Duca di Calabria, 1/1
Casella postale 552

1-50125 Firenze

Tel. (39) 05564831

Fax (39) 055641257

URL: http://www.ftbcc.it/licosa

\section{LUXEMBOURG}

Messageries du livre SARL

5, rue Raiffeisen

Tél.

Fax. (352) 401020

E-mail:mail@mdl.1

URL: http://www.mdl.lu

NEDERLAND

SDU Servicecentrum Uitgevers

Christoffel Plantijnstraat 2

Postbus 20014

2500 EA Den Haag

Tel. (31-70) 3789880

Fax (31-70) 3789783

URL: http://www.sdu,n

\section{ÖSTERREICH}

Manz'sche Verlags- und

Universitätsbuchhandlung $\mathrm{GmbH}$

Kohlmarkt 16

Tei. (43-1) 53161100

Fax (43-1) 53161167

E-Mail: bestellen@manz.co.at

URL: http://www.manz.at/index.htm

PORTUGAL

Distribuidora de Livros Bertrand Ld. ${ }^{a}$

Grupo Bertrand, SA

Rua das Terras dos Vales, 4-A

Apartado 60037

Tel. (351-1) 4959050

Imprensa Nacional-Casa da Moeda, EP

Rua Marquês Sá da Bandeira, 16-A

P-1050 Lisboa Codex

Tel. (351-1) 3530399

E-mail: del.incm@mail.telepac.p

URL: http://www.incm.pt

SUOMI/FINLAND

\section{Akateeminen Kirjakauppa
Akademiska Bokhandeln}

Akademiska Bokhandeln

Keskuskat

FIN-00101 Helsinki/Helsingfors

P./tfn (358-9) 1214418

Sähkoposti: akatilaus@ @akateeminen.com

URL: http://www.akateeminen.com

\begin{tabular}{l}
\hline SVERIGE \\
\hline BTJ AB \\
Traktorvägen 11 \\
S-221 82 Lund \\
Tfn (46-46) 180000 \\
Fax (46-46) 307947 \\
E-post: btjeu-pub@btj.se \\
URL: http://www.btj.se \\
\hline UNITED KINGDOM
\end{tabular}

The Stationery Office Ltd

nternational Sales Agency

51 Nine Elms Lane

Tel. (44-171) 8739090

Fax (44-171) 8738463

E-mail: ipa.enquiries@ theso.co.uk

JRL: http://www.the-stationery-nffice.ro.uk

\section{iSLAND}

Bokabud Larusar Blöndal

Skólavördustig, 2

IS-101 Reykjavik

Tel. (354) 5515650
Fax (354) 5525560

\section{NORGE}

Swets Norge AS

Ostenjoveien 18

Tel. (47-22)

Tel. (47-22) 974500

SCHWEIZ/SUISSE/SVIZZERA

Euro Info Center Schweiz

c/O OSEC

Stampfenbachstraße 85

$\mathrm{CH}-8035$ Zürich

Tel. (41-1) 3655315

Fax (41-1) 3655411

URL: http://www.osec.ch/eics

\section{BĂLGARIJA}

Europress Euromedia Ltd

59, blvd Vitosha

Tel. (359-2) 9803766

E-mail: Milena@mbox.cit.bg

ČESKÁ REPUBLIKA

ÚSIS

NIS-prodejna

Havelkova 22

CZ-130 00 Praha 3

Tel. (420-2) 24231486

Fax (420-2) 24231114

E-mail: nkposp@ @ec.r

CYPRUS

Cyprus Chamber of Commerce and Industry

PO Box 1455

CY-1509 Nicosia

Tel. (357-2) 669500

2) 661044

E-mail: demetrap@ccci.org.cy

EESTI

Eesti Kaubandus-Tööstuskoda (Estonian

Chamber of Commerce and Industry)

Toom-Kooli 17

EE-0001 Tallinn

Tel. (372) 6460244

Fax (372) 646024

E-mail: einfo@ @oda.ee

\section{HRVATSKA}

Mediatrade Ltd

Pavla Hatza 1

Tel. (385-1) 481 (34 11

Fax (385-1) 4819411

MAGYARORSZÁG

Euro Info Service

Európa Ház

Margitszige

H-1396 Budapest 62

Tel. (36-1) 3508025

E-mail: euroinfo@mail.matav.hu

URL: http://www.euroinfo.hu/index.htm

MALTA

Miller Distributors Ltd

Malta International Airport

P B 2505

Tel. (356) 664488

Fax (356) 676799

E-mail: gwirth@usa.net

POLSKA

Ars Polona

Krakowskie Przedmiescie

Skr. pocztowa 100

PL-00-950 Warszawa

Tel. (48-22) 826120

E-mail: ars_pol@bevy.hsn.com.pl

ROMÂNIA

\section{Euromedia}

Str. G-ral Berthelot $\mathrm{Nr} 41$

RO-70749 Bucuresti

Tel. (40-1) 3154403
Fax (40-1) 3142286

ROSSIYA

CCEC

60-letiya Oktyabrya Av. 9

117312 Moscow

Tel. (7-095) 1355227
Fax (7-095) 1355227

\section{SLOVAKIA}

Centrum VTI SR

Nám. Slobody, 19

Tel. (421-7) 54418364

Fax (421-7) 54418364

E-mail: europ@ tbb1.sltk.stuba.sk

URL: http://www.sltk.stuba.sk

SLOVENIJA

Gospodarski Vestnik

Dunajska cesta 5

Tel. (386) 613091640

Fax (386) 613091645

E-mail: europ @ gvestnik.si

URL: http://www.gvestnik.si

\section{TÜRKIYE}

\section{Dünya Infotel AS}

100, Yil Mahallessi 34440

TR-80050 Bagcilar-Istanb

Tel. $(90-212) 6294689$
Fax $(90-212) 6294627$

E-mail: infotel@dunya-gazete.com.tr

AUSTRALIA

Hunter Publications

PO Box 404

P067 Abbotsford. Victori

Fax (61-3) 94105154

E-mail: jpdavies@ozemail.com.au

\section{CANADA}

Les éditions La Liberté Inc.

3020, chemin Sainte-Foy
G1X 3V Sainte-Foy, Quebe

Tel. (1-418) 6583763

Fax $(1-800) 5675449$

E-mail: liberte@mediom.qc.ca

Renouf Publishing Co. Ltd

5369 Chemin Canotek Road Unit

K1J 9J3 Ottawa, Ontario

Tel. (1-613) 7452665

Fax (1-613) 7457660

E-mall. order.dept@renoufbooks.co

oks.com

FGYPT

The Middle East Observer

41 Sherif Street

Cairo

Tel. (20-2) 3926919
Fax (20-2) 3939732

Fax (20-2) 3939732

E-mail:malouda@meobserver.com.eg

INDIA

EBIC India

3rd Floor, Y. B. Chavan Centre

Gen. J. Bhosale Marg

400021 Mumbai

Tel. (91-22) 2826064

Fax (91-22) 2854564

E-mail: ebic @ giasbm01.vsnl.net.in
URL: http://www.ebicindia.com

\section{ISRAËL}

ROY International

41. Mishmar Hayarden Street

Po Box 13056

Tel. (972-3) 6499469 
Price (excluding VAT) in Luxembourg: EUR 32

EUR

European Economy ( 2 issues and 3 reports per year)

\section{Supplements}

Single copy

Series A - 'Economic trends' (11 issues per year)

Series B - 'Business and consumer survey results' (11 issues per year)

Series C - 'Economic reform monitor'

( 4 issues per year)

Complete series of supplements

Combined subscription - European Economy and supplements

* * * OFFICE FOR OFFICIAL PUBLICATIONS

* $\frac{\text { EUR }}{0}$ * OF THE EUROPEAN COMMUNITIES

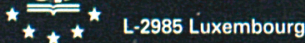

112

The annual subscription runs from 1 January to 31 December of each year.

Payments to be made only to the agents in the countries listed on page 3 of the cover of European Economy.

7

46

46

24

90

190

http://europa.eu.int/comm/dg02

ISBN $92-828-6755-2$

These are surface mail rates; for air subscription rates please apply to the sales offices.

Series $C$ is added for free to the subscription to Supplement Series A. 